\title{
Predicting Psychological and Subjective Well-Being from Personality: A Meta-Analysis
}

\author{
Jeromy Anglim ${ }^{1}$, Sharon Horwood ${ }^{1}$, Luke D. Smillie ${ }^{2}$, Rosario J. Marrero ${ }^{3}$, Joshua K. Wood ${ }^{1}$
}

\begin{abstract}
This study reports the most comprehensive assessment to date of the relations that the domains and facets of Big Five and HEXACO personality have with self-reported subjective wellbeing (SWB: life satisfaction, positive affect, and negative affect) and psychological well-being (PWB: positive relations, autonomy, environmental mastery, purpose in life, self-acceptance, and personal growth). It presents a meta-analysis $(n=334,567, k=462)$ of the correlations of Big Five and HEXACO personality domains with the dimensions of SWB and PWB. It provides the first meta-analysis of personality and well-being to examine (a) HEXACO personality, (b) PWB dimensions, and (c) a broad range of established Big Five measures. It also provides the first robust synthesis of facet-level correlations and incremental prediction by facets over domains in relation to SWB and PWB using four large datasets comprising data from prominent, long-form hierarchical personality frameworks: NEO PI-R $(n=1,673)$, IPIP-NEO $(n=903)$, HEXACO PI$\mathrm{R}(n=465)$, and Big Five Aspect Scales $(n=706)$. Meta-analytic results highlighted the importance of Big Five neuroticism, extraversion, and conscientiousness. The pattern of correlations between Big Five personality and SWB was similar across personality measures (e.g., BFI, NEO, IPIP, BFAS, Adjectives). In the HEXACO model, extraversion was the strongest wellbeing correlate. Facet-level analyses provided a richer description of the relationship between personality and well-being, and clarified differences between the two trait frameworks. Prediction by facets was typically around $20 \%$ better than domains, and this incremental prediction was larger for some well-being dimensions than others.

Keywords: HEXACO, Big Five, subjective well-being, psychological well-being, personality facets

Citation (check publisher for updated year, volume and page numbers): Anglim, J., Horwood, S., Smillie, L. D., Marrero, R. J., \& Wood, J. K. (2020). Predicting Psychological and Subjective Well-Being from Personality: A Meta-Analysis. Psychological Bulletin. https://dx.doi.org/10.1037/bul0000226

Author Note. 1. School of Psychology, Deakin University, Geelong, Australia; 2. Melbourne School of Psychological Sciences, The University of Melbourne, Australia; 3. Department of Clinical Psychology, Psychobiology and Methodology. Faculty of Psychology. Universidad de La Laguna; Correspondence concerning this article should be addressed to Jeromy Anglim, School of Psychology, Deakin University, Locked Bag 20000, Geelong, 3220 Australia. Email: jeromy.anglim@deakin.edu.au

Data, scripts, materials, and supplementary analyses are available at https://osf.io/42rsy. We are grateful to Jessie Sun and Ingo Zettler for their valuable feedback on an initial draft of this manuscript.

CAmerican Psychological Association, 2019. This paper is not the copy of record and may not exactly replicate the authoritative document published in the APA journal. Please do not copy or cite without author's permission. The final article is available, upon publication, at: https://dx.doi.org/10.1037/bul0000226
\end{abstract}




\section{Public Significance Statement}

This meta-analysis provides a comprehensive and detailed overview of the substantial links between personality traits and well-being. It is the first investigation to incorporate the two most widely accepted frameworks for measuring personality (i.e., the Big Five and the HEXACO model) as well as two of the most influential models of human well-being (i.e., subjective and psychological well-being). Results of the meta-analysis provide important insights into the various pathways through which people build well-being in their lives.

\section{Introduction}

Decades of research shows that personality traits play a critical role in how we experience, approach, and appraise our lives (DeNeve \& Cooper, 1998; Headey \& Wearing, 1989; Steel, Schmidt, \& Shultz, 2008). Many researchers assess the "good life" in terms of subjective wellbeing (SWB): a composite of life satisfaction, high levels of positive affect, and low levels of negative affect (Diener, 1984). Whereas SWB largely avoids making assumptions about the causes of happiness, other conceptualizations of well-being draw more strongly on eudaimonic and humanistic perspectives in conceptualizing well-being (Waterman, 1993). In particular, the sixdimensional model of psychological well-being (PWB) identifies a broader set of well-being dimensions, comprising positive relations, autonomy, environmental mastery, personal growth, purpose in life, and self-acceptance (Ryff, 1989). Previous research shows that major dimensions of personality are robustly associated with both SWB and PWB, along with other indices of human happiness (e.g., Anglim \& Grant, 2016; Sun et al., 2018).

To date, most research examining the personality correlates of SWB has focused on the Big Five (DeNeve \& Cooper, 1998; Steel et al., 2008). These five broad 'domains' of personality emerged from decades of research seeking to identify the major lines of covariation among trait terms, and provide a robust organizing framework for personality psychology as a whole (Anglim \& O'Connor, 2019; John \& Srivastava, 1999). However, the Big Five domains do not providenor were they ever intended to provide - a complete description of personality. Personality traits can be hierarchically arranged at multiple levels both above (e.g., Anusic, Schimmack, Pinkus, \& Lockwood, 2009; DeYoung, 2006; Digman, 1997; Musek, 2007; Veselka et al., 2009) and below (e.g., Costa \& McCrae, 1995; DeYoung, Quilty, \& Peterson, 2007; Mõttus, Kandler, Bleidorn, Riemann, \& McCrae, 2017; Mõttus, McCrae, Allik, \& Realo, 2014) the five broad domains. In addition, a prominent alternative to the Big Five, the six-factor HEXACO model (Ashton, Lee, \& De Vries, 2014), has received increasing interest and support. Researchers have thus begun to expand knowledge of the relation between personality and well-being by shifting to different levels in the personality trait hierarchy within the Big Five, as well as within the HEXACO framework (Aghababaei \& Arji, 2014; Anglim \& Grant, 2016; Marrero Quevedo \& Carballeira Abella, 2011; Schimmack et al., 2004; Sun et al., 2018).

To strengthen and consolidate this emerging research, we aim to address several fundamental gaps in the literature. First, despite meta-analytic work relating the Big Five domains to SWB (DeNeve \& Cooper, 1998; Steel et al., 2008), no equivalent meta-analysis has examined how the Big Five relates to PWB, or how the HEXACO model relates to either SWB or PWB. Second, the meta-analysis of Steel et al. (2008) focused exclusively on the NEO and the metaanalysis of DeNeve and Cooper (1998) largely relied on categorizing personality measures that predated the Big Five. Third, existing research examining facets of the Big Five and their incremental prediction of well-being above and beyond the Big Five domains suffers from several methodological limitations, including small sample sizes, biased statistics, invalid meta- 
analytically derived correlation matrices, and incomplete reporting (see the section below on "Incremental Prediction" for details; for a critical review, see Anglim \& Grant, 2014). Fourth, there has been no robust examination of how facets of the HEXACO model map to dimensions of wellbeing. To address these gaps, we present a meta-analysis that synthesizes the existing literature, and a systematic examination of the datasets with the largest sample sizes that have examined facet-level associations of Big Five and HEXACO frameworks with both SWB and PWB. We believe this research provides the most comprehensive assessment yet of how personality traits are linked to indices of human flourishing.

\section{Subjective and Psychological Well-Being}

Whereas previous studies have adopted a range of different perspectives on well-being (Diener \& Choi, 2009; Diener, Oishi, \& Lucas, 2003; Diener, Suh, Lucas, \& Smith, 1999; Lucas $\&$ Diener, 2008), we focus on the complementary perspectives of SWB and PWB. Several decades ago, Ed Diener and colleagues operationalized SWB as high life satisfaction combined with high levels of positive affect and low levels of negative affect (Deci \& Ryan, 2008; Diener, 1984; Lucas, Diener, \& Suh, 1996). Contrastingly, Carol Ryff and colleagues have operationalized PWB using a six-dimensional framework comprising positive relations, autonomy, environmental mastery, personal growth, purpose in life, and self-acceptance (McGregor \& Little, 1998; Ryan \& Deci, 2001; Ryff \& Keyes, 1995). Definitions and example items for all of these dimensions are depicted in Table 1. Although all nine well-being dimensions have moderate to large intercorrelations, they each appear to capture discrete aspects of well-being (Anglim \& Grant, 2016; Sun et al., 2018).

Despite the influence of situational factors on short-term fluctuation in mood, and the longer-term impact that significant life events appear to have on well-being-e.g., marital transition (Lucas, Clark, Georgellis, \& Diener, 2003), acquiring a disability (Lucas, 2007), or approaching death (Gerstorf et al., 2008) — measures of well-being otherwise appear very stable over time (Fujita \& Diener, 2005; Schimmack \& Oishi, 2005). For example, in a recent, large panel study, Anglim, Weinberg, and Cummins (2015) obtained 8-year test-retest correlations for life satisfaction approaching .80. Furthermore, twin studies suggest that SWB is reasonably heritable (Weiss, Bates, \& Luciano, 2008). For example, in a large sample of Norwegian Twins, Røysamb et al. (2018) found the twin-cotwin correlations for life satisfaction for monozygotic twins $(r=.31)$ was much larger than for dizygotic twins $(r=.15)$. Grounded in the idea of the "hedonic treadmill" (Brickman \& Campbell, 1971), various "set-point" theories have been proposed to explain these findings. From this perspective, well-being is a homeostatic process that fluctuates around a relatively stable set-point (Cummins, 2015; Headey \& Wearing, 1989; Headey $\&$ Wearing, 1992). People differ in their set-points, and personality describes the dispositional mechanisms that influence how people experience and perceive the world, which in turn influences set-point dynamics (Headey \& Wearing, 1989; Headey \& Wearing, 1992).

\section{Descriptive Models of Personality Traits}

Personality traits describe relatively stable patterns of affect, cognition, and behavior. The early history of research on personality traits was characterized by a huge proliferation of trait constructs and scales to measure them. Subsequently, emerging from the lexical tradition in the United States, the Big Five traits of neuroticism, extraversion, openness, agreeableness, and conscientiousness has functioned as a powerful synthesizing framework (Costa \& MacCrae, 1992; Goldberg, 1993; McCrae \& John, 1992). However, the Big Five is not the 'only game in town'. In particular, the six factor HEXACO model, derived from the same lexical approach but in different (European and East Asian) language groups, has emerged as a prominent alternative to the Big Five (see Ashton et al., 2004; De Raad et al., 2014; Lee \& Ashton, 2004; Saucier, 2009). HEXACO 
is an acronym for the six broad traits of honesty-humility, emotionality, extraversion, agreeableness, conscientiousness, and openness.

There are strong similarities but also important differences between the Big Five and the HEXACO models (Ashton \& Lee, 2005; Ashton et al., 2014; Gaughan, Miller, \& Lynam, 2012; Ludeke et al., 2019). In particular, Big Five agreeableness and neuroticism are repartitioned in the HEXACO model to form the three domains of honesty-humility, agreeableness, and emotionality. Honesty-humility, characterized by integrity and modesty, is negatively correlated with antisocial personality traits (e.g., within the 'Dark Triad' framework; Lee \& Ashton, 2014) and positively correlated with the modesty and straightforwardness facets from Big Five agreeableness (Ashton \& Lee, 2005). HEXACO agreeableness captures patience, forgiveness, and a disposition to not experience anger towards others. Emotionality includes both the negative emotions of anxiety and fearfulness as well as more neutral emotional tendencies such as dependence and sentimentality. In general, conscientiousness, openness, and extraversion in the HEXACO framework are notionally close analogues to their Big Five equivalents (e.g., cross-correlations all above .75 for the NEO-PI R, Gaughan et al., 2012).

Both Big Five and HEXACO models are hierarchical frameworks, where each broad domain is characterized by a set of narrower traits or "facets" (see Table 1; for discussion see Anglim \& O'Connor, 2019). In the context of the Big Five, a range of facet-level frameworks have been proposed (e.g., Soto \& John, 2017), but the most popular hierarchical framework in research settings has been the NEO Model which characterizes the Big Five in terms of 30 facets (Costa \& McCrae, 1995). This model can be measured using the NEO PI-R, NEO PI-3, or the IPIP NEO (a public domain equivalent). More recently, an intermediate level between facets and domains has been proposed, whereby each Big Five domain is divided into two trait 'aspects' (DeYoung et al., 2007). Unlike the facets of the Big Five, the aspects were derived empirically, informed by quantitative genetic models and other considerations, and are thus purported to less arbitrarily cut nature "at the joints". The HEXACO model also has a hierarchical representation that includes 25 facets and 6 domains (4 facets for each domain and one interstitial facet) (Lee \& Ashton, 2018).

\section{Personality Traits and Well-Being: What We Know So Far}

Most research on the relation between personality and well-being has focused on the Big Five and the three dimensions of SWB (DeNeve \& Cooper, 1998; Steel et al., 2008). The results of Steel et al. (2008) were a watershed in this literature, as by this time the Big Five was sufficiently well-established, whereas the earlier meta-analysis by DeNeve and Cooper (1998) required many stand-alone traits to be identified by the authors as proxies of Big Five domains. Focusing exclusively on studies using the Costa and McCrae's NEO, Steel et al. (2008) found that neuroticism was the most consistent correlate of SWB followed by extraversion and then conscientiousness. The research also highlighted the unique profile of correlations across the dimensions of SWB where, for example, relatively larger correlations are seen between neuroticism and negative affect, extraversion and positive affect, and openness and positive affect.

Although no equivalent meta-analysis exists in relation to PWB, an emerging literature of primary studies has examined correlates with the Big Five (e.g., Grant et al., 2009; Schmutte \& Ryff, 1997; Shulman \& Hemenover, 2006). Initial research has highlighted the importance of neuroticism, extraversion, and conscientiousness in predicting PWB. Some research suggests that the Big Five may predict PWB more strongly than SWB (Anglim \& Grant, 2016). Importantly, each of the six scales have particular Big Five traits that appear to correlate more prominently (Anglim \& Grant, 2016; Grant et al., 2009; Meléndez et al., 2019; Sun et al., 2018), for instance, agreeableness and extraversion with positive relations, openness with personal growth, and 
conscientiousness with purpose in life. However, meta-analytic estimates are needed to provide a more definitive assessment of these unique cross-correlations.

More recently, researchers have correlated the six HEXACO personality domains with dimensions of SWB and PWB (Aghababaei, 2014; Aghababaei \& Arji, 2014; Aghababaei et al., 2016; MacInnis et al., 2013; Pollock et al., 2016; Romero et al., 2015; Sibley, 2011; Visser \& Pozzebon, 2013). Perhaps the most prominent difference seen in the results of these studies, compared to those based on the Big Five, is that HEXACO extraversion is the main correlate of well-being, whereas emotionality has a much weaker relationship. A comparative facet-level analysis of HEXACO and Big Five correlates would assist in understanding these differences.

Despite several existing meta-analyses mapping the Big Five domains with dimensions of SWB (DeNeve \& Cooper, 1998; Steel, Schmidt, Bosco, \& Uggerslev, 2019; Steel et al., 2008), there is a need for an updated meta-analysis of the relationship between the Big Five and SWB. The results of Steel et al. (2008) suggested much stronger and more nuanced relationships between personality and well-being than implied by the meta-analysis of DeNeve and Cooper (1998). However, Steel and colleagues restricted their focus to NEO personality measures, which represents only a fraction of the personality measures used in research. It is presently unknown whether the results of Steel et al. (2008) generalize to a wider range of Big Five measures. Furthermore, no meta-analysis exists relating the Big Five to the six dimensions of PWB and no meta-analysis exists relating HEXACO domains to either SWB or PWB. Fortunately, as a result of growing interest in these associations, there are now a sufficient number of primary studies to make such a meta-analysis worthwhile. Such an examination would complete the mapping of HEXACO and Big Five domains onto the dimensions of SWB and PWB and provide a more robust assessment of the relationship between Big Five personality and SWB.

Research Question 1: What are the meta-analytic correlations of the HEXACO and Big Five personality domains with SWB and PWB?

\section{Beyond Domains: How Well do Narrow Traits Predict Well-being?}

Several researchers have also considered the role of narrow traits of the Big Five in predicting well-being. Some of this research has focused on life satisfaction (Schimmack et al., 2004; Steel et al., 2019), SWB (Marrero Quevedo \& Carballeira Abella, 2011; Steel et al., 2008), or both SWB and PWB (Anglim \& Grant, 2016; Marrero, Rey, \& Hernández-Cabrera, 2016; Sun et al., 2018). Such research has often highlighted facets such as depression and positive emotions as important predictors, which in turn has highlighted how construct overlap may be relevant. This research fits into a broader literature discussing the importance of narrow traits in providing a more nuanced perspective on criteria of interest (Anglim \& Grant, 2014; Anglim \& O'Connor, 2019; Judge, Rodell, Klinger, Simon, \& Crawford, 2013; Mõttus et al., 2017; Ones \& Viswesvaran, 1996; Paunonen \& Ashton, 2001; Paunonen \& Jackson, 2000). It also relates to several unanswered questions about the relative predictive validity of broad and narrow traits, and the need for more empirical evidence regarding the factors that influence the degree of incremental prediction at the facet-level. Such factors may include personality-criteria correspondence, choice of hierarchical personality framework, sample characteristics, criteria characteristics, and measurement approaches.

In contrast to the Big Five, no robust facet-level analysis of the HEXACO model and wellbeing has been conducted. Importantly, reliable estimation would require large samples and the use of the 8-item per facet HEXACO 200 (Anglim \& O'Connor, 2019). At present, the best available data comes from a facet-level analysis performed by Aghababaei (2014) who correlated the facets of the HEXACO 60 (i.e., 2 or 3 items per facet) with a single item measure of life 
satisfaction in a sample of 288 students. They found that social self-esteem and liveliness had notably stronger correlations than the other HEXACO extraversion facets. The agreeableness facet of patience and the honesty-humility facet of fairness were also notably larger than other facets in their respective HEXACO domains. Also using the HEXACO 60, Aghababaei and Arji (2014) report correlations $(n=215)$ just for the honesty-humility facets with PWB dimensions and life satisfaction. They found that sincerity and fairness tended to have slightly larger correlations with PWB than the facets of greed-avoidance and modesty.

Although these studies have provided important insights, they have not satisfied the methodological requirements for a robust assessment of facet-level correlations and the incremental prediction of facets (Anglim \& Grant, 2014; Anglim \& O'Connor, 2019). First, facets and domains need to be measured reliably. In particular, a valid assessment of incremental prediction by facets requires reliable measurement of the variance in facets not shared with personality domains. This is best achieved through the use of long-form measures of personality such as the HEXACO 200, IPIP 300, and NEO PI R 240. Second, large samples are also required. A comprehensive examination of the facet-level correlates of HEXACO with well-being should also help to explain the differences between the HEXACO and Big Five frameworks. Furthermore, relatively little research has systematically examined facet-level correlates between Big Five and SWB / PWB. Some studies have suffered from small sample sizes, and there is a need for a consistent data analytic approach. In particular, examining semi-partial correlations between facets and criteria, after overlap with broad traits is removed provides a powerful way to identify which facets provide unique prediction. Thus, there is a need for large sample studies combining different personality frameworks including the Big Five and HEXACO perspectives.

Research Question 2: What are the correlations of the HEXACO and Big Five personality facets with SWB and PWB?

\section{Incremental Prediction of Facets over Domains}

Beyond estimating facet-level correlates, the degree to which facets provide incremental prediction of well-being remains a fundamental question. In particular, incremental prediction of facets overs domains is important for justifying the loss of parsimony that results from facet-level analyses. The degree to which facets incrementally predict well-being has been actively debated in the literature, especially in relation to life satisfaction (Anglim \& Grant, 2016; Steel et al., 2019; Steel et al., 2008). Although some data suggests that the variance explained in life satisfaction might double at the facet-level (Marrero Quevedo \& Carballeira Abella, 2011; Steel et al., 2019; Steel et al., 2008; Stephan, 2009), we suspect that the incremental prediction, though substantial, may be more modest than these data suggest. First, Marrero Quevedo and Carballeira Abella (2011) compared predictive validity of the NEO Big Five to a model that includes both the 30 facets of the NEO as well as optimism, self-esteem, and social support (i.e., variables outside the NEO framework). When focusing only on the 30 facets, incremental prediction was around $50 \%$. Second, Stephan (2009) examined the incremental validity of facets only with respect to their parent domain (i.e., the facets of openness were compared only to the domain of openness). However, this approach does not control for overlap that facets have with all other domains. It therefore risks over-estimating incremental variance explained by facets. Third, some early literature using small sample sizes (e.g., <200) compared unadjusted r-squared values of domain versus facet regression models. As discussed in Anglim and Grant (2014), applying a correction for the number of predictors in order to obtain unbiased estimates of population variance explained is essential, and one reasonable approach is to use an adjusted r-squared correction. This is particularly important in the context of domain and facet regression comparison because of the 
large difference in the number of predictors.

Fourth, Steel and colleagues (Steel et al., 2019; Steel et al., 2008) have conducted metaanalytic regression models to estimate facet-level prediction. However, because researchers rarely report facet-level intercorrelations, these meta-analytic facet-level regressions have to rely on sources other than the primary studies (e.g., test manuals). Facet-level correlations vary from study to study and the inability to accurately represent multicollinearity can dramatically inflate or distort variance explained in regression equations. This is already problematic for meta-analytic regression involving the Big Five domains, and is of more serious concern for regressions comprising 30 highly correlated facet predictors.

Finally, the few studies that have compared domain and facet regression models predicting life satisfaction using the NEO framework and reasonable sample sizes have obtained the following domain and facet adjusted r-squared values, respectively: .40 versus .52 with $n=337$ (Anglim \& Grant, 2016); .16 versus .22 with $n=554$ (based on stepwise facet regression, Marrero Quevedo \& Carballeira Abella, 2011); and .24 versus .32 with $n=1,516$ (Røysamb et al., 2018). Thus, an increase in prediction by facets relative to domains of between $20 \%$ and $60 \%$ seems more likely for life satisfaction. Beyond life satisfaction, Anglim and Grant (2016) also examined incremental prediction in relation to the nine SWB and PWB variables. Although their sample size was too small to yield precise estimates, they found some evidence for levels of incremental prediction varying across outcomes whereby life satisfaction, autonomy, purpose in life, and selfacceptance had relatively more incremental prediction.

In summary, the question of incremental prediction of facets over domains in relation to well-being remains unanswered, and methods for synthesizing research findings regarding incremental prediction are still in their infancy. We propose that in addition to measuring criteria of interest, primary studies need to measure reliable full-length hierarchical measures of personality (i.e., typically 8 or more items per facet), and they need to provide (a) raw data, (b) a full inter-correlation matrix between facets, domains, and criteria, or (c) a valid estimate of incremental variance explained consistent with the approach adopted in the meta-analysis; i.e., typically this would be the difference in adjusted r-squared between domain and facet regression models, but other approaches such as bifactor models also have merit (Anglim, Morse, De Vries, MacCann, \& Marty, 2017; Chen et al., 2012). In addition, particularly large samples are needed when estimating incremental prediction of facets with the necessary precision. By obtaining such data, it would be possible to estimate incremental prediction of facets in each sample, and synthesize these findings. Such research could examine how incremental prediction of facets varies across well-being scales (e.g., SWB and PWB scales), personality questionnaires (e.g., IPIP NEO versus NEO PI), personality frameworks (Big Five versus HEXACO), and target populations.

Research Question 3: What is the relative prediction of broad and narrow personality traits in relation to SWB and PWB and how does this vary across the Big Five and HEXACO?

\section{The Present Research}

In seeking to answer these three research questions, the overall objective of this research is to thoroughly describe relations that the domains and facets of HEXACO and Big Five personality have with the dimensions of SWB and PWB. To achieve these aims, we conducted a set of comprehensive analyses of published domain-level correlations and facet-level datasets. To understand domain-level correlations (RQ1), we conducted a meta-analysis of the domain-level correlates of HEXACO and Big Five personality with the dimensions of SWB and PWB.

To provide a systematic assessment of facet-level correlations (RQ2) and incremental 
prediction of facets-over-domains (RQ3) across well-being measures and various Big Five and HEXACO frameworks, we adopted a multi-pronged approach. This included collecting new data, re-analyzing partially reported raw-data, merging datasets where equivalent measures were used, and analyzing complete correlation matrices where these were reported. All of the datasets involved included (a) the nine well-being variables, (b) reliable, full-length personality measures, and (c) moderate to large sample sizes. Importantly, the combined sample size of these datasets is an order of magnitude larger than previous attempts to estimate incremental prediction of facets, and will thus provide the first robust examination of that question.

\section{Method}

All data, scripts, materials, and supplementary analyses are available on the Open Science Framework: https://osf.io/42rsy

\section{Meta-Analysis}

Our meta-analysis served to estimate cross-sectional self-report relations that the HEXACO and Big Five Domains have with SWB and PWB.

Literature search. The literature search sought to identify any study that reported a correlation between Big Five or HEXACO Personality and the dimensions of SWB or PWB. The final literature search reported in this study was conducted in August 2019. Keyword searches were conducted in Scopus and PsycInfo, which included dissertations and foreign language articles. The primary search sought to identify articles that included (a) at least one personalityrelated keyword indicating that the Big Five or HEXACO was used, which included any personality domain name (e.g., extraversion, neuroticism, honesty-humility) or a common test or framework name (e.g., BFI, NEO, HEXACO, Big Five, Big 5, FFM, Five Factor Model, etc.) (b) the word "personality", and (c) a well-being related term (e.g., SWB, PWB, subjective wellbeing, life satisfaction, satisfaction with life, positive affect, negative affect, etc.). Second, a search for well-being related terms was performed on the more than 600 HEXACO-related references listed on http://hexaco.org/references. Third, references from key meta-analyses on personality and well-being were included (i.e., DeNeve \& Cooper, 1998; Heller, Watson, \& Ilies, 2004; Lucas \& Fujita, 2000; Steel et al., 2019; Steel et al., 2008).

After merging the above sources and removing obvious duplicates, the combined dataset consisted of 2472 articles. Based on title and abstracts screening, the full-text was examined for $60.5 \%$ of these articles.

In addition to the articles that met the inclusion criteria, a further 249 articles were identified where relevant variables were measured but the correlations were not reported or not completely reported. The corresponding author of each of these articles was sent an email inviting them to provide either the correlation matrix or the data from which we could compute the correlation matrix. When a working corresponding author's email could not be found, another author or Doctoral supervisor was emailed. Contacted authors also provided several additional studies that met the inclusion criteria of our meta-analysis. Several of these additional studies were unpublished or from articles where the correlations were not reported. This process of contacting authors resulted in 68 additional studies being included in the meta-analysis (11 supplied data; 57 supplied correlation matrices).

Several additional sources of correlations were as follows: We obtained correlations from 6 studies where the correlation matrices were not otherwise published that were reported in the meta-analysis on personality and various forms of satisfaction by Heller et al. (2004). We included the domain-level correlations from the two facet-level studies reported in the current paper that have not previously been reported (i.e., the Combined Dataset and the NEO Dataset). We also 
computed correlations for six studies that did not report correlation matrices but included a dataset with the publication (e.g., data on the OSF, PlosOne, other data repository).

After collating the studies, 17 studies were excluded for one of the following reasons. First, studies were excluded if they reported correlations that used a sample that overlapped with another study. This was common with large panel studies such as the GSOEP, HILDA, BHPS, and MIDUS as well as some individual small-scale studies. In these cases, we sought to retain the article that provided the most comprehensive study in terms of sample and measurement. Second, several studies were excluded because they used non-standard measurement of personality or well-being that was not initially excluded by our exclusion rules, but were flagged because they produced outlier correlations (e.g., IPIP HEXACO, asking about life satisfaction in the past, etc.). Third, we excluded studies that had outlier correlations combined with other concerns about data integrity. In several studies, there were strong indicators that a large proportion of participants were not completing the study conscientiously as evidenced by use of samples such as Mechanical Turk, very large average correlations between the Big Five (e.g., above .6), exclusion of large numbers of participants due to failing attention checks combined with attention checks that would not be sufficient to identify all non-conscientious responders, and relatively undifferentiated personalitywell-being correlations. Other indicators of concern included correlations close to zero between well-being variables and poorly written manuscripts.

The final cleaned database consisted of 377 articles and 462 studies. Note that in six samples both HEXACO and Big Five personality were measured and these were treated as two separate studies. Likewise, some articles reported correlations separately for different groups (e.g., males and females; patients and controls) and these were also treated as separate studies. Articles were retained if they reported a correlation between a relevant personality variable (i.e., HEXACO or Big Five) and a relevant well-being variable. In order to focus our primary meta-analytic estimates on studies that used reliable measures, we classified correlations into core and noncore. If the personality trait was measured with eight or more items and the well-being dimension was measured with five or more items, the correlation was classified as core. For reporting purposes, we classified a study as core if it had one or more core correlations. Sixteen studies had a mix of core and non-core correlations.

Importantly, in recent years there has been a proliferation of short-form measures of personality (e.g., TIPI, BFI 10, Mini-IPIP, etc.). There are also a wide range of short-form adaptations used in individual studies. In contrast, studies classified as core tended to use wellvalidated and well-established measures of personality and well-being. The focus on these core studies also makes results more comparable across the Big Five and HEXACO, where HEXACO personality is typically measured with 60,100 and 200 item formats. It also enables more direct comparison with the meta-analysis by Steel et al. (2008) which focused exclusively on the NEO where the most common formats involve 12 (NEO FFI) and 48 (NEO PI R) items per factor, respectively. It also reduces the need to rely on problematic assumptions related to estimating reliability and correcting for measurement error. Nonetheless, we do report results for the full set of studies in the section on moderator analysis.

Eligibility criteria and data coding procedures. Several criteria needed to be satisfied for correlations to be retained in the meta-analysis. For consistency, the study needed to involve self-report measurement of both personality and well-being. Second, personality needed to be measured with either a standard measure of the HEXACO (e.g., HEXACO 60, 100, 192, 200, etc.) or a measure explicitly designed to assess the Big Five. We excluded the one study by Churchyard, Pine, Sharma, and Fletcher (2014) that used the IPIP HEXACO, largely because 
this is based on an early model of HEXACO that excluded social self-esteem. This also resulted in the exclusion of studies that used the Eysenck Personality Inventory (EPI) or the Eysenck Personality Questionnaire (EPQ). Detailed meta-analysis of the EPI and EPQ are already available in Steel et al. (2008) and we wanted to focus on measures that were explicitly designed to partition personality trait variance into the Big Five or HEXACO. We similarly excluded measures that can be scored to derive a Big Five measure but were not designed to measure the Big Five.

Third, the well-being measure needed to be designed to measure satisfaction with life, positive affect, negative affect (i.e., SWB) or the six scales of Ryff's measure of PWB. In relation to life satisfaction, we sought to only include pure measures of life satisfaction. Life satisfaction was typically (82\%) measured using Diener's Satisfaction with Life Scale (Diener, Emmons, Larsen, \& Griffin, 1985). We also included single-item measures of life satisfaction, composite measures of life satisfaction that sum satisfaction with various life domains (e.g., Personal WellBeing Index), modified versions of the Satisfaction with Life Scale, and a few other focused scales. We excluded any life satisfaction measure which included a broader set of well-being indicators.

To be included, positive affect and negative affect needed to be measured as the sum of items asking about the frequency of experiencing a set of positive and negative emotions, respectively. The vast majority $(86 \%)$ of studies used the PANAS (Watson, Clark, \& Tellegen, 1988) or a variant of the PANAS. We excluded studies that measured affect using experience sampling methods because there was a lack of standardization in how affect was measured and aggregated to the person-level. We also excluded measures of affect that were obtained following experimental manipulation or that were in response to stimuli.

To be included, PWB needed to be measured using an official measure of Ryff's conception of the six dimensions of PWB. This mostly included 42-, 54-, and 84-item versions of Ryff's scales and their translations. We focused exclusively on the six scales and not overall measures of PWB.

Data extraction. For each included study, we extracted the following study features: sample size, personality measure, life satisfaction measure, positive affect measures, PWB measure, proportion female, mean age, country of sample, type of sample (e.g., university students, Mechanical Turk, Workers, Community, etc.), the source of the correlations (e.g., from the article, provided following correspondence with author, etc.), reference details, and additional notes. Correlations were extracted by copying the correlation matrix into Excel, extracting the correlations in the order they appeared in the correlation matrix and then using data transformations to convert into a standardized order. All study feature and correlation extraction was performed by the first- and fifth-author of this paper. All correlations were extracted by one author and checked for accuracy by the other. To further identify data entry errors, reporting errors by original authors, and problematic studies, we obtained z-scores for all correlations by correlation type (i.e., there were 99 different types of correlations based on the 11 personality traits and 9 well-being variables). We closely examined correlations with absolute z-scores larger than 2.5. In a few cases, researchers had made an error in reporting their correlations (e.g., omitting the minus sign on correlations with neuroticism) and this was corrected. In other cases, we examined the study more carefully and identified indicators that the study was problematic (non-conscientious participants; failure to exhibit universal features of correlations in this area such as correlations between wellbeing), and these studies were excluded as described earlier.

Data analytic approach. Meta-analytic correlations were estimated using a randomeffects model using the metafor package in $R$ (Viechtbauer, 2010). The standard deviation of true effect sizes (i.e., $\tau$ ) was estimated using restricted maximum-likelihood estimation. Meta- 
analytic estimates were obtained using both observed correlations and correlations corrected for measurement error. Relatively few studies provided scale-level reliability information, so we relied on more general sources based on the test used, and where this was not available we estimated reliability as the average reliability for tests in the database with equivalent numbers of items per factor.

\section{Facet-Level Analysis}

Identifying datasets. In order to provide a comprehensive assessment of facet-level correlates and incremental prediction, we sought to identify all studies that had included a hierarchical measure of personality that enabled reliable facet-level measurement, and that included measurement of SWB and PWB. In order to estimate incremental prediction, we needed to have either (a) the raw data, (b) the full correlation matrix between facets, domains, and criteria, or (c) the adjusted r-squared values for the domain and facet regression equations. Based on these criteria, we identified three existing datasets that could be analyzed: the NEO Dataset (Marrero et al., 2016), the IPIP NEO Dataset (Anglim \& Grant, 2016), and the Big Five Aspects Dataset (Sun et al., 2018). We also conducted an additional study that measured 200-item HEXACO PI R, 300item IPIP NEO, and well-being. Importantly, this study provided a facet-level assessment using the HEXACO model, and substantially increased the sample size for the IPIP NEO. The resulting four datasets each provide the large samples needed for assessment of incremental variance explained by facets over domains.

We note that the identification of the above datasets was based on a systematic search of studies measuring personality facets with any measure of SWB or PWB. Common issues included (a) very small sample sizes for estimating incremental prediction (e.g., under 200), (b) only partial measurement of facets, (c) focus on a limited set of well-being measures (e.g., only life satisfaction was common), (d) use of non-standard measures of PWB, (e) the study was a meta-analysis, (f) the study was a re-analysis of existing data, or (g) the personality assessment had poor facet-level psychometric properties. We briefly note two relevant datasets that did involve large samples. First, Røysamb et al. (2018) does provide a valid estimate of incremental prediction of life satisfaction by the NEO PI-R. However, they did not measure any other well-being indicators. Second, Romero et al. (2015) reported domain-level correlations (but nothing at the facet-level) between personality (HEXACO 100 and NEO PI-R) and dimensions of SWB and PWB. However, we were unable to obtain the data or full facet-level correlations needed to estimate incremental prediction in this dataset.

\section{Datasets.}

NEO Dataset. Participants were 1,673 Spanish adults (52\% female; age in years $\mathrm{M}=38.9$, $\mathrm{SD}=13.3$, range: 17 to 89 ). Participants were recruited by university students instructed to target participants of different ages and professions. Participants completed Spanish translations of the NEO PI R and well-being measures, administered individually. Although a subset of this data was analyzed in Marrero et al. (2016), facet-level correlations and incremental prediction by facets were not reported. Thus, the analyses presented here are novel. Moreover, this is the largest sample yet reported examining a hierarchical measure of personality in combination with a full set of SWB and PWB measures. This large sample is particularly crucial for deriving precise estimates of incremental prediction.

Combined Dataset. We conducted a new study where me measured the HEXACO PI R, the IPIP NEO, and both SWB and PWB. This enabled (a) the first rigorous estimate of HEXACO correlates of SWB and PWB at the facet-level, (b) a more robust assessment of the correlates of the IPIP NEO with SWB and PWB, (c) clarity regarding the similarities and differences between 
the HEXACO and IPIP NEO frameworks, and (d) an opportunity to examine the combined prediction of HEXACO and the IPIP NEO. The final sample consisted of 465 Australian university students ( $79 \%$ female; age in years $\mathrm{M}=25.1, \mathrm{SD}=7.8$, range: 18 to 56 ), based on an initial sample of 578 , from which 113 cases were dropped because of incomplete data. Due to the large number of items, data was collected online over two sessions. In the first session, participants completed demographics, the 300-item IPIP personality measure, the well-being measures, and measures that did not form part of this study (i.e., problematic smartphone usage, reported in Horwood \& Anglim, 2018; Horwood \& Anglim, 2019). In the second session, completed on average 28 days later, participants completed the 200-item HEXACO PI R.

IPIP Dataset. This sample $(n=903)$ combines data from three related sources. First, it uses the IPIP NEO data from the Combined Dataset $(n=465)$. Second, it includes cases from the Combined Dataset that were excluded because they did not have matching HEXACO data $(n=$ 102). Finally, 336 cases were obtained from Anglim and Grant (2016), which was also based on an Australian university student sample and used identical measures of personality (i.e., the 300 item IPIP NEO Inventory) and well-being to those used in the Combined Study.

HEXACO Dataset. This is the Combined Dataset focusing on the HEXACO-PI-R data ( $n$ $=465)$.

Big Five Aspects Dataset. A study by Sun et al. (2018) examined the The Big Five Aspects in relation to SWB and PWB across two samples $(n 1=205, n 2=501)$. We pooled the correlations across the two datasets by weighting correlations by their respective sample sizes, giving a final sample size of 706. Although Sun et al. (2018) reported the variance explained by the 10 aspects, they did not report the variance explained by the Big Five. Thus, we sought to compute this value and thereby assess the incremental prediction of the 10 aspects over and above the Big Five. We calculated adjusted $\mathrm{r}$-squared using the setCor function in the psych package in $\mathrm{R}$ (Revelle, 2018) which enables regression analyses to be performed on correlation matrices.

\section{Measures.}

Satisfaction with Life Scale. This well-established 5-item measure (Diener et al., 1985) provides a measure of overall life satisfaction. Items were rated on a 7-point scale $(1=$ strongly disagree, $2=$ disagree, $3=$ slightly disagree, $4=$ neither agree nor disagree, $5=$ slightly agree, $6=$ agree, $7=$ strongly agree). The scale score was the mean of items. The NEO Dataset used the Spanish version of the measure (Vázquez, Duque, \& Hervás, 2013), and the English version was used in all other datasets.

Positive and Negative Affect. The IPIP, HEXACO, and NEO datasets measured positive and negative affect using the PANAS (Watson et al., 1988). The PANAS consists of two scales that measure the frequency with which positive and negative affect is experienced. In the current study, participants were asked about how frequently they had experienced the emotions in "the past few weeks". The 20 items each concerned a different emotion and were rated on a 5-point scale $(1=$ very slightly or not at all, $2=$ a little, $3=$ moderately, $4=$ quite a bit, $5=$ extremely $)$. Scales were scored as the mean of items. The NEO Dataset used a version of the measure translated into Spanish by Marrero et al. (2016). The Big Five Aspects Dataset measured positive and negative emotions using six-items from the PERMA-Profiler (Butler \& Kern, 2016).

Psychological Well-Being. Ryff's (1989) scales were used to measure the six proposed dimensions of psychological well-being. Items were rated on a 6-point scale $(1=$ strongly disagree, 2 = disagree somewhat, $3=$ disagree slightly, 4 = agree slightly, $5=$ agree somewhat, $6=$ strongly agree). The scale consisted of positively and negatively worded items, and scale scores were the mean after item reversal. The NEO Dataset used the 84-item Spanish translation of Ryff's PWB 
measure (Díaz et al., 2006). The IPIP and HEXACO datasets used the standard 84-item version. The Big Five Aspects datasets included two samples, where Sample 1 used the 54-item version and Sample 2 used the 42-item version.

NEO Personality. The NEO Dataset measured the Big Five and 30 Facets of the NEO model of personality using the official Spanish translation of the 240-item Revised NEO Personality Inventory. Four items were excluded because of low corrected-item-total correlations $(<.20)$.

IPIP NEO Personality. The IPIP and Combined Datasets measured the 30 facets and five domains of the NEO model (Costa \& McCrae, 2008) using the 300 item IPIP-NEO Inventory (Goldberg, 1999; Goldberg et al., 2006). Items were rated on a 5-point scale $(1=$ very inaccurate, $2=$ moderately inaccurate, $3=$ neither inaccurate nor accurate, $4=$ moderately accurate, $5=$ very accurate). Scale scores were the mean after any item reversal. The scales have an average correlation with corresponding NEO-PI-R scales of .73, or .94 when corrected for measurement error (Goldberg, 1999).

HEXACO Personality. The HEXACO Dataset measured personality traits using the fulllength 200-item version of the HEXACO PI-R (Ashton et al., 2014; Lee \& Ashton, 2004, 2006). The measure consists of six domain scales and 25 facet scales. Each domain scale consists of four facet scales, and there is one interstitial facet, altruism. Participants responded to items on a scale from $1=$ strongly disagree to $5=$ strongly agree. Scale scores were obtained as the mean of items after any necessary item reversal. To increase comparability with the Big Five, a HEXACO Neuroticism factor was computed as weighted composite facets as set out in Lee and Ashton (2013): HEXACO Neuroticism $=$ Fearfulness $+3 *$ (Anxiety) + Dependence $+3 *(6-$ Social Self-Esteem $)+(6$ - Liveliness $)+(6-$ Patience $)+(6-$ Prudence $)$.

Big Five Aspects Personality. In the Big Five Aspects Dataset, the 5 domains and 10 aspects were measured using the 100-item Big Five Aspect Scales (DeYoung et al., 2007). The Big Five Aspect Scales were developed using items from the IPIP. The response scale ranged from $1=$ strongly disagree to $5=$ strongly agree.

Data analytic approach. We broadly followed the methodology for reporting facet-level correlations and incremental prediction set out in Anglim and Grant (2014). For each personality measure we report zero-order correlations between facets and the dimensions of SWB and PWB. In the supplement, we report semi-partial correlations that remove the shared variance between the facet and the five domain-level personality factors. They provide an estimate of the unique prediction provided by the facets over and above the domains. The square of the semi-partial correlation is equivalent to the percentage of incremental variance explained by a regression model that adds the facet of interest (e.g., gregariousness) as a predictor to one with only the domains (e.g., the Big Five). Incremental prediction of facets over domains was obtained by taking the difference in the adjusted r-squared values for a regression model with domains as predictors to one with facets as predictors.

\section{Results}

\section{Summary of the Literature}

A summary of the studies included in the meta-analysis is provided in Table 2 with further details provided in the OSF repository. In total, the meta-analysis included 4,153 correlations (3,246 core; 907 noncore). Table 3 provides an overview of the included studies for the combined, core, and noncore samples. The combined sample consisted of 462 studies and a total sample of 334,567 participants. Most scales of personality measures involved 8 to 15 items. The most common personality frameworks were the NEO and the BFI. The number of studies that met the 
inclusion criteria has grown dramatically since the meta-analysis by Steel et al. (2008). More studies were from the five-year period from 2010-to-2014 than from before 2010, and in the last 4.5 years the number of studies per year has increased even further. This may reflect the general growth in science, the expanding number of journals, the accessibility of international journals and $\mathrm{PhD}$ theses, and the increasing popularity of the Big Five, the PANAS, and life satisfaction measurement.

\section{Meta-Analytic Correlations}

Table 4 provides an overall summary of the meta-analytic correlations between personality and well-being based on the core studies. Detailed reporting of the meta-analytic observed and reliability-corrected correlations between Big Five and SWB (Table 5), Big Five and PWB (Table 6), HEXACO and SWB (Table 7), and HEXACO and PWB (Table 8) are presented for the core studies.

Overall, the average correlation between personality domains and well-being was .28. If negative affect is reversed, the mean meta-analytic correlation averaged over the nine well-being indicators for the Big Five domains were -.46 (neuroticism), .37 (extraversion), .19 (openness), .25 (agreeableness), and .36 (conscientiousness). The corresponding values for HEXACO domains were .16 (honesty-humility), -.16 (emotionality), .48 (extraversion), .18 (agreeableness), .28 (conscientiousness), and .16 (openness). Thus, for the Big Five, neuroticism was the strongest correlate followed by extraversion and conscientiousness; correlations for openness and agreeableness were more moderate. For HEXACO, extraversion was clearly the strongest correlate. As discussed earlier, although the content of HEXACO emotionality has some similarity with Big Five neuroticism, it also has important differences, and thus it is perhaps not surprising that it had a much weaker correlation with well-being. HEXACO conscientiousness and openness exhibited similar correlations with well-being to their Big Five analogues. The average correlations with well-being for honesty-humility and HEXACO agreeableness were also similar to the correlation for Big Five agreeableness. Results also showed that the variance in observed correlations was greater for the Big Five than for the HEXACO; this is consistent with the greater variability in questionnaires used to measure the Big Five.

To assess which combinations of personality and well-being dimension were uniquely related, we performed a marginalization procedure on the meta-analytic corrected correlation matrix (see Online Supplement). Specifically, we reversed negative affect, neuroticism, and emotionality so that all variables were positively aligned with well-being. We then subtracted the overall mean correlation, and the row and column marginal means from the correlation matrix (for further details of the procedure see, Anglim \& Grant, 2016). Large residual cross-correlations (e.g., above .10 or .15) highlight the unique profile of the personality-well-being relationship, where positive residuals indicate that the pair of variables is more related than expected, and negative residuals indicate that the pair of variables is less related than expected. Absolute residuals greater than .12 for the Big Five were reversed neuroticism with reversed negative affect (.14), and personal growth (-.15); openness with personal growth (.22); agreeableness with positive relations (.13) and autonomy (-.13), and conscientiousness with purpose in life (.13). For HEXACO, these were reversed emotionality with reversed negative affect (.19), positive relations (-.18), autonomy (.22), and purpose in life (-.14); agreeableness with autonomy (-.13); conscientiousness with purpose in life (.18); and openness with autonomy (.12) and personal growth (.15).

Table 9 presents the meta-analytic estimate of the correlations between the Big Five and SWB across various moderators (i.e., core and non-core studies, item length, and personality measurement type) and compares results with past meta-analyses. It also reports the mean and 
standard deviation of correlations after reversing the negative correlations (i.e., $\mathrm{N}$ with PA, N with $\mathrm{SWL}$, and $\mathrm{E}, \mathrm{O}, \mathrm{A}, \mathrm{C}$ with NA). The mean correlation indexes the extent to which personality is related to well-being. The standard deviation of correlations indexes the degree to which a nuanced profile of personality correlates is provided as opposed to a more homogenous set of correlations. Overall, the pattern of correlations is fairly robust across different types of measures and different item lengths. Nonetheless, consistent with reduced reliability of measurement and potentially validity, noncore studies and extra-short measures had weaker correlations with well-being.

In general, there was a high degree of consistency across the different personality frameworks, although the TIPI was notably less consistent. The BFAS had somewhat stronger average correlations and the TIPI had weaker average correlations. The NEO and BFAS had larger standard deviations. To quantify the consistency across frameworks, we created a data frame that had 15 rows for the 15 absolute SWB correlations and 7 columns for the 7 personality frameworks. We then computed the average correlation each framework had with the other six frameworks. These correlations were .88 (NEO), .88 (IPIP), .90 (BFAS), .87 (BFI), .74 (TIPI), .90 (Adjectives), and .84 (Other).

Table 9 also compares meta-analytic correlations of the current study with that of previous meta-analyses. A major conclusion of Steel et al. (2008) was that personality is more strongly related to well-being than was found in the meta-analysis of DeNeve and Cooper (1998). Whereas DeNeve and Cooper (1998) synthesized a mostly pre-Big Five literature, Steel et al. (2008) focused exclusively on the NEO framework. The current meta-analysis found meta-analytic correlations between personality and well-being that were slightly larger than Steel et al. (2008). Importantly, the current results indicate that this finding is not limited to the NEO framework, but is shared across a broad range of personality measures that are intended to measure the Big Five.

The pattern of correlations in the current meta-analysis was almost identical to that obtained in Steel et al. (2008), but quite different to that of DeNeve and Cooper (1998). To quantify this, we first treated the 15 absolute correlations between Big Five personality and SWB (i.e., SWL, PA, NA) for the three meta-analyses (i.e., current study, Steel et al., and DeNeve \& Cooper) as a vector. The correlation between the 15 Big Five-SWB-absolute-correlations was $r=.991$ (Current study with Steel), $r=.689$ (Current study with DeNeve), and $r=.679$ (DeNeve with Steel). Thus, it seems that categorizing historical measures of personality into Big Five frameworks as was done by necessity in DeNeve and Cooper (1998) only provides an approximation of how Big Five personality actually correlates with well-being.

Finally, a publication bias analysis was conducted. There are several reasons to expect publication biases to be minimal in this context. First, the majority of primary studies have a high degree of power to detect the main correlations between personality and well-being. For example, a study with $n=200$ has $99 \%$ statistical power to detect a population correlation of .30 at a .05 significance threshold. Second, many studies measure personality and well-being incidentally as part of broader studies of individual differences and there is no obvious incentive to show a specific pattern of correlations between personality and well-being. Nonetheless, we examined funnel plots for the 99 correlation types (i.e., 11 personality traits by 9 well-being variables) and calculated the rank test for funnel asymmetry (Begg \& Mazumdar, 1994). After reversing neuroticism, emotionality, and negative affect, none of the correlations examined exhibited significant positive asymmetry.

\section{Well-Being Intercorrelations}

In order to contextualize the meta-analytic and facet-level analyses, we present estimates of the intercorrelations between dimensions of well-being. Table 10 presents correlations among 
the nine well-being scales for the Combined and the NEO Datasets. Reflecting a general wellbeing factor, the average correlation between well-being variables was .51 in the Combined Dataset. Consistent with the focus on the scale-level, when factor analysis is performed and two factors are extracted, loadings for the nine scales do not align with higher-order PWB and SWB dimensions. Life satisfaction shared the greatest overlap with self-acceptance, although correlations were relatively large for most other well-being scales, with the exception of autonomy and personal growth.

\section{Facet-Level Correlations}

We first examined the degree to which the domain correlations between personality and well-being in the facet-level datasets were consistent with the core meta-analytic estimates. In general, there was very strong convergence with the pattern of domain correlations for all the facetlevel datasets: NEO $(r=.94)$, IPIP $(r=.95)$, HEXACO $(r=.96)$, Big Five Aspects $(r=.89)$ datasets (see Supplement for details). Average correlations between personality and well-being were higher (mean difference study and meta-analytic correlations in parentheses) than metaanalytic estimates for the IPIP $(M=.06)$ and Big Five Aspects $(M=.12)$, but similar for HEXACO $(M=.03)$ and NEO $(M=-.03)$.

Zero-order correlations between personality facets and well-being are presented for NEO (Table 11), IPIP NEO (Table 12), and HEXACO (Table 13). Domain-level correlations for the NEO and IPIP NEO datasets are reported in the supplement. Semi-partial correlations that involved removing overlap between each facet and the corresponding domain scores are also reported in the supplement. For the NEO, the strongest average correlations with well-being are seen for depression (-.46), vulnerability (-.44), and competence (.41). For the IPIP NEO, semipartial correlations frequently highlighted depression as an incremental predictor over and above the Big Five. Positive emotions was also a prominent incremental predictor in relation to satisfaction with life, positive affect, and self-acceptance. Various other semi-partial correlations emerged consistent with the unique profile of the well-being variable (e.g., purpose in life with achievement striving and autonomy with angry hostility (+), self-consciousness (-), and assertiveness $(+))$. For the HEXACO, social self-esteem and liveliness emerged as the strongest average predictors of well-being. Differential correlations of emotionality facets highlight why emotionality correlated much less with well-being overall. Specifically, anxiety and to a lesser extent fearfulness had strong negative correlations with well-being whereas dependence and sentimentality did not. Similarly, with regards to conscientiousness, it was mostly diligence that had the stand-out correlations.

\section{Incremental Prediction of Facets over Domains}

In order to examine the variance explained by broad and narrow traits across the four datasets, regression models were estimated predicting each well-being variable from either the broad or the narrow traits for the given personality measure. The variance explained by broad and narrow traits (adjusted r-squared) for each measure is shown in Table 14. Two measures of incremental prediction of narrow traits are also provided: raw incremental prediction by narrow over broad traits and proportional increase of narrow traits relative to broad traits.

On average, broad traits explained $46 \%$ of variance and narrow traits explained $53 \%$ for an average proportional increase of facets over domains of $18 \%$ (21\% if you exclude the Big Five Aspects data). Despite differences in the overall magnitude of prediction (i.e., Big Five Aspects and IPIP NEO explained more than HEXACO and NEO), the general pattern of well-being predicted by domains and facets/aspects was similar across NEO, IPIP NEO, and HEXACO, but distinct for the Big Five Aspects. On average, PWB variables were better predicted by personality 
than SWB variables. IPIP NEO and HEXACO had larger incremental prediction than the NEO and Big Five Aspects, although the difference for the NEO was reduced when incremental prediction was defined as a proportion, due to the relatively lower levels of prediction in the NEO sample. Overall, the greatest proportional increase in variance explained by facets was seen for life satisfaction, autonomy, self-acceptance, and purpose in life.

\section{HEXACO versus Big Five Comparison}

In order to contextualize the meta-analytic finding and frame a comparison of HEXACO and Big Five, Table 15 presents the correlations between HEXACO and Big Five domains using the Combined Dataset. All analogous scales between HEXACO and Big Five correlated greater than .50. Interestingly - though unsurprisingly, given the rotational differences between the two models - honesty-humility correlated more with Big Five agreeableness than did HEXACO agreeableness. Of relevance to understanding correlations with well-being, HEXACO extraversion correlated more with neuroticism than did HEXACO emotionality.

Table 16 presents the domain-level correlations for HEXACO and IPIP NEO Domains with well-being dimensions in the combined dataset. The pattern of correlations is broadly similar to the meta-analytic findings, albeit the correlations are slightly stronger on average. This may reflect the use of particularly reliable personality and well-being measures in this study. We also computed the HEXACO Neuroticism domain score using the weighted facet-composite described in the method. This yielded a pattern of correlations that was very similar to IPIP NEO Neuroticism.

In order to compare the HEXACO and Big Five models of personality in terms of the prediction of well-being dimensions, regression models were estimated (using the Combined Dataset) predicting each well-being variable from various sets of personality predictors: i.e., HEXACO Domains, NEO Domains, HEXACO Facets, NEO Facets, and the different combinations of Domains and Facets from both instruments. The variance in well-being explained by each set of predictors, using adjusted r-squared to penalize for overfitting, is shown in Table 17. On average, NEO Domains explained more variance than HEXACO Domains and NEO facets explained more variance than HEXACO facets. HEXACO facets explained about $22 \%$ more variance (mean increase of adjusted r-squared of .09) than HEXACO domains, and NEO Facets explained about 18\% more variance than NEO domains (mean increase of adjusted r-squared of .12). Satisfaction with life showed the largest relative increase in prediction when moving from domains to facets: $52 \%$ for HEXACO and $41 \%$ for NEO, although in terms of absolute increase, self-acceptance showed similar increases. Whereas the HEXACO facets improved prediction when added to a model with NEO Domains, adding HEXACO Domains or HEXACO Facets to a model with NEO Facets led to almost no improvement in prediction.

\section{Discussion}

The present study provides a comprehensive examination of the links between self-reported personality and well-being, using both the HEXACO and Big Five frameworks of personality, broad and narrow traits within each of these frameworks, and both evaluative (i.e., SWB) and eudaimonic (i.e., PWB) conceptualizations of well-being. Whereas previous meta-analyses have either relied on pre-Big-Five measures or a single Big Five personality framework, the current study incorporated a broad range of Big Five measures and synthesized the large body of research that has emerged in recent years. Whereas previous meta-analyses have examined the relationship between the Big Five and SWB, none have examined the Big Five in relation to PWB, and none have examined the HEXACO framework at all. The study also provides the first robust assessment of incremental prediction by facets across both SWB and PWB and two major personality 
frameworks.

Several important findings emerged from this investigation. First, the research confirms that the overlap between basic personality traits and well-being dimensions is substantial. Second, whereas (lower) neuroticism is the strongest correlate of well-being within the Big Five framework, extraversion is the strongest correlate within the HEXACO framework. Conversely, conscientiousness - which previous research has rarely highlighted in relation to well-being - is a notable correlate within both frameworks. Third, correlations with personality mirror the unique characteristics of different dimensions of well-being. For example, notably strong correlations were observed between openness and personal growth, between conscientiousness and purpose in life, and between neuroticism and negative affect. Fourth, examination of facet-level correlates highlighted the unique importance of particular facets (e.g., depression and positive emotions in the Big Five framework and social self-esteem in the HEXACO framework) as well as explaining differences between the HEXACO and Big Five frameworks. Fifth, facets provided moderate levels of incremental prediction over and above domains when predicting well-being. Across multiple measures of the Big Five and HEXACO frameworks there were moderate levels of consistency in the degree of incremental prediction by facets. These findings have fundamental implications for understanding well-being, in terms of the role that both broad and narrow personality traits may play in human flourishing.

\section{Personality and Well-Being}

According to effect size guidelines in individual differences research (e.g., Gignac \& Szodorai, 2016), the relationship between personality and well-being is strong. The average correlation between personality domains and well-being was $r=.28$, considerably higher than the average correlation in individual differences research as a whole (i.e., $r \sim .20$ ). The strongest average correlations with well-being were -.46 for Big Five neuroticism and .48 for HEXACO extraversion. Regression models indicated that about half the observed variance in well-being scales can be explained by personality domains (46\%) and facets $(53 \%)$.

The domain-level correlations between Big Five personality and SWB were very similar to those reported in the meta-analysis by Steel et al. (2008) and larger and more nuanced than those reported in the meta-analysis by DeNeve and Cooper (1998). There are several reasons for this. First, DeNeve and Cooper (1998) included many studies that predated the Big Five and also used a mixture of different well-being measures. In contrast, Steel et al. (2008) focused on a small number of high-quality personality questionnaires such as the NEO and a limited set of reliable measures of SWB. Similar to Steel et al. (2008), we focused the core meta-analysis on a limited set of reliable personality and well-being measures. Our research extends that of Steel et al. (2008) by showing that the magnitude and pattern of correlations observed in Steel et al. (2008) is not limited to the NEO. A broadly similar magnitude and pattern of well-being correlations was found across a diverse range of Big Five measures. Second, the HEXACO and the Big Five frameworks have a strong focus on affect, well-being, and psychological functioning. In general, it seems likely that measures based on the Big Five and related lexical approaches, such as the HEXACO, will generally exhibit strong correlations with well-being.

\section{Broad and Narrow Personality Traits of the Big Five and HEXACO}

Overall, both the HEXACO and Big Five models are similarly effective in predicting wellbeing. For the Big Five model, neuroticism is a very strong predictor, extraversion and conscientiousness are fairly strong, and openness and agreeableness are more moderate. For the HEXACO model, extraversion is a very strong predictor (even stronger than Big Five neuroticism), conscientiousness is fairly strong, and honesty-humility, emotionality, 
agreeableness, and openness are more modest.

Differences in well-being correlations between the Big Five and HEXACO may largely result from how these models partition personality trait variance (for a review, see Ashton \& Lee, 2018; Ashton et al., 2014). These differences can be readily appreciated by examining (a) the correlations between the HEXACO and the Big Five (see Table 15 in the current paper and Table 1 in Gaughan et al., 2012), (b) the item content of relevant HEXACO and Big Five scales, and (c) the correlations between personality and well-being at the facet-level for HEXACO and the Big Five. For instance, HEXACO extraversion (a) correlates at -.65 with IPIP NEO neuroticism, (b) has many (reversed) items that relate to low self-esteem and depression (e.g., 'I sometimes feel that I am a worthless person'), and (c) shows correlations with well-being most prominently for the facets of social self-esteem and liveliness. In contrast, HEXACO emotionality (a) correlated only .56 with IPIP NEO neuroticism, and (b) combines traditional neuroticism facet scales such as fearfulness and anxiety (which correlate negatively with well-being) with more neutral emotional tendencies such as dependence (which is relatively uncorrelated with well-being) and prosocial tendencies such as sentimentality (which correlate positively with some aspects of wellbeing). HEXACO honesty-humility and HEXACO agreeableness both correlate most strongly with Big Five agreeableness, although HEXACO honesty-humility has a secondary correlation with Big Five conscientiousness, whereas HEXACO agreeableness has a secondary correlation with neuroticism, reflecting its content related to lower anger and hostility.

Although organized differently across the Big Five and HEXACO frameworks, the tendency to experience low levels of negative emotions and high levels of positive emotions accounts for much of the effect of personality on well-being. In the Big Five model, neuroticism captures the broad set of tendencies to experience negative emotions, whereas facets related to positive emotions form only part of extraversion. Facets such as depression, positive emotions, and social self-esteem are particularly strong predictors of well-being. It is not surprising that these characteristic ways of experiencing the world - viewing life through a more negative lens, ruminating on negative experiences, and emphasizing what's wrong rather than what's right with the world - translate into lower levels of well-being. On the other hand, Big Five extraversion may operate both through the tendency to experience positive emotion as well as the more instrumental pathways paved by the behavioral components of extraversion, such as facilitating positive social connections and actively engaging with environmental rewards (Smillie, Cooper, Wilt, \& Revelle, 2012; Smillie, Wilt, Kabbani, Garratt, \& Revelle, 2015; Sun et al., 2017).

Whereas most previous research has emphasized only neuroticism/emotionality and extraversion in relation to well-being (e.g., Diener et al., 1999; Schimmack et al., 2004; Smillie, Kern, \& Uljarevic, 2018), the present research reveals that conscientiousness is not far behind, and is perhaps even on par with extraversion. For instance, the average correlation for Big Five extraversion was .37 versus .36 for Big Five conscientiousness (.28 for HEXACO conscientiousness). Conscientiousness emerged as particularly important for purpose in life and environmental mastery, although was somewhat less related to negative affect and positive relations. Several processes described by conscientiousness could account for its positive implications for well-being. First, conscientiousness is related to a sense of competence in life, and the competence facet of conscientiousness was a particularly strong predictor of well-being. Second, conscientiousness describes effective self-regulation, as when one forgoes short-term pleasures for the attainment of longer-term goals, whether they be related to family, education, finance, or health (Roberts, Lejuez, Krueger, Richards, \& Hill, 2014). Third, achievement striving and diligence can connect people with a sense of purpose and meaning, that can facilitate a deeper 
sense of life satisfaction. However, as a small counterpoint, we note that a desire for order and perfection generally showed much weaker correlations with well-being. Consistent with highlighting the shortcomings of one's achievements relative to demanding expectations, perfectionism showed small negative semi-partial correlations with some well-being dimensions after controlling for personality domains (for further discussion of the benefits and costs of perfectionism, see Stoeber \& Otto, 2006; Stoeber \& Stoeber, 2009).

Both the Big Five and HEXACO conceptions of agreeableness, as well as HEXACO honesty-humility, had relatively modest correlations with well-being. Each of these 'prosocial' traits may plausibly improve well-being by reducing interpersonal conflict and helping to foster positive relations with others. Status seeking, manipulativeness, and greed (captured by honestyhumility and some facets of Big Five agreeableness) may also create instability of social networks, with negative consequences for well-being. Although self-interest may bring short-term benefits, excessive self-interest may, in the long term, damage one's reputation, social relationships, and sense of meaning in life. Furthermore, placing substantial value on status symbols and power places more weight on zero-sum aspects of life (Headey \& Wearing, 1992). As a counterpoint, we note that the modesty facet in both the Big Five and HEXACO models tended to be unrelated or negatively related to well-being. This may suggest that an inability or unwillingness to compare oneself favorably to others - whether this be in terms of income, wealth, health, physical attractiveness, or even popularity on social media - may have negative implications for well-being. Indeed, it is well-established that most people perceive their lives to be "better than average" (Alicke, Klotz, Breitenbecher, Yurak, \& Vredenburg, 1995; Headey \& Wearing, 1992), and that this rationalization may promote well-being.

Finally, openness to experience was also a modest but nevertheless meaningful predictor of well-being, with correlations approximating the average effect size in individual differences research. Openness comprises such characteristics as intellectual curiosity, an ability to adapt to change, and the tendency to seek novel experiences (Schmutte \& Ryff, 1997). Consistent with this, the current study revealed that openness was particularly related to personal growth, autonomy, and positive emotions. Whereas Stephan (2009) found openness to feelings and ideas to be the most important facets in relation to life satisfaction, our current findings varied somewhat across the different datasets. Openness to actions was a salient predictor to emerge in our data, particularly in relation to personal growth. Openness appears to reflect an orientation towards well-being that involves valuing novelty and non-conformity, and viewing life as a process of growth and change. This is reflected in the strong correlation between values and openness for the Big Five (ParksLeduc, Feldman, \& Bardi, 2015) and the HEXACO (Anglim, Knowles, Dunlop, \& Marty, 2017), whereby people who are high on openness tend to value self-direction, stimulation, and universalist values and are less interested in power and conformity. Given that openness is relatively unrelated to life satisfaction, it may provide an example of a personality trait that influences not just the experience of well-being, but the process through which a person achieves the good life. For those high on openness to experience, variety and growth are important, for those low in openness to experience, stability, safety and maintaining tradition may be more critical.

\section{Well-Being Dimensions}

One of the main insights revealed by the present study concerns the differential patterns of correlations between personality and well-being as one shifts between SWB and PWB. Whereas SWB focuses on the evaluation of the good life, PWB is more strongly reflective of eudaimonic perspectives. It is important to note, however, that this distinction is theoretical and conceptual, whereas the empirical differences between these models are less clear cut. All nine dimensions of 
well-being are positively intercorrelated (after reversing negative affect), despite each capturing important unique variance. Additionally, the nine scales do not segregate into distinct SWB and PWB factors. Thus, it is important to consider both the broad and the scale-specific patterns of personality correlates.

First, and in line with recent research (e.g., Anglim \& Grant, 2016), many PWB scales showed a much stronger overlap with personality compared to SWB scales. In the meta-analysis, correlations were larger for environmental mastery, personal growth, and self-acceptance, and smaller for life satisfaction, although the PWB scale of autonomy also had smaller correlations. In the domain- and facet-level regression models this pattern was also observed, although positive and negative affect were also predicted somewhat less well. These differences may partially be methodological. PWB is often measured with a 14-item per scale format whereas the standard life satisfaction measure (Diener et al., 1985) involves only 5 items. Nonetheless, as we discuss below, there are several theoretical reasons why some PWB scales overlap more with particular personality traits.

Second, of the three components of SWB, life satisfaction was less well predicted by personality compared with positive and negative affect. This is perhaps unsurprising given that the tendency to experience positive and negative emotions is part of the core content of personality scales (Pytlik Zillig, Hemenover, \& Dienstbier, 2002). In contrast, life satisfaction is a cognitive appraisal, influenced both by expectations and evaluations, and the individual's choice of what factors are relevant to that judgment. It is therefore a step removed from summaries of a person's typical behavior and experience. Such factors may help explain why life satisfaction shows a much more modest overlap with personality compared to other dimensions of well-being. Interestingly, the facets of modesty and perfectionism showed negative semi-partial correlations with life satisfaction. Thus, whether through objective circumstance, arrogance, or pleasant self-deception, very high life satisfaction is often related to seeing oneself and one's life as superior to those around you. Furthermore, perfectionism may lead people to focus on ways that their life could conceivably be better.

At a more general level, it was apparent that each well-being dimension was characterized by a coherent pattern of personality correlates. Specifically, positive affect, unsurprisingly, was well-predicted by extraversion and facets related to the tendency to experience positive emotions. Negative affect was strongly related to neuroticism, and most prominently with the facet of depression. Positive relations showed close connections with agreeableness and to some extent extraversion. Autonomy combined common well-being correlates with a fairly unique set of personality correlates that combine impulsiveness, non-compliance, and low trust, with assertiveness and social boldness. Environmental mastery correlated fairly uniformly across personality traits although it did show some elevation for conscientiousness. Personal growth was characterized most uniquely by openness with some amplification for diligence and achievement striving. Purpose in life was particularly well characterized by conscientiousness and especially diligence and achievement striving. Finally, self-acceptance showed a somewhat similar pattern of correlations to that of life satisfaction albeit at much greater levels. Although self-acceptance and life satisfaction are highly correlated, self-acceptance places relatively less emphasis on the external conditions of life. This emphasis on liking or loathing oneself brings it very close to several dimensions of personality, as seen by the particularly large correlation with the facet of depression. Some of these cross-correlations have already been noted in previous research (e.g., Anglim \& Grant, 2016; Grant et al., 2009; Sun et al., 2018), and the current study consolidates these observations through the first comprehensive, large sample assessment. 


\section{Incremental Prediction by Narrow Traits}

One of the most critical contributions of the present study concerns estimation of the proportional increase in variance explained by facets above and beyond domains. Average incremental variance explained by facets was $17 \%, 22 \%$, and $24 \%$ for NEO, IPIP NEO and HEXACO taxonomies, respectively. The amount of incremental prediction showed some systematic variation across these three measures, although much less consistency was observed for the Big Five Aspect Scales. In particular, life satisfaction, autonomy, and self-acceptance showed the greatest incremental prediction. These scales are not obviously broader or narrower than other well-being dimensions. Rather they may exhibit a complexity that means that several facets are important as is the case with autonomy. Equally, there may be a particular facet that aligns very closely, perhaps as can be seen with depression and social self-esteem in relation to self-acceptance.

A major focus of the literature on incremental facet prediction has been on life satisfaction (Røysamb et al., 2018; Schimmack et al., 2004; Steel et al., 2019), and this exhibited somewhat greater increases of between $24 \%$ and $51 \%$ depending on the personality framework. This estimate is broadly consistent with the largest study to report incremental facet prediction to date, albeit limited to life satisfaction, which obtained 33\% incremental prediction (Røysamb et al., 2018). Steel et al. (2019) reported a 78\% increase based on a meta-analytic correlation matrix, but it is important to note that meta-analytic regression is problematic. In particular, estimating a regression model with 30 highly correlated predictors, where facet-level intercorrelations are not provided in the primary studies leads to unreliable and often inflated estimates of variance explained.

More generally, we consider the proportional increase of $10 \%$ to $50 \%$ when using hierarchical instruments as noteworthy. Even though much of the perceived value of narrow traits is owing to the idea that facets might double prediction, more modest incremental prediction is still of practical and theoretical importance. Facets also provide a richer profile of how and why different domains correlate with relevant criteria, and provide a more nuanced picture of the personality-well-being interface.

Interestingly, the HEXACO model was characterized by larger incremental facet prediction (as a proportion) than the Big Five, both in terms of the NEO and IPIP NEO. This is striking, given that the NEO model has fewer domains and more facets than does the HEXACO model, which should lead the NEO model to have stronger incremental prediction. The IPIP NEO also has more items per facet, which should yield more reliable measurement of the unique aspects of each facet. On the other hand, the HEXACO model incudes the interstitial trait of altruism, which is not used in scoring the domains, whereas all of the items of the Big Five facets/aspects are used to compute the domain scores. Critically, none of the HEXACO domains capture the general tendency to experience negative emotions in the same way as Big Five neuroticism (Gaughan et al., 2012). Rather, the HEXACO model distributes content from Big Five neuroticism over various domains including extraversion $(r=-.50)$, emotionality $(r=.52)$, and agreeableness $(r=-.38)$ (Gaughan et al., 2012). The most salient observation regarding incremental facet prediction within the HEXACO concerned the emotionality facet of anxiety and the extraversion facets of social selfesteem and liveliness, all of which seem to capture the most affect-related influences on wellbeing.

\section{Limitations and Future Research}

Because the current meta-analysis is based on self-report measures of personality and wellbeing, some care is required when generalizing the findings to the latent constructs. Participants 
vary in the degree to which social desirability influences their responses, and items and scales vary in their degree of socially desirable content (Anglim, Morse, et al., 2017; McCrae \& Costa, 1983; Wiggins, 1968). Person- and item-level variance in socially desirable responding can lead to elevated correlations between personality and well-being. This is particularly evident in the minority of studies using low-paid participant samples where many participants engage in satisficing and semi-random responding. We observed that in such studies, correlations between broad personality traits were often elevated, which presumably translates to elevated correlations between personality and well-being. As a consequence, care is needed when evaluating personality measures in terms of how much variance they explain in self-reported well-being. One measure might predict self-reported well-being better because it has more socially desirable items. This may partially explain why the IPIP NEO predicted well-being better than the HEXACO PI R. Similarly, if one sample has more evaluative variance, then this may lead to elevated correlations between personality and well-being. For example, the greater prediction of well-being in the Big Five Aspects dataset may partially be explained by the use of a Mechanical Turk sample. While several studies have examined other-reports of personality and well-being (Dobewall, Realo, Allik, Esko, \& Metspalu, 2013; Schimmack et al., 2004), more research is needed in this area, particularly involving large samples, full hierarchical measures of personality, and multidimensional models of well-being.

Finally, it is worth considering the degree to which the correlations between personality and well-being are due to artefactual measurement overlap (Anglim \& Grant, 2016; Schmutte \& Ryff, 1997). Theoretically, the concepts of personality and well-being can be distinguished in terms of temporal frame-of-reference, implied stability, and degree of attribution to the person versus the situation. Whereas personality is defined as relatively stable and originating more from the person, well-being captures the experience and appraisal of life at a given moment. Nonetheless, it is unsurprising that an individual's general approach to acting in and experiencing the world (i.e., their personality) predicts his or her momentary emotional experiences and evaluations of life. Importantly, the correlations between personality and well-being index the extent and nature of this relationship. So, for example, to remove negative affect from neuroticism, or positive affect from extraversion is to fundamentally change the nature of these personality traits. However, many important research questions remain regarding the causal processes that relate personality and well-being. Facet-level analysis provides some perspective about which aspects of a given trait are more or less important in predicting different dimensions of well-being. Nonetheless, the literature would benefit from more experimental and experience sampling research exploring these questions (e.g., Jacques-Hamilton et al., 2019).

\section{Conclusion}

The current research re-affirms that personality is critical to the experience of well-being. This is consistent with set-point theories of well-being (Cummins, 2015; Headey \& Wearing, 1989; Headey \& Wearing, 1992), and the idea that well-being is relatively stable despite short-term fluctuations in response to many transient events. However, it is also important to remember that personality traits are not 'set like plaster', but malleable, with a wealth of evidence that traits change across the lifespan (Ashton \& Lee, 2016; McCrae et al., 1999; Soto, John, Gosling, \& Potter, 2011), after specific experiences (e.g., Zimmermann \& Neyer, 2013) or interventions (e.g., Roberts et al., 2017), and even according to one's trait change-goals (e.g., Hudson \& Fraley, 2015). It would therefore be inappropriate to interpret the strong relation between personality and wellbeing as indicative of the immutability of human happiness. Rather, efforts to improve well-being might target the most critical aspects of one's habitual or characteristic patterns of behavior and 
experience, as reflected in basic personality traits.

In summary, we have provided the most comprehensive assessment yet of the relations between personality traits and dimensions of well-being. Our study expands the mapping of personality to well-being by encompassing both the Big Five and the increasingly popular HEXACO model of personality, and also both Diener's SWB perspective as well as Ryff's PWB perspective on well-being. Moreover, our analyses span domain-level traits and narrower aspects and facets within the personality trait hierarchy, while contributing more broadly to methods for synthesizing facet-level research. Taken together, the findings reported here expand and enrich our understanding of the role that personality traits play in pathways to the good life.

\section{References}

References marked with an asterisk were included in the meta-analysis.

*Agbo, A. A., \& Ngwu, C. N. (2017). Aversion to happiness and the experience of happiness: The moderating roles of personality. Personality and Individual Differences, 111, 227-231.

*Aghababaei, N. (2014). God, the good life, and HEXACO: the relations among religion, subjective well-being and personality. Mental Health, Religion \& Culture, 17, 284-290.

*Aghababaei, N., \& Arji, A. (2014). Well-being and the HEXACO model of personality. Personality and Individual Differences, 56, 139-142.

*Aghababaei, N., Błachnio, A., Arji, A., Chiniforoushan, M., Tekke, M., \& Fazeli Mehrabadi, A. (2016). Honesty-Humility and the HEXACO Structure of Religiosity and Well-Being. Current Psychology, 35, 421-426.

*Aghababaei, N., \& Tabik, M. T. (2013). Gratitude and mental health: differences between religious and general gratitude in a Muslim context. Mental Health, Religion \& Culture, 16, 761-766.

*Ahadi, S. A., \& Puente-Diaz, R. (2011). Acculturation, personality, and psychological adjustment. Psychological Reports, 109, $842-862$.

*Albrecht, A. G., Dilchert, S., Deller, J., \& Paulus, F. M. (2014). Openness in cross-cultural work settings: a multicountry study of expatriates. Journal of Personality Assessment, 96, 64-75.

*Albuquerque, I., de Lima, M. P., Matos, M., \& Figueiredo, C. (2012). Personality and Subjective Well-Being: What Hides Behind Global Analyses? Social Indicators Research, 105, 447-460.

*Alfonsi, G., Conway, M., \& Pushkar, D. (2011). The lower subjective social status of neurotic individuals: multiple pathways through occupational prestige, income, and illness. Journal of Personality, 79, 619-642.

Alicke, M. D., Klotz, M. L., Breitenbecher, D. L., Yurak, T. J., \& Vredenburg, D. S. (1995). Personal contact, individuation, and the better-thanaverage effect. Journal of Personality and Social Psychology, 68, 804.

*Anand, S., Vidyarthi, P., Singh, S., \& Ryu, S. (2015). Family interference and employee dissatisfaction: Do agreeable employees better cope with stress? Human Relations, 68, 691-708.

*Anglim, J., \& Grant, S. (2016). Predicting Psychological and Subjective Well-Being from Personality: Incremental Prediction from 30 Facets Over the Big 5. Journal of Happiness Studies, 17, 59-80.

Anglim, J., \& Grant, S. L. (2014). Incremental criterion prediction of personality facets over factors: Obtaining unbiased estimates and confidence intervals. Journal of Research in Personality, 53, 148-157.

*Anglim, J., \& Horwood, S. (2019). HEXACO IPIP Well-being data. Unpublished dataset presented in the current article.

Anglim, J., Knowles, E. R., Dunlop, P. D., \& Marty, A. (2017). HEXACO personality and Schwartz's personal values: A facet-level analysis. Journal of Research in Personality, 68, 23-31.

Anglim, J., Morse, G., De Vries, R. E., MacCann, C., \& Marty, A. (2017). Comparing job applicants to non-applicants using an item-level bifactor model on the HEXACO personality inventory. European journal of personality, 31, 669-684.

Anglim, J., \& O'Connor, P. (2019). Measurement and research using the Big Five, HEXACO, and narrow traits: A primer for researchers and practitioners. Australian Journal of Psychology, 71, 16-25.

Anglim, J., Weinberg, M. K., \& Cummins, R. A. (2015). Bayesian hierarchical modeling of the temporal dynamics of subjective well-being: A 10 year longitudinal analysis. Journal of Research in Personality, 59, 1-14.

*Antunes, A. C., Caetano, A., \& Pina, E. C. M. (2017). Reliability and Construct Validity of the Portuguese Version of the Psychological Capital Questionnaire. Psychological Reports, 120, 520-536.

Anusic, I., Schimmack, U., Pinkus, R. T., \& Lockwood, P. (2009). The nature and structure of correlations among Big Five ratings: The halo-alphabeta model. Journal of Personality and Social Psychology, 97, 1142-1156.

*Anwar, C. M. (2017). Linkages between personality and knowledge sharing behavior in workplace: mediating role of affective states. $E+M$ Ekonomie a management, 20, 102-115

Ashton, M. C., \& Lee, K. (2005). Honesty-humility, the Big Five, and the five - factor model. Journal of Personality, 73, 1321-1354.

Ashton, M. C., \& Lee, K. (2016). Age trends in HEXACO-PI-R self-reports. Journal of Research in Personality, 64, $102-111$.

Ashton, M. C., \& Lee, K. (2018). How well do Big Five measures capture HEXACO scale variance? Journal of Personality Assessment, 1-7.

Ashton, M. C., Lee, K., \& De Vries, R. E. (2014). The HEXACO Honesty-Humility, Agreeableness, and Emotionality factors: A review of research and theory. Personality and Social Psychology Review, 18, 139-152.

Ashton, M. C., Lee, K., Perugini, M., Szarota, P., De Vries, R. E., Di Blas, L., . . . De Raad, B. (2004). A six-factor structure of personalitydescriptive adjectives: solutions from psycholexical studies in seven languages. Journal of Personality and Social Psychology, 86, 356366.

*Augusto Landa, J. M., Martos, M. P., \& López-Zafra, E. (2010). Emotional Intelligence and Personality Traits as Predictors of Psychological Well-Being in Spanish Undergraduates. Social Behavior and Personality: an international journal, 38, 783-793.

*Austin, E., Saklofske, D., \& Mastoras, S. (2010). Emotional intelligence, coping and exam-related stress in Canadian undergraduate students. Australian Journal of Psychology, 62, 42-50.

*Aykac, B., Copuroglu, C., Ozcan, M., Ciftdemir, M., \& Yalniz, E. (2011). Postoperative evaluation of quality of life in lumbar spinal stenosis patients following instrumented posterior decompression. Acta Orthopaedica et Traumatologica Turcica, 45, 47-52. 
*Balgiu, B. A. (2018). The psychometric properties of the Big Five inventory-10 (BFI-10) including correlations with subjective and psychological well-being. Global Journal of Psychology Research: New Trends and Issues, 8, 61-69.

*Baltes, B. B., Zhdanova, L. S., \& Clark, M. A. (2010). Examining the Relationships Between Personality, Coping Strategies, and Work-Family Conflict. Journal of Business and Psychology, 26, 517-530.

*Barr, P. (2018). Personality Traits, State Positive and Negative Affect, and Professional Quality of Life in Neonatal Nurses. Journal of Obstetric, Gynecologic, and Neonatal Nursing, 47, 771-782.

*Baselmans, B. M. L., van de Weijer, M. P., Abdellaoui, A., Vink, J. M., Hottenga, J. J., Willemsen, G., . . Bartels, M. (2019). A Genetic Investigation of the Well-Being Spectrum. Behavior Genetics, 49, 286-297.

*Baudin, N., Aluja, A., Rolland, J.-P., \& Blanch, A. (2011). The role of personality in satisfaction with life and sport. Behavioral Psychology/ Psicologia Conductual, 19, 333-345.

*Bauer, J. J., \& McAdams, D. P. (2010). Eudaimonic growth: Narrative growth goals predict increases in ego development and subjective wellbeing 3 years later. Developmental Psychology, 46, 761-772.

*Beer, A., Watson, D., \& McDade-Montez, E. (2013). Self-other agreement and assumed similarity in neuroticism, extraversion, and trait affect: distinguishing the effects of form and content. Assessment, 20, 723-737.

Begg, C. B., \& Mazumdar, M. (1994). Operating characteristics of a rank correlation test for publication bias. Biometrics, 1088-1101.

*Belsky, J., Crnic, K., \& Woodworth, S. (1995). Personality and parenting: exploring the mediating role of transient mood and daily hassles. Journal of Personality, 63, 905-929.

*Benet-Martínez, V., \& Karakitapoğlu-Aygün, Z. (2003). The interplay of cultural syndromes and personality in predicting life satisfaction: Comparing Asian Americans and European Americans. Journal of Cross-Cultural Psychology, 34, 38-60.

*Benotsch, E. G., Lutgendorf, S. K., Watson, D., Fick, L. J., \& Lang, E. V. (2000). Rapid anxiety assessment in medical patients: evidence for the validity of verbal anxiety ratings. Annals of Behavioral Medicine, 22, 199-203.

*Bianchi, R., Rolland, J. P., \& Salgado, J. F. (2018). Burnout, Depression, and Borderline Personality: A 1,163-Participant Study. Frontiers in Psychology, 8, 2336.

*Biderman, M. D., McAbee, S. T., Chen, Z. J., \& Hendy, N. T. (2018). Assessing the evaluative content of personality questionnaires using bifactor models. Journal of Personality Assessment, 100, 375-388.

*Blatný, M., Květon, P., Jelínek, M., Šolcová, I., Zábrodská, K., Mudrák, J., \& Machovcová, K. (2018). The influence of personality traits on life satisfaction through work engagement and job satisfaction among academic faculty members. Studia Psychologica, 60, 274-286.

*Blatný, M., Millová, K., Jelínek, M., \& Osecká, T. (2015). Personality predictors of successful development: Toddler temperament and adolescent personality traits predict well-being and career stability in middle adulthood. PloS One, 10, e0126032.

*Bogin, L. (2018). A portrait of college success: Grit, theories of intelligence, and cumulative life adversity. (Doctoral dissertation), Pace University, Pleasantville, NY, United States.

*Boland, A., \& Cappeliez, P. (1997). Optimism and neuroticism as predictors of coping and adaptation in older woman. Personality and Individual Differences, 22, 909-919.

*Bono, T. J. (2011). What good is engagement? Predicting academic performance and college satisfaction from personality, social support, and student engagement. (Doctoral thesis), Washington University, Saint Louis, Missouri, United States.

*Boudreau, J. W., Boswell, W. R., \& Judge, T. A. (2001). Effects of Personality on Executive Career Success in the United States and Europe. Journal of Vocational Behavior, 58, 53-81.

*Brailovskaia, J., Bierhoff, H. W., \& Margraf, J. (2019). How to Identify Narcissism With 13 Items? Validation of the German Narcissistic Personality Inventory-13 (G-NPI-13). Assessment, 26, 630-644.

*Brailovskaia, J., \& Margraf, J. (2016). Comparing Facebook users and Facebook non-users: Relationship between personality traits and mental health variables, ÄîAn exploratory study. PloS One, 11, e0166999.

*Brailovskaia, J., \& Margraf, J. (2018). What does media use reveal about personality and mental health? An exploratory investigation among German students. PloS One, 13, e0191810.

*Brajša-Žganec, A., Ivanović, D., \& Lipovčan, L. K. (2011). Personality traits and social desirability as predictors of subjective well-being. Psihologijske teme, 20, 261-276.

*Bratko, D., \& Sabol, J. (2006). Personality and basic psychological needs as predictors of life satisfaction: Results of the on-line study [Osobine ličnosti i osnovne psihološke potrebe kao prediktori zadovoljstva životom: Rezultati on-line istraživanja]. Drustvena Istrazivanja, 15, 693-711.

*Brenner, K., St-Hilaire, A., Liu, A., Laplante, D. P., \& King, S. (2011). Cortisol response and coping style predict quality of life in schizophrenia. Schizophrenia Research, 128, 23-29.

Brickman, P., \& Campbell, D. T. (1971). Hedonic relativism and planning the good society. In M. H. Apley (Ed.), Adaptation-level theory (pp. 287-305). New York: Academic Press.

*Burles, F., Guadagni, V., Hoey, F., Arnold, A. E., Levy, R. M., O'Neill, T., \& Iaria, G. (2014). Neuroticism and self-evaluation measures are related to the ability to form cognitive maps critical for spatial orientation. Behavioural Brain Research, 271, 154-159.

*Burton, C. M., Plaks, J. E., \& Peterson, J. B. (2015). Why Do Conservatives Report Being Happier Than Liberals? The Contribution of Neuroticism. Journal of Social and Political Psychology, 3, 89-102.

Butler, J., \& Kern, M. L. (2016). The PERMA-Profiler: A brief multidimensional measure of flourishing. International Journal of Wellbeing, 6.

*Bye, D., \& Pushkar, D. (2009). How need for cognition and perceived control are differentially linked to emotional outcomes in the transition to retirement. Motivation and Emotion, 33, 320-332.

*Cabrera-Darias, M., \& Marrero-Quevedo, R. J. (2015). Motivos, personalidad y bienestar subjetivo en el voluntariado. Anales de Psicología, 31, 791-801.

*Caprara, G. V., Alessandri, G., Eisenberg, N., Kupfer, A., Steca, P., Caprara, M. G., . . Abela, J. (2012). The positivity scale. Psychological Assessment, 24, 701-712.

*Caprara, G. V., Fratte, A., \& Steca, P. (2002). Determinanti personali del benessere nell'adolescenza: Indicatori e predittori [Personal determinants of well-being in adolescence: Indicators and predictors]. Psicologia Clinica dello Sviluppo, 6, 203-233.

*Carciofo, R., \& Song, N. (2019). The Chinese Morningness-Eveningness-Stability-Scale improved (MESSi): validity, reliability, and associations with sleep quality, personality, affect and life satisfaction. Chronobiology International, 36, 1036-1046.

*Carmona-Halty, M. A., \& Rojas-Paz, P. P. (2014). Rasgos de personalidad, necesidad de cognición y satisfacción vital en estudiantes universitarios chilenos. Universitas Psychologica, 13, 83-93.

*Carrillo, E., Prado-Gascó, V., Fiszman, S., \& Varela, P. (2012). How personality traits and intrinsic personal characteristics influence the 
consumer's choice of reduced-calorie food. Food Research International, 49, 792-797.

*Castro Solano, A., \& Cosentino, A. C. (2018). IVyF abreviado-IVyFabre: Análisis psicométrico y de estructura factorial en Argentina. Avances en Psicología Latinoamericana, 36, 619-637.

*Cellini, N., Duggan, K. A., \& Sarlo, M. (2017). Perceived sleep quality: The interplay of neuroticism, affect, and hyperarousal. Sleep Health, 3 , 184-189.

*Chambers, B. J. (2004). Adjustment to career termination in professional hockey players. (Doctoral thesis), Simon Fraser University.

*Chan, B., Luciano, M., \& Lee, B. (2018). Interaction of physical activity and personality in the subjective wellbeing of older adults in Hong Kong and the United Kingdom. Behavioral Sciences, 8, 71.

*Chen, C. (2015). Incremental Validity of Achievement Goals in Predicting Subjective Well-Being Among University Students. Journal of Cognitive Education and Psychology, 14, 38-62.

${ }^{*}$ Chen, F. F., Hayes, A., Carver, C. S., Laurenceau, J.-P., \& Zhang, Z. (2012). Modeling general and specific variance in multifaceted constructs: A comparison of the bifactor model to other approaches. Journal of Personality, 80, 219-251.

*Chen, M. M. (2011). A study of the criterion and incremental validity of the Structured Interview for DSM-IV personality, the revised neuroticism, extraversion, openness - personality inventory, and schedule for adaptive and nonadaptive personality. (Doctoral thesis), St. John's University New York, New York, United States.

*Chen, S. X., \& Carey, T. P. (2009). Assessing Citizenship Behavior in Educational Contexts. Journal of Psychoeducational Assessment, 27, 125137.

*Choi, Y., \& Lee, D. (2014). Psychological capital, Big Five traits, and employee outcomes. Journal of Managerial Psychology, 29, $122-140$.

*Chopik, W. J., \& Lucas, R. E. (2019). Actor, partner, and similarity effects of personality on global and experienced well-being. Journal of Research in Personality, 78, 249-261.

Churchyard, J. S., Pine, K. J., Sharma, S., \& Fletcher, B. C. (2014). Same traits, different variance: Item-level variation within personality measures. SAGE Open, 4.

*Cikrikci, O. (2019). An exploration of the associations among positivity, general distress and internet addiction: The mediating effect of general distress. Psychiatry Research, 272, 628-637.

*Clark, M. A., Lelchook, A. M., \& Taylor, M. L. (2010). Beyond the Big Five: How narcissism, perfectionism, and dispositional affect relate to workaholism. Personality and Individual Differences, 48, 786-791.

*Clifton, J. D. W., Baker, J. D., Park, C. L., Yaden, D. B., Clifton, A. B. W., Terni, P., . . Seligman, M. E. P. (2019). Primal world beliefs. Psychological Assessment, 31, 82-99.

*Compton, W. C., Smith, M. L., Cornish, K. A., \& Qualls, D. L. (1996). Factor structure of mental health measures. Journal of Personality and Social Psychology, 71, 406-413.

*Correa, T., Hinsley, A. W., \& de Zúñiga, H. G. (2010). Who interacts on the Web?: The intersection of users' personality and social media use. Computers in Human Behavior, 26, 247-253.

*Costa, P. T., \& MacCrae, R. R. (1992). Revised NEO personality inventory (NEO PI-R) and NEO five-factor inventory (NEO-FFI): Professional manual. Odessa, Fl: PAR: Psychological Assessment Resources, Incorporated.

Costa, P. T., \& McCrae, R. R. (1995). Domains and facets: Hierarchical personality assessment using the Revised NEO Personality Inventory. Journal of Personality Assessment, 64, 21-50.

Costa, P. T., \& McCrae, R. R. (2008). The Revised NEO Personality Inventory (NEO-PI-R). The SAGE handbook of personality theory and assessment, 2, 179-198.

*Cotter, E. W., \& Fouad, N. A. (2011). The Relationship Between Subjective Well-Being and Vocational Personality Type. Journal of Career Assessment, 19, 51-60.

*Courneya, K. S., Bobick, T. M., Rhodes, R. E., Jones, L. W., Friedenreich, C. M., \& Arthur, K. (2000). Personality Correlates of Patients' Subjective Well-Being After Surgery for Colorectal Cancer. Journal of Psychosocial Oncology, 18, 61-72.

*Cowan, H. R. (2019). Can a Good Life Be Unsatisfying? Within-Person Dynamics of Life Satisfaction and Psychological Well-Being in Late Midlife. Psychological Science, 30, 697-710.

*Crouch, T. B. (2016). A latent profile analysis of affect regulation patterns among young adults and relations with early life stress, executive functioning, and risky substance use. (Doctoral dissertation), University of Maryland, Baltimore County, United States.

*Crowe, M. L., LoPilato, A. C., Campbell, W. K., \& Miller, J. D. (2016). Identifying Two Groups of Entitled Individuals: Cluster Analysis Reveals Emotional Stability and Self-Esteem Distinction. Journal of Personality Disorders, 30, 762-775.

*Csarny, R. J. (1998). The incremental validity of religious constructs in predicting quality of life, racism, and sexual attitudes. (Doctoral dissertation), Loyola College in Maryland, Baltimore, Maryland, United States.

Cummins, R. A. (2015). The theory of subjective wellbeing homeostasis: A contribution to understanding life quality. In F. Maggino (Ed.), A Life Devoted to Quality of Life - Festschrift in Honor of Alex C. Michalos. Dordrecht, Netherlands: Springer.

*Datu, J. A. D. (2014). Forgiveness, gratitude and subjective well-being among Filipino adolescents. International Journal for the Advancement of Counselling, 36, 262-273.

*Datu, J. A. D., Yuen, M., \& Chen, G. (2018). The triarchic model of grit is linked to academic success and well-being among Filipino high school students. School Psychology Quarterly, 33, 428-438.

*de Frias, C. M., Dixon, R. A., \& Backman, L. (2003). Use of memory compensation strategies is related to psychosocial and health indicators. Journals of Gerontology. Series B: Psychological Sciences and Social Sciences, 58, P12-22.

*De Gucht, V., Fischler, B., \& Heiser, W. (2004). Neuroticism, alexithymia, negative affect, and positive affect as determinants of medically unexplained symptoms. Personality and Individual Differences, 36, 1655-1667.

De Raad, B., Barelds, D. P., Timmerman, M. E., De Roover, K., Mlačić, B., \& Church, A. T. (2014). Towards a pan - cultural personality structure: Input from 11 psycholexical studies. European Journal of Personality, 28, 497-510.

Deci, E. L., \& Ryan, R. M. (2008). Hedonia, eudaimonia, and well-being: An introduction. Journal of Happiness Studies, 9, 1-11.

*Delfabbro, P. H., Winefield, A. H., Anderson, S., Hammarstrom, A., \& Winefield, H. (2011). Body image and psychological well-being in adolescents: the relationship between gender and school type. Journal of Genetic Psychology, 172, 67-83.

DeNeve, K. M., \& Cooper, H. (1998). The happy personality: a meta-analysis of 137 personality traits and subjective well-being. Psychological Bulletin, 124, 197-229.

*Denovan, \& Michael, A. (2018). Investigating student stress from a positive psychology perspective. (Doctoral thesis), Sheffield Hallam University, Sheffield, England.

*Deventer, J., Ludtke, O., Nagy, G., Retelsdorf, J., \& Wagner, J. (2019). Against all odds - is a more differentiated view of personality development 
in emerging adulthood needed? The case of young apprentices. British Journal of Psychology, 110, 60-86.

DeYoung, C. G. (2006). Higher-order factors of the Big Five in a multi-informant sample. Journal of Personality and Social Psychology, 91, 11381151.

DeYoung, C. G., Quilty, L. C., \& Peterson, J. B. (2007). Between facets and domains: 10 aspects of the Big Five. Journal of Personality and Social Psychology, 93, 880-896.

*Di Fabio, A., \& Kenny, M. E. (2018). Academic relational civility as a key resource for sustaining well-being. Sustainability, $10,1914$.

*Di Fabio, A., \& Palazzeschi, L. (2015). Hedonic and eudaimonic well-being: the role of resilience beyond fluid intelligence and personality traits. Frontiers in Psychology, 6, 1367.

*Di Fabio, A., Palazzeschi, L., \& Bucci, O. (2017). In an unpredictable and changing environment: Intrapreneurial self-capital as a key resource for life satisfaction and flourishing. Frontiers in Psychology, 8, 1819.

*Di Fabio, A., \& Saklofske, D. H. (2014). Promoting individual resources: The challenge of trait emotional intelligence. Personality and Individual Differences, 65, 19-23.

*Di Nuovo, S. (2009). Variables and quantity: what else? Integrative Psychological \& Behavioral Science, 43, 84-88.

Díaz, D., Rodríguez-Carvajal, R., Blanco, A., Moreno-Jiménez, B., Gallardo, I., Valle, C., \& Van Dierendonck, D. (2006). Adaptación española de las escalas de bienestar psicológico de Ryff. Psicothema, 18, 572-577.

Diener, E. (1984). Subjective well-being. Psychological Bulletin, 95, 542-575.

Diener, E., \& Choi, D.-W. (2009). Culture and well-being: Springer.

Diener, E., Emmons, R. A., Larsen, R. J., \& Griffin, S. (1985). The satisfaction with life scale. Journal of Personality Assessment, 49, 71-75.

Diener, E., Oishi, S., \& Lucas, R. E. (2003). Personality, culture, and subjective well-being: Emotional and cognitive evaluations of life. Annual Review of Psychology, 54, 403-425.

Diener, E., Suh, E. M., Lucas, R. E., \& Smith, H. L. (1999). Subjective well-being: Three decades of progress. Psychological Bulletin, 125, 276302.

Digman, J. M. (1997). Higher-order factors of the Big Five. Journal of Personality and Social Psychology, 73, 1246-1256.

*Dijkstra, P., \& Barelds, D. P. (2009). Women's well-being: the role of individual differences. Scandinavian Journal of Psychology, $50,309-315$.

*Dimotakis, N., Conlon, D. E., \& Ilies, R. (2012). The mind and heart (literally) of the negotiator: personality and contextual determinants of experiential reactions and economic outcomes in negotiation. Journal of Applied Psychology, 97, 183-193.

Dobewall, H., Realo, A., Allik, J., Esko, T., \& Metspalu, A. (2013). Self-other agreement in happiness and life-satisfaction: The role of personality traits. Social Indicators Research, 114, 479-492.

*Donofrio, A. (2005). The relationship between the five factor model of personality and relationally based measures of Judeo-Christian spirituality: A correlational analysis between NEO PI-R facet scores and subscales of the spiritual assessment inventory and faith maturity scale. (thesis), University of Akron.

*Drezno, M., Stolarski, M., \& Matthews, G. (2019). An in-depth look into the association between morningness-eveningness and well-being: evidence for mediating and moderating effects of personality. Chronobiology International, 36, 96-109.

*Drobnjaković, E. (2019). Unpublished data on HEXACO Personality and PANAS.

*Drobnjaković, E., Dinić, B., \& Mihić, L. (2017). Distinktivnost u okviru pozitivnog i negativnog afekta: Validacija srpske adaptacije inventara za procenu pozitivnog i negativnog afekta (panas). Primenjena Psihologija, 10, 203-225.

*Duckworth, A. L., Weir, D., Tsukayama, E., \& Kwok, D. (2012). Who does well in life? Conscientious adults excel in both objective and subjective success. Frontiers in Psychology, 3, 356.

*Dumitrache, M. O., Matei, I. A., Ionica, A. M., Kalmar, Z., D'Amico, G., Siko-Barabasi, S., . . Mihalca, A. D. (2015). Molecular detection of Anaplasma phagocytophilum and Borrelia burgdorferi sensu lato genospecies in red foxes (Vulpes vulpes) from Romania. Parasit Vectors, 8, 514 .

*Eakman, A. M., \& Eklund, M. (2012). The Relative Impact of Personality Traits, Meaningful Occupation and Occupational Value on Meaning in Life and Life Satisfaction. Journal of Occupational Science, 19, 165-177.

*Ebner, K., Thiele, L., Spurk, D., \& Kauffeld, S. (2018). Validation of the German Career Decision-Making Profile-An Updated 12-Factor Version. Journal of Career Assessment, 26, 111-136.

*Egan, V., Chan, S., \& Shorter, G. W. (2014). The Dark Triad, happiness and subjective well-being. Personality and Individual Differences, 67, $17-22$.

*Etxeberria, I., Urdaneta, E., \& Galdona, N. (2019). Factors associated with health-related quality of life (HRQoL): differential patterns depending on age. Quality of Life Research, 28, 2221-2231.

*Fagley, N. S. (2012). Appreciation uniquely predicts life satisfaction above demographics, the Big 5 personality factors, and gratitude. Personality and Individual Differences, 53, 59-63.

*Fagley, N. S. (2018). Appreciation (including gratitude) and affective well-being: Appreciation predicts positive and negative affect above the Big Five personality factors and demographics. SAGE Open, https://doi.org/10.1177/2158244018818621.

*FitzMedrud, E. J. (2009). The correlates of playfulness in adults. (Doctoral thesis), Institute of Transpersonal Psychology, Palo Alto, California, United States.

*Fortunato, F. D. (2002). Midlife pursuits: Expansive or consistent with current roles. (Doctoral thesis), George Mason University.

*Fossum, T. A., \& Barrett, L. F. (2000). Distinguishing Evaluation from Description in the Personality-Emotion Relationship. Personality and Social Psychology Bulletin, 26, 669-678.

*Fowler, S. A., Davis, L. L., Both, L. E., \& Best, L. A. (2018). Personality and perfectionism as predictors of life satisfaction: The unique contribution of having high standards for others. FACETS, 3, 227-241.

*Fox, A. G., \& Moore, M. T. (2019). Extraversion and neuroticism: Associated responses to a positive mood induction. Psychology of Music, 115.

*Freund, A. M., \& Baltes, P. B. (1998). Selection, optimization, and compensation as strategies of life management: Correlations with subjective indicators of successful aging. Psychology and Aging, 13, 531-543.

*Froehlich, J. P. (2005). Spirituality and fraternity: Spiritual maturity and social support in a national study of a male religious order. (Doctoral thesis), Loyola College Maryland, Baltimore, Maryland, United States.

Fujita, F., \& Diener, E. (2005). Life satisfaction set point: Stability and change. Journal of Personality and Social Psychology, 88, 158-164.

*Furler, K., Gomez, V., \& Grob, A. (2013). Personality similarity and life satisfaction in couples. Journal of Research in Personality, 47, $369-375$.

*Furr, R. M., \& Funder, D. C. (1998). A multimodal analysis of personal negativity. Journal of Personality and Social Psychology, 74, $1580-1591$.

*Galea, M. (2014). Assessing the Incremental Validity of Spirituality in Predicting Nurses' Burnout. Archive for the Psychology of Religion, 36 , 
118-136.

*Ganginis Del Pino, H. V. (2012). Work-family experiences among employed mothers. (Doctoral thesis), University of Maryland.

*Gannon, N., \& Ranzijn, R. (2005). Does emotional intelligence predict unique variance in life satisfaction beyond IQ and personality? Personality and Individual Differences, 38, 1353-1364.

*Garcia, D. (2011). Two models of personality and well-being among adolescents. Personality and Individual Differences, 50, $1208-1212$.

*Garcia, D., \& Erlandsson, A. (2011). The Relationship Between Personality and Subjective Well-Being: Different Association Patterns When Measuring the Affective Component in Frequency and Intensity. Journal of Happiness Studies, 12, 1023-1034.

Gaughan, E. T., Miller, J. D., \& Lynam, D. R. (2012). Examining the utility of general models of personality in the study of psychopathy: A comparison of the HEXACO-PI-R and NEO PI-R. Journal of Personality Disorders, 26, 513-523.

Gerstorf, D., Ram, N., Estabrook, R., Schupp, J., Wagner, G. G., \& Lindenberger, U. (2008). Life satisfaction shows terminal decline in old age: longitudinal evidence from the German Socio-Economic Panel Study (SOEP). Developmental Psychology, 44, 1148.

*Gibson, J. E. M. (2007). Interpersonal perception: Don't worry, be happy. (Doctoral thesis), University of Victoria, Canada.

Gignac, G. E., \& Szodorai, E. T. (2016). Effect size guidelines for individual differences researchers. Personality and Individual Differences, 102, 74-78.

*Glidden, L. M., Billings, F. J., \& Jobe, B. M. (2006). Personality, coping style and well-being of parents rearing children with developmental disabilities. Journal of Intellectual Disability Research, 50, 949-962.

Goldberg, L. R. (1993). The structure of phenotypic personality traits. American Psychologist, 48, 26.

Goldberg, L. R. (1999). A broad-bandwidth, public domain, personality inventory measuring the lower-level facets of several five-factor models. Personality Psychology in Europe, 7, 7-28.

Goldberg, L. R., Johnson, J. A., Eber, H. W., Hogan, R., Ashton, M. C., Cloninger, C. R., \& Gough, H. G. (2006). The international personality item pool and the future of public-domain personality measures. Journal of Research in Personality, 40, 84-96.

*Goldberg, S. B., Flook, L., Hirshberg, M. J., Findley, D., Kesebir, P., Schaefer, S. M., \& Davidson, R. J. (2017). Getting a Grip on the Handgrip Task: Handgrip Duration Correlates with Neuroticism But Not Conscientiousness. Frontiers in Psychology, 8, 1367.

*Golden, J. L. (2002). Spirituality as a predictor of burnout among United Methodist clergy: An incremental validity study. (thesis), Loyola College in Maryland.

*Goldstein, A. L., \& Flett, G. L. (2009). Personality, alcohol use, and drinking motives: a comparison of independent and combined internal drinking motives groups. Behavior Modification, 33, 182-198.

*Gore, J. S., Davis, T., Spaeth, G., Bauer, A., Loveland, J. M., \& Palmer, J. K. (2014). Subjective Well-Being Predictors of Academic Citizenship Behavior. Psychological Studies, 59, 299-308.

*Goswami, H. (2014). Children's Subjective Well-being: Socio-demographic Characteristics and Personality. Child Indicators Research, 7, 119140.

*Grady, A. B. (1996). Coping effectiveness as an explanation of the relationship between personality and affect in daily stressful circumstances. (Doctoral thesis), Simon Fraser University.

*Graham, J. D. B. (2012). Elements of human effectiveness: Intelligences, traits, and abilities that lead to success and fulfillment in life. (Doctoral thesis), University of California, Los Angeles.

*Grant, S., Langan-Fox, J., \& Anglim, J. (2009). The big five traits as predictors of subjective and psychological well-being. Psychological Reports, $105,205-231$

*Grevenstein, D., Aguilar-Raab, C., \& Bluemke, M. (2018). Mindful and Resilient? Incremental Validity of Sense of Coherence Over Mindfulness and Big Five Personality Factors for Quality of Life Outcomes. Journal of Happiness Studies, 19, 1883-1902.

*Grevenstein, D., \& Bluemke, M. (2015). Can the Big Five explain the criterion validity of Sense of Coherence for mental health, life satisfaction, and personal distress? Personality and Individual Differences, 77, 106-111.

*Guilera, G., Barrios, M., Penelo, E., Morin, C., Steel, P., \& Gomez-Benito, J. (2018). Validation of the Spanish version of the Irrational Procrastination Scale (IPS). PloS One, 13, e0190806.

*Gutiérrez, G. J. L., Moreno-Jiménez, B., Hernández, E. G., \& Puente, C. P. (2005). Personality and subjective well-being: big five correlates and demographic variables. Personality and Individual Differences, 38, 1561-1569.

*Habarth, J. M. (2009). Thinking 'straight': Heteronormativity and associated outcomes across sexual orientation. (Doctoral thesis), University of Michigan.

*Halama, P. (2010). Hope as a mediator between personality traits and life satisfaction. Studia Psychologica, 52, 309-314.

*Halama, P., \& Dědová, M. (2007). Meaning in life and hope as predictors of positive mental health: Do they explain residual variance not predicted by personality traits? Studia Psychologica, 49, 191-200.

*Halama, P., Martos, T., \& Adamovováú, L. (2010). Religiosity and well-being in Slovak and Hungarian student samples: The role of personality traits. Studia Psychologica, 52, 101-116.

*Harris, P. R. (2002). Constructive thinking as a mediator of the relationships between neuroticism, extraversion, and subjective well-being. (thesis), ProQuest Information \& Learning.

*Hart, P. M. (1999). Predicting employee life satisfaction: A coherent model of personality, work, and nonwork experiences, and domain satisfactions. Journal of Applied Psychology, 84, 564-584.

*Hayes, N., \& Joseph, S. (2003). Big 5 correlates of three measures of subjective well-being. Personality and Individual Differences, 34, $723-727$.

Headey, B., \& Wearing, A. (1989). Personality, life events, and subjective well-being: toward a dynamic equilibrium model. Journal of Personality and Social Psychology, 57, 731-739.

Headey, B., \& Wearing, A. J. (1992). Understanding happiness: A theory of subjective well-being. Melbourne: Longman Cheshire.

*Hébert, A., \& Weaver, A. (2014). An examination of personality characteristics associated with BDSM orientations. The Canadian Journal of Human Sexuality, 23, 106-115.

*Heller, D. (2004). The dynamic process of life satisfaction: The role of job and marital satisfaction, life events, personality and mood. (Doctoral thesis), University of Iowa.

*Heller, D., Judge, T. A., \& Watson, D. (2002). The confounding role of personality and trait affectivity in the relationship between job and life satisfaction. Journal of Organizational Behavior, 23, 815-835.

Heller, D., Watson, D., \& Ilies, R. (2004). The role of person versus situation in life satisfaction: A critical examination. Psychological Bulletin, $130,574-600$.

*Hemenover, S. H. (2001). Self-Reported Processing Bias and Naturally Occurring Mood: Mediators between Personality and Stress Appraisals. Personality and Social Psychology Bulletin, 27, 387-394. 
*Hengartner, M. P., Graf, M., \& Schreiber, M. (2017). Traits across the personality hierarchy differentially relate to positive and negative affect: Evidence for the predictive validity of empirically derived meta-traits. Personal Ment Health, 11, 132-143.

*Hengartner, M. P., Kawohl, W., Haker, H., Rossler, W., \& Ajdacic-Gross, V. (2016). Big Five personality traits may inform public health policy and preventive medicine: Evidence from a cross-sectional and a prospective longitudinal epidemiologic study in a Swiss community. Journal of Psychosomatic Research, 84, 44-51.

*Henriett, B.-N. (2018). Személyiség, érzelmi intelligencia és élettel való elégedettség. Mentálhigiéné és Pszichoszomatika, 19, 158-175.

*Herringer, L. G. (1998). Facets of extraversion related to life satisfaction. Personality and Individual Differences, 24, 731-733.

*Hill, P. L., \& Allemand, M. (2011). Gratitude, forgivingness, and well-being in adulthood: Tests of moderation and incremental prediction. The Journal of Positive Psychology, 6, 397-407.

*Hirsh, J. B., Guindon, A., Morisano, D., \& Peterson, J. B. (2010). Positive mood effects on delay discounting. Emotion, 10, 717-721.

*Hofer, J., Busch, H., \& Kiessling, F. (2008). Individual Pathways to Life Satisfaction: The Significance of Traits and Motives. Journal of Happiness Studies, 9, 503-520.

*Hogan, J. M. (2006). Individual differences as predictors of complementary and alternative medicine use in rheumatology patients. (Doctoral thesis), University of Hawaii.

*Holder, M. D., Love, A. B., \& Timoney, L. R. (2015). The Poor Subjective Well-Being Associated with Alexithymia is Mediated by Romantic Relationships. Journal of Happiness Studies, 16, 117-133.

Horwood, S., \& Anglim, J. (2018). Personality and problematic smartphone use: A facet-level analysis using the Five Factor Model and HEXACO frameworks. Computers in Human Behavior, 85, 349-359.

Horwood, S., \& Anglim, J. (2019). Problematic smartphone usage and subjective and psychological well-being. Computers in Human Behavior, $97,44-50$.

*Hossack, R. C. (1997). Salutogenic and pathogenic orientations to life: Attachment, personality, sense of coherence and well-being in late adolescence: A structural equation model. (Doctoral dissertation), University of Manitoba, Winnipeg, Manitoba, Canada.

*Howell, R. T. (2006). Models of happiness: The role of personality traits and daily experience in understanding life satisfaction. (thesis), University of California Riverside.

Hudson, N. W., \& Fraley, R. C. (2015). Volitional personality trait change: Can people choose to change their personality traits? Journal of Personality and Social Psychology, 109, 490.

*Hudson, N. W., \& Roberts, B. W. (2014). Goals to change personality traits: Concurrent links between personality traits, daily behavior, and goals to change oneself. Journal of Research in Personality, 53, 68-83.

*Hutz, C. S., Midgett, A., Pacico, J. C., Bastianello, M. R., \& Zanon, C. (2014). The Relationship of Hope, Optimism, Self-Esteem, Subjective Well-Being, and Personality in Brazilians and Americans. Psychology (Scientific Research), 05, 514-522.

*Ioannidis, C. A., \& Siegling, A. B. (2015). Criterion and incremental validity of the emotion regulation questionnaire. Frontiers in Psychology, 6, 247.

*Isaacowitz, D. M., \& Smith, J. (2003). Positive and negative affect in very old age. The Journals of Gerontology: Series B, 58, 143-152.

*Işı, Ş., \& Üzbe, N. (2015). Personality traits and positive/negative affects: An analysis of meaning in life among adults. Educational Sciences: Theory \& Practice, 15, 587-595.

*Jacques-Hamilton, R., Sun, J., \& Smillie, L. D. (2019). Costs and benefits of acting extraverted: A randomized controlled trial. Journal of Experimental Psychology: General, 148, 1538-1556.

*Jaksic, N., Aukst-Margetic, B., Rozsa, S., Brajkovic, L., Jovanovic, N., Vuksan-Cusa, B., . . Jakovljevic, M. (2015). Psychometric properties and factor structure of the Temperament and Character Inventory-Revised (TCI-R) in a Croatian psychiatric outpatient sample. Comprehensive Psychiatry, 57, 177-186.

*James, C., Bore, M., \& Zito, S. (2012). Emotional Intelligence and Personality as Predictors of Psychological Well-Being. Journal of Psychoeducational Assessment, 30, 425-438.

*Jennings, P. A. (2004). The role of personality, stress, and coping in the development of wisdom. (Doctoral thesis), University of California Davis.

*Jensen, R. A. A., Kirkegaard Thomsen, D., O'Connor, M., \& Mehlsen, M. Y. (2019). Age differences in life stories and neuroticism mediate age differences in subjective well - being. Applied Cognitive Psychology, https://doi.org/10.1002/acp.3580.

*Jibeen, T. (2014). Personality Traits and Subjective Well-Being: Moderating Role of Optimism in University Employees. Social Indicators Research, 118, 157-172.

John, O. P., \& Srivastava, S. (1999). The Big Five trait taxonomy: History, measurement, and theoretical perspectives. Handbook of personality: Theory and research, 2, 102-138.

*Johnson, D. K. (2003). Biases in negative affect and aging. (Doctoral thesis), Washington University.

*Jokela, M., Bleidorn, W., Lamb, M. E., Gosling, S. D., \& Rentfrow, P. J. (2015). Geographically varying associations between personality and life satisfaction in the London metropolitan area. Proceedings of the National Academy of Sciences of the United States of America, 112, 725-730.

*Jones, N., Hill, C., \& Henn, C. (2015). Personality and job satisfaction: their role in work-related psychological well-being. Journal of Psychology in Africa, 25, 297-304.

*Joshanloo, M., \& Afshari, S. (2011). Big Five Personality Traits and Self-Esteem as Predictors of Life Satisfaction in Iranian Muslim University Students. Journal of Happiness Studies, 12, 105-113.

*Joshanloo, M., \& Nosratabadi, M. (2009). Levels of Mental Health Continuum and Personality Traits. Social Indicators Research, 90, $211-224$.

*Jovanovic, V. (2011). Do humor styles matter in the relationship between personality and subjective well-being? Scandinavian Journal of Psychology, 52, 502-507.

*Jovanović, V. (2014). Psychometric evaluation of a Serbian version of the Subjective Happiness Scale. Social Indicators Research, 119 , 10951104.

*Jovanović, V. (2019). Adolescent life satisfaction: The role of negative life events and the Big Five personality traits. Personality and Individual Differences, 151, 109548.

Judge, T. A., Rodell, J. B., Klinger, R. L., Simon, L. S., \& Crawford, E. R. (2013). Hierarchical representations of the five-factor model of personality in predicting job performance: integrating three organizing frameworks with two theoretical perspectives. Journal of Applied Psychology, 98, 875.

*Kahlbaugh, P., \& Huffman, L. (2017). Personality, Emotional Qualities of Leisure, and Subjective Well-Being in the Elderly. International Journal of Aging and Human Development, 85, 164-184.

*Kahn, J. H., \& Hessling, R. M. (2001). Measuring the Tendency to Conceal Versus Disclose Psychological Distress. Journal of Social and Clinical 
Psychology, 20, 41-65.

*Kampfe, T., \& Parriaux, O. (2010). Parameter-tolerant binary gratings. Journal of the Optical Society of America A: Optics, Image Science, and Vision, 27, 2660-2669.

*Kandler, C., Pfattheicher, S., Geiger, M., Hartung, J., Weiss, S., \& Schindler, S. (2017). Old Wine in New Bottles? The Case of Self-compassion and Neuroticism. European Journal of Personality, 31, 160-169.

*Kashdan, T. B., \& Steger, M. F. (2007). Curiosity and pathways to well-being and meaning in life: Traits, states, and everyday behaviors. Motivation and Emotion, 31, 159-173.

*Kaynak, H. (2018). Relations Among Emotional Mood State, Personality Dimensions and Social Desirability in Older Adults. The Turkish Journal of Geriatrics, 21, 596-606.

*Kim, H., Schimmack, U., Cheng, C., Webster, G. D., \& Spectre, A. (2016). The Role of Positive Self-Evaluation on Cross-Cultural Differences in Well-Being. Cross-Cultural Research, 50, 85-99.

*Kirkland, T., Gruber, J., \& Cunningham, W. A. (2015). Comparing Happiness and Hypomania Risk: A Study of Extraversion and Neuroticism Aspects. PloS One, 10, e0132438.

*Kjell, O. N. E., Nima, A. A., Sikström, S., Archer, T., \& Garcia, D. (2013). Iranian and Swedish adolescents: differences in personality traits and well-being. PeerJ, 1:e197.

*Kluemper, D. H. (2008). Trait emotional intelligence: The impact of core-self evaluations and social desirability. Personality and Individual Differences, 44, 1402-1412.

*Knöpfli, B., Morselli, D., \& Perrig-Chiello, P. (2016). Trajectories of psychological adaptation to marital breakup after a long-term marriage. Gerontology, 62, 541-552.

*Kokinda, L. (2011). The effects of meditation on openness, awareness, and acceptance: A correlational study. (Doctoral thesis), Alliant International University, Los Angeles.

*Kong, F., Wang, X., Hu, S., \& Liu, J. (2015). Neural correlates of psychological resilience and their relation to life satisfaction in a sample of healthy young adults. Neuroimage, 123, 165-172.

*Kong, F., Zhao, J., You, X., \& Xiang, Y. (2019). Gratitude and the brain: Trait gratitude mediates the association between structural variations in the medial prefrontal cortex and life satisfaction. Emotion, http://dx.doi.org/10.1037/emo0000617.

*Kovacs, A. (2007). The leisure personality: Relationships between personality, leisure satisfaction, and life satisfaction. (thesis), Indiana University.

*Koydemir, S., \& Schütz, A. (2012). Emotional intelligence predicts components of subjective well-being beyond personality: A two-country study using self- and informant reports. The Journal of Positive Psychology, 7, 107-118.

*Krick, A., \& Felfe, J. (2019). Who benefits from mindfulness? The moderating role of personality and social norms for the effectiveness on psychological and physiological outcomes among police officers. Journal of Occupational Health Psychology, https://psycnet.apa.org/doi/10.1037/ocp0000159.

*Kwan, V. S. Y., Bond, M. H., \& Singelis, T. M. (1997). Pancultural explanations for life satisfaction: Adding relationship harmony to self-esteem. Journal of Personality and Social Psychology, 73, 1038-1051.

*Lai, C. C. W. (2018). The Mediating Role of Sleep Quality in the Relationship Between Personality and Subjective Well-Being. SAGE Open, 8.

*Lang, F. R., Lüdtke, O., \& Asendorpf, J. B. (2001). Testgüte und psychometrische Äquivalenz der deutschen Version des Big Five Inventory (BFI) bei jungen, mittelalten und alten Erwachsenen. Diagnostica, 47, 111-121.

*Langvik, E., Hjemdal, O., \& Nordahl, H. M. (2016). Personality traits, gender differences and symptoms of anhedonia: What does the Hospital Anxiety and Depression Scale (HADS) measure in nonclinical settings? Scandinavian Journal of Psychology, 57, 144-151.

*Lee, J. E., Sudom, K. A., \& Zamorski, M. A. (2013). Longitudinal analysis of psychological resilience and mental health in Canadian military personnel returning from overseas deployment. Journal of Occupational Health Psychology, 18, 327-337.

Lee, K., \& Ashton, M. C. (2004). Psychometric properties of the HEXACO personality inventory. Multivariate Behavioral Research, 39, $329-358$.

Lee, K., \& Ashton, M. C. (2006). Further assessment of the HEXACO Personality Inventory: two new facet scales and an observer report form. Psychological Assessment, 18, 182-191.

Lee, K., \& Ashton, M. C. (2013). Prediction of self-and observer report scores on HEXACO-60 and NEO-FFI scales. Journal of Research in Personality, 47, 668-675.

Lee, K., \& Ashton, M. C. (2014). The dark triad, the big five, and the HEXACO model. Personality and Individual Differences, 67, 2-5.

Lee, K., \& Ashton, M. C. (2018). Psychometric properties of the HEXACO-100. Assessment, 25, 543-556.

*Leffel, G. M., Oakes Mueller, R. A., Ham, S. A., Karches, K. E., Curlin, F. A., \& Yoon, J. D. (2018). Project on the Good Physician: Further Evidence for the Validity of a Moral Intuitionist Model of Virtuous Caring. Teaching and Learning in Medicine, 30, 303-316.

*Letrzing, T. (2019). Unpublished data of self-ratings of Satisfaction with Life, the BFI, trait PANAS, and Ryff's PWB.

*Letzring, T. D. (2015). Observer judgmental accuracy of personality: Benefits related to being a good (normative) judge. Journal of Research in Personality, 54, 51-60.

*Levinson, C. A., \& Rodebaugh, T. L. (2011). Validation of the Social Appearance Anxiety Scale: factor, convergent, and divergent validity. Assessment, 18, 350-356.

*Lightsey, O. R., Gharibian Gharghani, G., Katz, A. M., McKinney, V. A., \& Rarey, E. B. (2013). Positive Automatic Cognitions Mediate the Relationship Between Personality and Trait Positive Affect. Journal of Happiness Studies, 14, 115-134.

*Lodewyk, K. R. (2018). Associations between university students' personality traits and victimization and its negative affect in school physical education. Journal of Physical Education and Sport, 2018, 937-943.

*Lönnqvist, J.-E., \& große Deters, F. (2016). Facebook friends, subjective well-being, social support, and personality. Computers in Human Behavior, 55, 113-120.

*Lönnqvist, J.-E., \& Itkonen, J. V. A. (2014). It's all about Extraversion: Why Facebook friend count doesn't count towards well-being. Journal of Research in Personality, 53, 64-67.

*Lopez, A., Sanderman, R., Smink, A., Zhang, Y., van Sonderen, E., Ranchor, A., \& Schroevers, M. J. (2015). A Reconsideration of the SelfCompassion Scale's Total Score: Self-Compassion versus Self-Criticism. PloS One, 10, e0132940.

*Losoncz, I. (2007). Personality traits in HILDA. Retrieved from https://melbourneinstitute.unimelb.edu.au/assets/documents/hildabibliography/hilda-conference-papers/2007/Losoncz,-Ibolya final-paper.pdf

*Lounsbury, J. W., Tatum, H. E., Chambers, W., Owens, K. S., \& Gibson, L. W. (1999). An investigation of career decidedness in relation to "big five" personality constructs and life satisfaction. College Student Journal, 33, 646.

Lucas, R. E. (2007). Long-term disability is associated with lasting changes in subjective well-being: evidence from two nationally representative 
longitudinal studies. Journal of Personality and Social Psychology, 92, 717-730.

Lucas, R. E., Clark, A. E., Georgellis, Y., \& Diener, E. (2003). Reexamining adaptation and the set point model of happiness: reactions to changes in marital status. Journal of Personality and Social Psychology, 84, 527-539.

Lucas, R. E., \& Diener, E. (2008). Subjective well-being. Handbook of Emotions, 471-484.

Lucas, R. E., Diener, E., \& Suh, E. (1996). Discriminant validity of well-being measures. Journal of Personality and Social Psychology, 71, 616628.

*Lucas, R. E., \& Fujita, F. (2000). Factors influencing the relation between extraversion and pleasant affect. Journal of Personality and Social Psychology, 79, 1039-1056.

Ludeke, S. G., Bainbridge, T., Liu, J., Zhao, K., Smillie, L. D., \& Zettler, I. (2019). Using the Big Five Aspect Scales to translate between the HEXACO and Big Five personality models. Journal of Personality.

*Luhmann, M., Hawkley, L. C., \& Cacioppo, J. T. (2014). Thinking About One's Subjective Well-Being: Average Trends and Individual Differences. Journal of Happiness Studies, 15, 757-781.

*MacCann, C., Lipnevich, A. A., Burrus, J., \& Roberts, R. D. (2012). The best years of our lives? Coping with stress predicts school grades, life satisfaction, and feelings about high school. Learning and Individual Differences, 22, 235-241.

*MacInnis, C. C., Busseri, M. A., Choma, B. L., \& Hodson, G. (2013). The happy cyclist: Examining the association between generalized authoritarianism and subjective well-being. Personality and Individual Differences, 55, 789-793.

*Mangino, A. M. (2018). Connectedness to nature, life satisfaction, and personality: Humans, nature, and therapy. (thesis), Alliant International University, Sacramento.

*Marcionetti, J., \& Rossier, J. (2016). Global Life Satisfaction in Adolescence. Journal of Individual Differences, 37, 135-144.

*Margolis, S., \& Lyubomirsky, S. (2019). Experimental manipulation of extraverted and introverted behavior and its effects on well-being. Journal of Experimental Psychology: General, http://dx.doi.org/10.1037/xge0000668.

*Margolis, S., Schwitzgebel, E., Ozer, D. J., \& Lyubomirsky, S. (2018). A New Measure of Life Satisfaction: The Riverside Life Satisfaction Scale. Journal of Personality Assessment, 1-10.

*Marrero Quevedo, R. J., \& Carballeira Abella, M. (2011). Well-being and personality: Facet-level analyses. Personality and Individual Differences, 50, 206-211.

*Marrero, R. J. (2019). Dataset on NEO PI R Personality and well-being partially based on Marrero et al (2016) doi:10.1017/sjp.2016.95.

Marrero, R. J., Rey, M., \& Hernández-Cabrera, J. A. (2016). Can Big Five Facets Distinguish between Hedonic and Eudaimonic Well-Being? A Dominance Analysis. Spanish Journal of Psychology, 19, E84.

*Marshall, G. N., Wortman, C. B., Kusulas, J. W., Hervig, L. K., \& et, a. (1992). Distinguishing optimism from pessimism: Relations to fundamental dimensions of mood and personality. Journal of Personality and Social Psychology, 62, 1067-1074.

*Martin, A. J., Nejad, H. G., Colmar, S., \& Liem, G. A. D. (2013). Adaptability: How students' responses to uncertainty and novelty predict their academic and non-academic outcomes. Journal of Educational Psychology, 105, 728-746.

*Martinez-Molina, A., \& Arias, V. B. (2018). Balanced and positively worded personality short-forms: Mini-IPIP validity and cross-cultural invariance. PeerJ, 6, e5542.

McCrae, R. R., \& Costa, P. T. (1983). Social desirability scales: More substance than style. Journal of consulting and clinical psychology, $51,882$.

*McCrae, R. R., \& Costa, P. T. (1991). Adding Liebe und Arbeit: The full five-factor model and well-being. Personality and Social Psychology Bulletin, 17, 227-232.

McCrae, R. R., Costa, P. T., de Lima, M. P., Simões, A., Ostendorf, F., Angleitner, A., . . Barbaranelli, C. (1999). Age differences in personality across the adult life span: parallels in five cultures. Developmental Psychology, 35, 466.

McCrae, R. R., \& John, O. P. (1992). An introduction to the five-factor model and its applications. Journal of Personality, 60, 175-215.

*McCullough, M. E., Emmons, R. A., \& Tsang, J.-A. (2002). The grateful disposition: A conceptual and empirical topography. Journal of Personality and Social Psychology, 82, 112-127.

McGregor, I., \& Little, B. R. (1998). Personal projects, happiness, and meaning: On doing well and being yourself. Journal of Personality and Social Psychology, 74, 494-512.

*McKay, D. A. (2017). A facet and domain-level analysis of two trait models of personality: Relationship with subjective well-being. (Doctoral dissertation), The University of Akron, Akron, Ohio, United States.

*McMahan, E. A., Renken, M. D., Kehn, A., \& Nitkova, M. (2013). Individual conceptions of well-being predict psychological and subjective well-being: Beyond the big five. In F. Sarracino (Ed.), The happiness compass: Theories, actions and perspectives for well-being (pp. 3-16). Hauppauge, NY: Nova Science Publishers.

*Meléndez, J. C., Satorres, E., Cujiño, M., \& Reyes, M. (2019). Big Five and psychological and subjective well-being in Colombian older adults. Archives of Gerontology and Geriatrics, 82, 88-93.

*Mellor, D. J., Cummins, R. A., Karlinski, E., \& Storer, S. P. (2003). The management of subjective quality of life by short-stay hospital patients: an exploratory study. Health Qual Life Outcomes, $1,39$.

*Michel, J. S., \& Clark, M. A. (2013). Investigating the relative importance of individual differences on the work-family interface and the moderating role of boundary preference for segmentation. Stress Health, 29, 324-336.

*Miciuk, Ł. R., Jankowski, T., Laskowska, A., \& Oleś, P. (2016). Positive Orientation and the Five-Factor Model. Polish Psychological Bulletin, $47,141-148$.

*Miciuk, Ł. R., Jankowski, T., \& Oleś, P. (2016). Incremental validity of positive orientation: predictive efficiency beyond the five-factor model. Health Psychology Report, 4, 294-302.

*Mongrain, M., Barnes, C., Barnhart, R., \& Zalan, L. B. (2018). Acts of kindness reduce depression in individuals low on agreeableness. Translational Issues in Psychological Science, 4, 323-334.

*Montasem, A., Brown, S. L., \& Harris, R. (2013). Do core self-evaluations and trait emotional intelligence predict subjective well-being in dental students? Journal of Applied Social Psychology, 43, 1097-1103.

*Morris, M. B., Burns, G. N., Periard, D. A., \& Shoda, E. A. (2015). Extraversion-Emotional Stability Circumplex Traits and Subjective WellBeing. Journal of Happiness Studies, 16, 1509-1523.

*Morrison, K. A. (1997). Personality correlates of the Five-Factor Model for a sample of business owners/managers: associations with scores on Self-Monitoring, Type A Behavior, Locus of Control, and Subjective Well-being. Psychological Reports, 80, 255-272.

*Morsunbul, U. (2014). The validity and reliability study of the Turkish version of Quick Big Five Personality Test. Dusunen Adam: The Journal of Psychiatry and Neurological Sciences, 27, 316-322.

Mõttus, R., Kandler, C., Bleidorn, W., Riemann, R., \& McCrae, R. R. (2017). Personality Traits Below Facets: The Consensual Validity, 
Longitudinal Stability, Heritability, and Utility of Personality Nuances. Journal of Personality and Social Psychology, 112, 474-490.

Mõttus, R., McCrae, R. R., Allik, J., \& Realo, A. (2014). Cross-rater agreement on common and specific variance of personality scales and items. Journal of Research in Personality, 52, 47-54.

*Murray, G. (2002). The relationship between the Big-5 personality factors and life satisfaction in two community samples. Unpublished data. Correlations reported in Heller et al (2004) meta-analysis.

Musek, J. (2007). A general factor of personality: Evidence for the Big One in the five-factor model. Journal of Research in Personality, 41, 12131233.

*Naukkarinen, S., Karkkola, P., Kuittinen, M., \& Räty, H. (2016). Suomenkielisen MAAS-mittarin psykometrinen rakenne ja yhteydet persoonallisuuspiirteisiin sekä hyvinvointiin [The psychometric structure of the Finnish MAAS measure and associations with personality and well-being]. Psykologia, 51, 343-359.

*Navarro-Prados, A. B., Serrate-Gonzalez, S., Munoz-Rodriguez, J. M., \& Diaz-Orueta, U. (2018). Relationship Between Personality Traits, Generativity, and Life Satisfaction in Individuals Attending University Programs for Seniors. International Journal of Aging and Human Development, 87, 184-200.

*Neff, K. D., Rude, S. S., \& Kirkpatrick, K. L. (2007). An examination of self-compassion in relation to positive psychological functioning and personality traits. Journal of Research in Personality, 41, 908-916.

*Ng, W. (2015). Processes Underlying Links to Subjective Well-being: Material Concerns, Autonomy, and Personality. Journal of Happiness Studies, 16, 1575-1591.

*Ng, W., Russell Kua, W. S., \& Kang, S. H. (2019). The Relative Importance of Personality, Financial Satisfaction, and Autonomy for Different Subjective Well-Being Facets. Journal of Psychology, 153, 680-700.

*Nishimura, T., \& Suzuki, T. (2016). Basic Psychological Need Satisfaction and Frustration in Japan: Controlling for the Big Five Personality Traits. Japanese Psychological Research, 58, 320-331.

*Novak, J. R., Anderson, J. R., Johnson, M. D., Hardy, N. R., Walker, A., Wilcox, A., . . Robbins, D. C. (2017). Does Personality Matter in Diabetes Adherence? Exploring the Pathways between Neuroticism and Patient Adherence in Couples with Type 2 Diabetes. Applied Psychology: Health and Well Being, 9, 207-227.

*Novakov, I., \& Popovic-Petrovic, S. (2017). Personality traits as predictors of the affective state in patients after breast cancer surgery. Archive of Oncology, 23, 3-8.

* Novoa, C., \& Barra, E. (2015). Influencia del apoyo social percibido y los factores de personalidad en la satisfacción vital de estudiantes universitarios. Terapia psicológica, 33, 239-245.

*O'Rourke, N. (2004). Cognitive adaptation and women's adjustment to conjugal bereavement. Journal of Women and Aging, 16, 87-104.

*O'Rourke, N. (2005). Personality, cognitive adaptation, and marital satisfaction as predictors of well-being among older married adults. Canadian Journal on Aging, 24, 211-224.

*Odac1, H., \& Cikrikci, Ö. (2018). Cognitive Flexibility Mediates the Relationship between Big Five Personality Traits and Life Satisfaction. Applied Research in Quality of Life, 1-18.

*Oishi, S., Kohlbacher, F., \& Choi, H. (2018). Does A Major Earthquake Change Attitudes and Well-Being Judgments? A Natural Experiment. Social Psychological and Personality Science, 9, 364-371.

*Oishi, S., Krochik, M., Roth, D., \& Sherman, G. D. (2012). Residential Mobility, Personality, and Subjective and Physical Well-Being. Social Psychological and Personality Science, 3, 153-161.

*Oken, B. S., Wahbeh, H., Goodrich, E., Klee, D., Memmott, T., Miller, M., \& Fu, R. (2017). Meditation in Stressed Older Adults: Improvements in self-rated mental health not paralleled by improvements in cognitive function or physiological measures. Mindfulness (N Y), 8, 627638.

*Olesen, M. H., Thomsen, D. K., \& O’Toole, M. S. (2015). Subjective well-being: Above neuroticism and extraversion, autonomy motivation matters. Personality and Individual Differences, 77, 45-49.

Ones, D. S., \& Viswesvaran, C. (1996). Bandwidth-fidelity dilemma in personality measurement for personnel selection. Journal of Organizational Behavior, 17, 609-626.

*Osma, J., Suso-Ribera, C., Garcia-Palacios, A., Crespo-Delgado, E., Robert-Flor, C., Sanchez-Guerrero, A., . . Torres-Alfosea, M. Á. (2018). Efficacy of the unified protocol for the treatment of emotional disorders in the Spanish public mental health system using a group format: study protocol for a multicenter, randomized, non-inferiority controlled trial. Health and Quality of Life Outcomes, 16, 46.

*Panaccio, A., \& Vandenberghe, C. (2012). Five-factor model of personality and organizational commitment: The mediating role of positive and negative affective states. Journal of Vocational Behavior, 80, 647-658.

*Parker, P. D., Martin, A. J., \& Marsh, H. W. (2008). Factors Predicting Life Satisfaction: A Process Model of Personality, Multidimensional SelfConcept, and Life Satisfaction. Australian Journal of Guidance and Counselling, 18, 15-29.

Parks-Leduc, L., Feldman, G., \& Bardi, A. (2015). Personality traits and personal values: A meta-analysis. Personality and Social Psychology Review, 19, 3-29.

*Paulson, D., \& Leuty, M. E. (2015). Dispositional Coping, Personality Traits, and Affective Style Relating to Conflict between Work and Family Domains. Journal of Family and Economic Issues, 37, 519-539.

Paunonen, S. V., \& Ashton, M. C. (2001). Big Five factors and facets and the prediction of behavior. Journal of Personality and Social Psychology, 81, 524-539.

Paunonen, S. V., \& Jackson, D. N. (2000). What is beyond the big five? Plenty! Journal of Personality, 68, 821-835.

*Pavani, J.-B., Le Vigouroux, S., Kop, J.-L., Congard, A., Dauvier, B., \& Denissen, J. (2017). A Network Approach to Affect Regulation Dynamics and Personality Trait-Induced Variations: Extraversion and Neuroticism Moderate Reciprocal Influences between Affect and Affect Regulation Strategies. European Journal of Personality, 31, 329-346.

*Pavot, W., Diener, E., \& Suh, E. (1998). The Temporal Satisfaction With Life Scale. Journal of Personality Assessment, 70, $340-354$.

*Pazda, A. D., \& Thorstenson, C. A. (2018). Extraversion predicts a preference for high-chroma colors. Personality and Individual Differences, $127,133-138$.

*Petrides, K. V., Pita, R., \& Kokkinaki, F. (2007). The location of trait emotional intelligence in personality factor space. British Journal of Psychology, 98, 273-289.

*Plopa, M., Plopa, W., \& Skuzinska, A. (2017). Bullying at work, personality and subjective well-being. Journal of Occupational Health Psychology, 22, 19-27.

*Pollock, N. C., Noser, A. E., Holden, C. J., \& Zeigler-Hill, V. (2016). Do orientations to happiness mediate the associations between personality traits and subjective well-being? Journal of Happiness Studies, 17, 713-729. 
*Pratt, A. K. (2006). Role of cognitive ability and personality factors in coping with work-family conflict. (Doctoral thesis), Wayne State University.

*Purvis, A., Howell, R. T., \& Iyer, R. (2011). Exploring the role of personality in the relationship between maximization and well-being. Personality and Individual Differences, 50, 370-375.

*Pychyl, T. A., \& Little, B. R. (1998). Dimensional specificity in the prediction of subjective well-being: Personal projects in pursuit of the PhD. Social Indicators Research, 45, 423-473.

Pytlik Zillig, L. M., Hemenover, S. H., \& Dienstbier, R. A. (2002). What do we assess when we assess a Big 5 trait? A content analysis of the affective, behavioral, and cognitive processes represented in Big 5 personality inventories. Personality and Social Psychology Bulletin, $28,847-858$.

*Qing-Guo, Z., O'Shea, B., Bajpai, M., Bajpai, W., \& Yu-Bo, Z. (2011). The influence of Big Five personality traits on subjective well-being: Mediation of job satisfaction. International Conference on Management Science and Engineering - Annual Conference Proceedings, $717-725$.

*Ramanaiah, N. V., Detwiler, F. R., \& Byravan, A. (1995). Sex-role orientation and satisfaction with life. Psychological Reports, 77, $1260-1262$.

*Rammstedt, B., Lechner, C. M., \& Danner, D. (2018). Relationships between Personality and Cognitive Ability: A Facet-Level Analysis. J Intell, 6.

*Reich, W. A., Sangiorgio, C., \& Young, J. (2019). Self-Role Integration: A Person-Specific Predictor of Life Satisfaction and Prosocial Behavior. Journal of Psychology, 153, 649-666.

Revelle, W. (2018). psych: Procedures for Personality and Psychological Research (Version 1.8.4). Northwestern University, Evanston, Illinois, USA. Retrieved from https://cran.r-project.org/package $=$ psych

*Rigby, B. T., \& Huebner, E. S. (2005). Do causal attributions mediate the relationship between personality characteristics and life satisfaction in adolescence? Psychology in the Schools, 42, 91-99.

*Ro, E. (2011). Conceptualization of psychosocial functioning: Understanding structure and relations with personality and psychopathology. (Doctoral thesis), University of Iowa.

Roberts, B. W., Lejuez, C., Krueger, R. F., Richards, J. M., \& Hill, P. L. (2014). What is conscientiousness and how can it be assessed? Developmental Psychology, 50, 1315.

Roberts, B. W., Luo, J., Briley, D. A., Chow, P. I., Su, R., \& Hill, P. L. (2017). A systematic review of personality trait change through intervention. Psychological Bulletin, 143, 117.

*Robinson, M. D., Goetz, M. C., Wilkowski, B. M., \& Hoffman, S. J. (2006). Driven to tears or to joy: response dominance and trait-based predictions. Personality \& Social Psychology Bulletin, 32, 629-640.

*Robinson, O. C., Demetre, J. D., \& Corney, R. (2010). Personality and retirement: Exploring the links between the Big Five personality traits, reasons for retirement and the experience of being retired. Personality and Individual Differences, 48, $792-797$.

*Rodgers, J. D., Lodi-Smith, J., Hill, P. L., Spain, S. M., Lopata, C., \& Thomeer, M. L. (2018). Brief Report: Personality Mediates the Relationship between Autism Quotient and Well-Being: A Conceptual Replication using Self-Report. Journal of Autism and Developmental Disorders, 48, 307-315.

*Romero, E., Gómez-Fraguela, J. A., \& Villar, P. (2012). Life aspirations, personality traits and subjective well-being in a Spanish sample. European Journal of Personality, 26, 45-55.

*Romero, E., Luengo, M. A., Gómez-Fraguela, J. A., \& Sobral, J. (2002). The structure of personality traits in adolescents: The five-factor model and the alternative five [La estructura de los rasgos de personalidad en adolescentes: El modelo de Cinco factores y los Cinco alternativos]. Psicothema, 14, 134-143.

*Romero, E., Villar, P., \& López-Romero, L. (2015). Assessing six factors in Spain: Validation of the HEXACO-100 in relation to the Five Factor Model and other conceptually relevant criteria. Personality and Individual Differences, 76, 75-81.

*Romero, E., Villar, P., Luengo, M. Á., \& Gómez-Fraguela, J. A. (2009). Traits, personal strivings and well-being. Journal of Research in Personality, 43, 535-546.

*Røysamb, E., Nes, R. B., Czajkowski, N. O., \& Vassend, O. (2018). Genetics, personality and wellbeing. A twin study of traits, facets and life satisfaction. Scientific Reports, 8, 12298.

*Ryan, L. H., Newton, N. J., Chauhan, P. K., \& Chopik, W. J. (2017). Effects of Pre-Retirement Personality, Health and Job Lock on PostRetirement Subjective Well-being. Translational Issues in Psychological Science, 3, 378-387.

Ryan, R. M., \& Deci, E. L. (2001). On happiness and human potentials: A review of research on hedonic and eudaimonic well-being. Annual Review of Psychology, 52, 141-166.

*Ryan, R. M., \& Frederick, C. (1997). On energy, personality, and health: subjective vitality as a dynamic reflection of well-being. Journal of Personality, 65, 529-565.

Ryff, C. D. (1989). Happiness is everything, or is it? Explorations on the meaning of psychological well-being. Journal of Personality and Social Psychology, 57, 1069-1081.

Ryff, C. D., \& Keyes, C. L. M. (1995). The structure of psychological well-being revisited. Journal of Personality and Social Psychology, 69, 719727.

*Rzeszutek, M., Gruszczyńska, E., \& Firląg-Burkacka, E. (2018). Socio-medical and personality correlates of psychological well-being among people living with HIV: a latent profile analysis. Applied Research in Quality of Life, 1-15.

*Sadiković, S., Smederevac, S., Mitrović, D., \& Milovanović, I. (2018). Behavioral genetics foundations of relations between personality traits and satisfaction with life. Primenjena Psihologija, 11, 487-502.

*Saeed Abbasi, I., Rattan, N., Kousar, T., \& Khalifa Elsayed, F. (2018). Neuroticism and Close Relationships: How Negative Affect is Linked with Relationship Disaffection in Couples. The American Journal of Family Therapy, 46, 139-152.

*Saeki, M., Oishi, S., Maeno, T., \& Gilbert, E. (2014). Self-informant agreement for subjective well-being among Japanese. Personality and Individual Differences, 69, 124-128.

*Saiz, J., Álvaro, J. L., \& Martínez, I. (2011). Relación entre rasgos de personalidad y valores personales en pacientes dependientes de la cocaína. Adicciones, 23, 125-132.

*Saklofske, D. H., Austin, E. J., Mastoras, S. M., Beaton, L., \& Osborne, S. E. (2012). Relationships of personality, affect, emotional intelligence and coping with student stress and academic success: Different patterns of association for stress and success. Learning and Individual Differences, 22, 251-257.

*Salter, J. E., Smith, S. D., \& Ethans, K. D. (2013). Positive and negative affect in individuals with spinal cord injuries. Spinal Cord, 51 , 252-256. Saucier, G. (2009). Recurrent personality dimensions in inclusive lexical studies: Indications for a Big Six structure. Journal of Personality, 77, $1577-1614$ 
Schimmack, U., \& Oishi, S. (2005). The influence of chronically and temporarily accessible information on life satisfaction judgments. Journal of Personality and Social Psychology, 89, 395-406.

*Schimmack, U., Oishi, S., Furr, R. M., \& Funder, D. C. (2004). Personality and life satisfaction: a facet-level analysis. Personality \& Social Psychology Bulletin, 30, 1062-1075.

*Schimmack, U., Schupp, J., \& Wagner, G. G. (2008). The Influence of Environment and Personality on the Affective and Cognitive Component of Subjective Well-being. Social Indicators Research, 89, 41-60.

*Schmutte, P. S., \& Ryff, C. D. (1997). Personality and well-being: Reexamining methods and meanings. Journal of Personality and Social Psychology, 73, 549-559.

*Schneider, T. R., Rench, T. A., Lyons, J. B., \& Riffle, R. R. (2012). The influence of neuroticism, extraversion and openness on stress responses. Stress Health, 28, 102-110.

*Schoeps, K., González, R., \& Montoya-Castilla, I. (2016). Personalidad, relaciones familiares ysatisfacción con la vida en parejas casadas [Personality, family relations and satisfaction with life in married couples]. Revista Mexicana de Psicología, 33, 89-100.

*Schwartz, C. E., Michael, W., Zhang, J., Rapkin, B. D., \& Sprangers, M. A. G. (2018). Assessing reserve-building pursuits and person characteristics: psychometric validation of the Reserve-Building Measure. Quality of Life Research, 27, 423-436.

*Seder, J. P., \& Oishi, S. (2012). Intensity of Smiling in Facebook Photos Predicts Future Life Satisfaction. Social Psychological and Personality Science, 3, 407-413.

*Selnes, M., Marthinsen, K., \& Vittersø, J. (2004). Hedonisme og eudaimonia: To separate dimensjoner av livskvalitet? [Hedonism and eudaimonia: Two distinct quality-of-life dimensions?]. Tidsskrift for Norsk Psykologforening, 41, 179-187.

*Selvarajan, T. T., Singh, B., \& Cloninger, P. A. (2016). Role of personality and affect on the social support and work family conflict relationship. Journal of Vocational Behavior, 94, 39-56.

*Sheu, H.-B., Liu, Y., \& Li, Y. (2017). Well-Being of College Students in China. Journal of Career Assessment, 25, 144-158.

*Sheu, H. B., Mejia, A., Rigali-Oiler, M., Prime, D. R., \& Chong, S. S. (2016). Social cognitive predictors of academic and life satisfaction: Measurement and structural equivalence across three racial/ethnic groups. Journal of Counseling Psychology, 63, 460-474.

*Shi, Y., Luo, Y. L. L., Liu, Y., \& Yang, Z. (2019). Affective experience on social networking sites predicts psychological well-being off-line. Psychological Reports, 122, 1666-1677.

*Shulman, T. E., \& Hemenover, S. H. (2006). Is dispositional emotional intelligence synonymous with personality? Self and Identity, 5, 147-171.

*Shyh Shin, W., Boon Ooi, L., Ang, R. P., Oei, T. P. S., \& Aik Kwang, N. (2009). Personality, Health, and Coping. Cross-Cultural Research, 43, 251-279.

*Sibley, C. G. (2011). The BIAS-Treatment Scale (BIAS-TS): A measure of the subjective experience of active and passive harm and facilitation. Journal of Personality Assessment, 93, 300-315.

*Sibley, C. G., Luyten, N., Purnomo, M., Mobberley, A., Wootton, L. W., Hammond, M. D., . . West-Newman, T. (2011). The Mini-IPIP6: Validation and extension of a short measure of the Big-Six factors of personality in New Zealand. New Zealand Journal of Psychology, $40,142-159$.

*Şimşek, Ö. F. (2011). An intentional model of emotional well-being: The development and initial validation of a measure of subjective well-being. Journal of Happiness Studies, 12, 421-442.

*Şimşek, Ö. F., \& Kocayörük, E. (2013). Affective reactions to one's whole life: Preliminary development and validation of the ontological wellbeing scale. Journal of Happiness Studies, 14, 309-343.

*Şimşek, Ö. F., \& Koydemir, S. (2013). Linking metatraits of the Big Five to well-being and ill-being: Do basic psychological needs matter? Journal of Happiness Studies, 112, 221-238.

*Singh, B., \& Shejwal, B. R. (2017). Role of mental image, and personality in emotions and affect among NCC cadets. Journal of the Indian Academy of Applied Psychology, 43, 276-285.

*Sirianni Molnar, D. (2011). The light and dark sides of perfectionism implications for health and well-being. (Doctoral thesis), Brock University.

*Skomorovsky, A., \& Sudom, K. A. (2011). Psychological well-being of Canadian Forces officer candidates: the unique roles of hardiness and personality. Military Medicine, 176, 389-396.

*Sliter, M., Withrow, S., \& Jex, S. M. (2015). It happened, or you thought it happened? Examining the perception of workplace incivility based on personality characteristics. International Journal of Stress Management, 22, 24-45.

Smillie, L. D., Cooper, A. J., Wilt, J., \& Revelle, W. (2012). Do extraverts get more bang for the buck? Refining the affective-reactivity hypothesis of extraversion. Journal of Personality and Social Psychology, 103, 306-326.

Smillie, L. D., Kern, M. L., \& Uljarevic, M. (2018). Description, Development, and Mechanisms. Handbook of Personality Development, 118.

Smillie, L. D., Wilt, J., Kabbani, R., Garratt, C., \& Revelle, W. (2015). Quality of social experience explains the relation between extraversion and positive affect. Emotion, 15, 339-349.

*Sobocko, K., \& Zelenski, J. M. (2015). Trait sensory-processing sensitivity and subjective well-being: Distinctive associations for different aspects of sensitivity. Personality and Individual Differences, 83, 44-49.

*Sodermans, A. K., \& Matthijs, K. (2014). Joint physical custody and adolescents' subjective well-being: a personality x environment interaction. Journal of Family Psychology, 28, 346-356.

*Sorondo, B. M. (2017). Associations between affect, personality, and job satisfaction among library employees: Efficient and ethical assessment of library staff. Advances in Library Administration and Organization, 37, 35-56.

*Soto, C. J., \& John, O. P. (2017). The next Big Five Inventory (BFI-2): Developing and assessing a hierarchical model with 15 facets to enhance bandwidth, fidelity, and predictive power. Journal of Personality and Social Psychology, 113, 117-143.

Soto, C. J., John, O. P., Gosling, S. D., \& Potter, J. (2011). Age differences in personality traits from 10 to 65: Big Five domains and facets in a large cross-sectional sample. Journal of Personality and Social Psychology, 100, 330.

*Soto, C. J., \& Luhmann, M. (2013). Who Can Buy Happiness? Social Psychological and Personality Science, 4, 46-53.

*Soubelet, A., \& Salthouse, T. A. (2011). Influence of social desirability on age differences in self-reports of mood and personality. Journal of Personality, 79, 741-762.

*Spörrle, M., Strobel, M., \& Tumasjan, A. (2010). On the incremental validity of irrational beliefs to predict subjective well-being while controlling for personality factors. Psicothema, 22, 543-548.

*Stamatopoulou, M., Galanis, P., \& Prezerakos, P. (2016). Psychometric properties of the Greek translation of the Trait Emotional Intelligence Questionnaire-Short Form (TEIQue-SF). Personality and Individual Differences, 95, 80-84.

*Stanton, K., Gruber, J., \& Watson, D. (2017). Basic dimensions defining mania risk: A structural approach. Psychological Assessment, 29, 304319. 
*Stanton, K., Rozek, D. C., Stasik-O'Brien, S. M., Ellickson-Larew, S., \& Watson, D. (2016). A transdiagnostic approach to examining the incremental predictive power of emotion regulation and basic personality dimensions. Journal of Abnormal Psychology, 125, 960-975.

*Steca, P., Capanna, C., Mecaroni, M., \& Delle Fratte, A. (2005). La soddisfazione di vita e le sue relazioni con i cinque fattori di personalità [Life satisfaction and its relation with the big five personality factors]. Rassegna di Psicologia, 22, 21-33.

Steel, P., Schmidt, J., Bosco, F., \& Uggerslev, K. (2019). The effects of personality on job satisfaction and life satisfaction: A meta-analytic investigation accounting for bandwidth-fidelity and commensurability. Human Relations, 72, 217-247.

Steel, P., Schmidt, J., \& Shultz, J. (2008). Refining the relationship between personality and subjective well-being. Psychological Bulletin, 134, 138-161.

Stephan, Y. (2009). Openness to experience and active older adults' life satisfaction: A trait and facet-level analysis. Personality and Individual Differences, 47, 637-641.

*Stimson, T. S. (2010). The precursors and outcomes of goal choice and attainment. (Doctoral thesis), University of California Riverside.

Stoeber, J., \& Otto, K. (2006). Positive conceptions of perfectionism: Approaches, evidence, challenges. Personality and Social Psychology Review, 10, 295-319.

Stoeber, J., \& Stoeber, F. S. (2009). Domains of perfectionism: Prevalence and relationships with perfectionism, gender, age, and satisfaction with life. Personality and Individual Differences, 46, 530-535.

*Stolarski, M. (2016). Not restricted by their personality: Balanced Time Perspective moderates well-established relationships between personality traits and well-being. Personality and Individual Differences, 100, 140-144.

*Suh, E., Diener, E., \& Fujita, F. (1996). Events and subjective well-being: Only recent events matter. Journal of Personality and Social Psychology, 70, 1091-1102.

*Sulaiman, W. S. W., Kadir, N. B. A., Halim, F. W., Omar, F., Latiff, R. A., \& Sulaiman, W. S. W. (2013). Structural relations between personality traits, coping strategy, social support and well-being among adolescents. Pertanika Journal of Social Science and Humanities, 21, 121134.

*Suldo, S. M., R. Minch, D., \& Hearon, B. V. (2015). Adolescent Life Satisfaction and Personality Characteristics: Investigating Relationships Using a Five Factor Model. Journal of Happiness Studies, 16, 965-983.

*Sun, J., Kaufman, S. B., \& Smillie, L. D. (2018). Unique Associations Between Big Five Personality Aspects and Multiple Dimensions of WellBeing. Journal of Personality, 86, 158-172.

*Sun, J., Stevenson, K., Kabbani, R., Richardson, B., \& Smillie, L. D. (2017). The pleasure of making a difference: Perceived social contribution explains the relation between extraverted behavior and positive affect. Emotion, 17, 794-810.

*Szcześniak, M., Sopińska, B., \& Kroplewski, Z. (2019). Big Five personality traits and life satisfaction: The mediating role of religiosity. Religions, $10,437$.

*Tan, W. H., Sheffield, J., Khoo, S. K., Byrne, G., \& Pachana, N. A. (2017). Influences on psychological well-being and ill-being in older women. Australian Psychologist, 53, 203-212.

*Tanksale, D. (2015). Big Five personality traits: are they really important for the subjective well-being of Indians? International Journal of Psychology, 50, 64-69.

*Tartaglia, S., Miglietta, A., \& Gattino, S. (2017). Life Satisfaction and Cannabis Use: A Study on Young Adults. Journal of Happiness Studies, $18,709-718$.

*Teachman, B. A., Siedlecki, K. L., \& Magee, J. C. (2007). Aging and symptoms of anxiety and depression: structural invariance of the tripartite model. Psychology and Aging, 22, 160-170.

*Terracciano, A. (2003). The Italian version of the NEO PI-R: conceptual and empirical support for the use of targeted rotation. Personality and Individual Differences, 35, 1859-1872.

*Tett, R. P., Fox, K. E., \& Wang, A. (2005). Development and validation of a self-report measure of emotional intelligence as a multidimensional trait domain. Personality \& Social Psychology Bulletin, 31, 859-888.

*Thingujam, N. S. (2011). Emotional intelligence and life satisfaction: Re-examining the link and mediating role of affectivity and personality in India. Journal of the Indian Academy of Applied Psychology, 37, 27-34.

*Thomas, E. A. (2011). Personality characteristics and behavioral outcomes associated with engagement in work-related roles. (thesis), Alliant International University.

*Thoresen, C. J. (2000). Antecedents and consequences of coping with setbacks at work: A theory-driven framework. (PhD thesis), University of Iowa.

*Thorpe, K. (2015). The role of humor, mindfulness, coping, and personality in psychological health. (Doctoral thesis), St John's University New York.

*Tian, L.-L., \& Zheng, X. (2007). Relationship between five personality factors and multi-dimensional life satisfaction in middle school students. Chinese Mental Health Journal, 21, 165-168.

*Tov, W. (2012). Daily experiences and well-being: do memories of events matter? Cognition \& Emotion, 26, 1371-1389.

*Trankle, S. A., \& Haw, J. (2009). Predicting Australian health behaviour from health beliefs. E-Journal of Applied Psychology, 5, 42979.

*Tuce, Đ., \& Fako, I. (2014). Odrednice zadovoljstva životom kod adolescenata [The determinants of satisfaction with life in adolescents]. Psihologijske Teme, 23, 407-433.

*van Allen, Z. M., \& Zelenski, J. M. (2018). Testing Trait-State Isomorphism in a New Domain: An Exploratory Manipulation of Openness to Experience. Frontiers in Psychology, 9, 1964.

Vázquez, C., Duque, A., \& Hervás, G. (2013). Satisfaction with life scale in a representative sample of Spanish adults: validation and normative data. The Spanish Journal of Psychology, 16.

Veselka, L., Schermer, J. A., Petrides, K. V., Cherkas, L. F., Spector, T. D., \& Vernon, P. A. (2009). A General Factor of Personality: Evidence from the HEXACO Model and a Measure of Trait Emotional Intelligence. Twin Research and Human Genetics, 12, 420-424.

Viechtbauer, W. (2010). Conducting meta-analyses in R with the metafor package. Journal of Statistical Software, 36, 1-48.

*Vilhena, E., Pais-Ribeiro, J., Silva, I., Pedro, L., Meneses, R. F., Cardoso, H., . . . Mendonca, D. (2014). Optimism on quality of life in Portuguese chronic patients: moderator/mediator? Revista da Associacao Medica Brasileira, 60, 373-380.

*Villieux, A., Sovet, L., Jung, S.-C., \& Guilbert, L. (2016). Psychological flourishing: Validation of the French version of the Flourishing Scale and exploration of its relationships with personality traits. Personality and Individual Differences, 88, 1-5.

Visser, B. A., \& Pozzebon, J. A. (2013). Who are you and what do you want? Life aspirations, personality, and well-being. Personality and Individual Differences, 54, 266-271.

*Vittersø, J. (2001). Personality traits and subjective well-being. Personality and Individual Differences, 31, 903-914. 
*Vollmann, M., Pukrop, J., \& Salewski, C. (2016). Coping mediates the influence of personality on life satisfaction in patients with rheumatic diseases. Clinical Rheumatology, 35, 1093-1097.

*Vorkapić, S. T., \& Lončarić, D. (2013). Posreduje li profesionalno sagorijevanje učinke osobina ličnosti na zadovoljstvo životom odgojitelja predškolske djece? Psihologijske teme, 22, 431-445.

*Wahl, H. W., Heyl, V., \& Schilling, O. (2012). Robustness of personality and affect relations under chronic conditions: the case of age-related vision and hearing impairment. Journals of Gerontology. Series B: Psychological Sciences and Social Sciences, 67, 687-696.

*Wang, D., Hu, M., Li, S., \& Tao, S. (2017). Psychometric Properties of the Temperament and Character Inventory-Revised in Chinese Young Adults. Current Psychology, 38, 1276-1284.

Waterman, A. S. (1993). Two conceptions of happiness: Contrasts of personal expressiveness (eudaimonia) and hedonic enjoyment. Journal of Personality and Social Psychology, 64, 678.

*Watson, D., \& Clark, L. A. (1992). On traits and temperament: general and specific factors of emotional experience and their relation to the fivefactor model. Journal of Personality, 60, 441-476.

Watson, D., Clark, L. A., \& Tellegen, A. (1988). Development and validation of brief measures of positive and negative affect: the PANAS scales. Journal of Personality and Social Psychology, 54, 1063-1070.

*Watson, D., Hubbard, B., \& Wiese, D. (2000). Self-other agreement in personality and affectivity: The role of acquaintanceship, trait visibility, and assumed similarity. Journal of Personality and Social Psychology, 78, 546-558.

*Watson, D., Klohnen, E. C., Casillas, A., Nus Simms, E., Haig, J., \& Berry, D. S. (2004). Match makers and deal breakers: Analyses of assortative mating in newlywed couples. Journal of Personality, 72, 1029-1068.

*Watson, D., O'Hara, M. W., Simms, L. J., Kotov, R., Chmielewski, M., McDade-Montez, E. A., ... Stuart, S. (2007). Development and validation of the Inventory of Depression and Anxiety Symptoms (IDAS). Psychological Assessment, 19, 253-268.

*Watson, D., Stanton, K., \& Clark, L. A. (2017). Self-report indicators of negative valence constructs within the research domain criteria (RDoC): A critical review. Journal of Affective Disorders, 216, 58-69.

*Watson, D., Stasik, S. M., Chmielewski, M., \& Naragon-Gainey, K. (2015). Development and validation of the Temperament and Affectivity Inventory (TAI). Assessment, 22, 540-560.

*Watson, D., Suls, J., \& Haig, J. (2002). Global self-esteem in relation to structural models of personality and affectivity. Journal of Personality and Social Psychology, 83, 185-197.

*Webb, C. A., Schwab, Z. J., Weber, M., DelDonno, S., Kipman, M., Weiner, M. R., \& Killgore, W. D. S. (2013). Convergent and divergent validity of integrative versus mixed model measures of emotional intelligence. Intelligence, 41, 149-156.

*Weber, M., \& Huebner, E. S. (2015). Early adolescents' personality and life satisfaction: A closer look at global vs. domain-specific satisfaction. Personality and Individual Differences, 83, 31-36.

Weiss, A., Bates, T. C., \& Luciano, M. (2008). Happiness Is a personal(ity) thing: The genetics of personality and well-being in a representative sample. Psychological Science, 19, 205-210.

*West, N. M. (2007). The relationship among personality traits, character strengths, and life satisfaction in college students. (Doctoral thesis), University of Tennessee, Knoxville.

*Whisman, M. A., Uebelacker, L. A., Tolejko, N., Chatav, Y., \& McKelvie, M. (2006). Marital discord and well-being in older adults: is the association confounded by personality? Psychology and Aging, 21, 626-631.

*White, G. A. (2011). Implications of relationship social comparison tendencies among dating and married individuals. (Doctoral thesis), University of Iowa.

*Wicker, A. D. (2016). The relationship between workplace sexual identity management and workplace satisfaction among Lesbian, Gay, and Bisexual professionals. (Doctoral thesis), Massachusetts School of Professional Psychology.

*Wigert, L. R. (2002). An investigation of the relationships among personality traits, locus of control, religious orientation, and life satisfaction: A path analytical study. (Doctoral thesis), University of Nebraska.

Wiggins, J. S. (1968). Personality structure. Annual review of psychology, 19, 293-350.

*Williams, P. G., \& Wiebe, D. J. (2000). Individual differences in self-assessed health: Gender, neuroticism and physical symptom reports. Personality and Individual Differences, 28, 823-835.

*Williams, T. F., \& Simms, L. J. (2018). Personality traits and maladaptivity: Unipolarity versus bipolarity. Journal of Personality, 86, 888-901.

*Wilt, J. A., Grubbs, J. B., Exline, J. J., \& Pargament, K. I. (2016). Personality, religious and spiritual struggles, and well-being. Psychology of Religion and Spirituality, 8, 341-351.

*Wong, W. S., Lam, H. M., Chen, P. P., Chow, Y. F., Wong, S., Lim, H. S., . . Fielding, R. (2015). The fear-avoidance model of chronic pain: assessing the role of neuroticism and negative affect in pain catastrophizing using structural equation modeling. International Journal of Behavioral Medicine, 22, 118-131.

*Wood, D., Nye, C. D., \& Saucier, G. (2010). Identification and measurement of a more comprehensive set of person-descriptive trait markers from the English lexicon. Journal of Research in Personality, 44, 258-272.

*Woyciekoski, C., Natividade, J. C., \& Hutz, C. S. (2014). Contributions of personality and life events to the subjective well-being [As contribuições da personalidade e dos eventos de vida para o bem-estar subjetivo]. Psicologia: Teoria e Pesquisa, 30, 401-409.

*Wu, R., Liu, Z., Guo, Q., Cai, M., \& Zhou, J. (2019). Couple Similarity on Personality, Moral Identity and Spirituality Predict Life Satisfaction of Spouses and Their Offspring. Journal of Happiness Studies, https://doi.org/10.1007/s10902-10019-00108-10908.

*Xu, L., Liu, R. D., Ding, Y., Mou, X., Wang, J., \& Liu, Y. (2017). The Mediation Effect of Coping Style on the Relations between Personality and Life Satisfaction in Chinese Adolescents. Frontiers in Psychology, 8, 1076.

*Yeo, P. L. (2015). Religiosity, personality, and subjective wellbeing among Muslim adults in Indonesia. (Doctoral thesis), Regent University.

*Yilmaz, S., \& Kafadar, H. (2019). Investigating the relationship between decision-making processes and cognitive processes, personality traits, and affect via the structural equation model in young adults. Applied Neuropsychology: Adult, 1-12.

*Zeidner, M., \& Olnick-Shemesh, D. (2010). Emotional intelligence and subjective well-being revisited. Personality and Individual Differences, $48,431-435$.

*Zellars, K. L., Perrewe, P. L., Hochwarter, W. A., \& Anderson, K. S. (2006). The interactive effects of positive affect and conscientiousness on strain. Journal of Occupational Health Psychology, 11, 281-289.

*Zhai, Q., Willis, M., O'Shea, B., Zhai, Y., \& Yang, Y. (2013). Big Five personality traits, job satisfaction and subjective wellbeing in China. International Journal of Psychology. Journal International de Psychologie, 48, 1099-1108.

*Zhai, Q.-G., O'Shea, B., Mike, W., \& Yang, Y.-W. (2010). Subjective well-being, personality and environmental satisfaction in Urban China. 2010 International Conference on Management Science and Engineering, ICMSE 2010, 879-885. 
*Zhang, J., Mandl, H., \& Wang, E. (2010). Personality, acculturation, and psychosocial adjustment of Chinese international students in Germany. Psychological Reports, 107, 511-525.

*Zhang, J. W., \& Howell, R. T. (2011). Do time perspectives predict unique variance in life satisfaction beyond personality traits? Personality and Individual Differences, 50, 1261-1266.

*Zhang, R.-P., \& Tsingan, L. (2014). Extraversion and Neuroticism Mediate Associations Between Openness, Conscientiousness, and Agreeableness and Affective Well-Being. Journal of Happiness Studies, 15, 1377-1388.

*Zhu, X., Woo, S. E., Porter, C., \& Brzezinski, M. (2013). Pathways to happiness: From personality to social networks and perceived support. Social Networks, 35, 382-393.

Zimmermann, J., \& Neyer, F. J. (2013). Do we become a different person when hitting the road? Personality development of sojourners. Journal of Personality and Social Psychology, 105, 515. 
Table 1

Components and Sample Items for Personality, SWB, and PWB

\begin{tabular}{|c|c|}
\hline Construct & Components / Sample items \\
\hline \multicolumn{2}{|l|}{ Big Five } \\
\hline Neuroticism & $\begin{array}{l}\text { Facets: Anxiety, Hostility, Depression, Self-consciousness, Impulsiveness, } \\
\text { Vulnerability to Stress } \\
\text { Aspects: Withdrawal, Volatility }\end{array}$ \\
\hline Extraversion & $\begin{array}{l}\text { Facets: Warmth, Gregariousness, Assertiveness, Activity, Excitement Seeking, } \\
\text { Positive Emotion } \\
\text { Aspects: Enthusiasm, Assertiveness }\end{array}$ \\
\hline Openness & $\begin{array}{l}\text { Facets: Fantasy, Aesthetics, Feelings, Actions, Ideas, Values } \\
\text { Aspects: Openness/Creativity, Intellect }\end{array}$ \\
\hline Agreeableness & $\begin{array}{l}\text { Facets: Trust, Straightforwardness, Altruism, Compliance, Modesty, } \\
\text { Tendermindedness } \\
\text { Aspects: Politeness, Compassion }\end{array}$ \\
\hline Conscientiousness & $\begin{array}{l}\text { Facets: Competence, Order, Dutifulness, Achievement Striving, Self-Discipline, } \\
\text { Deliberation } \\
\text { Aspects: Orderliness, Industriousness }\end{array}$ \\
\hline \multicolumn{2}{|r|}{ P } \\
\hline Honesty-humility & Sincerity, Fairness, Geed Avoidance, Modesty \\
\hline Emotionality & Fearfulness, Anxiety, Dependence, Sentimentality \\
\hline Extraversion & Social Self-Esteem, Social Boldness, Sociability, Liveliness \\
\hline Agreeableness & Forgiveness, Gentleness, Flexibility, Patience \\
\hline Conscientiousness & Organization, Diligence, Perfectionism, Prudence \\
\hline Openness & Aesthetic Appreciation, Inquisitiveness, Creativity, Unconventionality \\
\hline Interstitial Traits & Altruism \\
\hline \multicolumn{2}{|l|}{ SWB } \\
\hline Satisfaction with life & e.g., "In most ways my life is close to my ideal", "I am satisfied with my life" \\
\hline Positive Affect & $\begin{array}{l}\text { Frequency of experiencing positive emotions in the last few weeks/months/etc.: e.g., } \\
\text { "interested", "excited", "strong", } \\
\text { "enthusiastic" }\end{array}$ \\
\hline Negative Affect & $\begin{array}{l}\text { Frequency of experiencing negative emotions in the last few weeks/months/etc.: e.g., } \\
\text { "depressed", "upset", "guilty", } \\
\text { "scared" }\end{array}$ \\
\hline \multicolumn{2}{|l|}{ PWB } \\
\hline Positive relations & $\begin{array}{l}\text { e.g., "Most people see me as loving and affectionate"; "I enjoy personal and mutual } \\
\text { conversations with family members or friends" }\end{array}$ \\
\hline Autonomy & $\begin{array}{l}\text { e.g., "Sometimes I change the way I act or think to be more like those around me"; } \\
\text { "My decisions are not usually influenced by what everyone else is doing" }\end{array}$ \\
\hline Environmental mastery & $\begin{array}{l}\text { e.g., "In general, I feel I am in charge of the situation in which I live"; "The demands } \\
\text { of everyday life often get me down" }\end{array}$ \\
\hline Personal growth & $\begin{array}{l}\text { e.g., "I am not interested in activities that will expand my horizons"; "In general, I feel } \\
\text { that I continue to learn more about myself as time goes by" }\end{array}$ \\
\hline Purpose in life & $\begin{array}{l}\text { e.g., "I feel good when I think of what I've done in the past and what I hope to do in } \\
\text { the future"; "I live life one day at a time and don't really think about the future" }\end{array}$ \\
\hline Self-acceptance & $\begin{array}{l}\text { e.g., "When I look at the story of my life, I am pleased with how things have turned } \\
\text { out"; "I feel like many of the people I know have gotten more out of life than I have" }\end{array}$ \\
\hline
\end{tabular}

Note. Sample items are from Satisfaction with Life Scale (Diener et al., 1985), PANAS (Watson et al., 1988), and Ryff's measure of PWB (Ryff \& Keyes, 1995). 
Table 2

Summary of Studies Included in Meta-Analysis

\begin{tabular}{|c|c|c|c|c|c|c|c|c|c|c|c|c|}
\hline Study & $\mathrm{N}$ & $\begin{array}{c}\text { Framewor } \\
\mathrm{k}\end{array}$ & $\begin{array}{c}\text { Ite } \\
\mathrm{m} \\
\mathrm{s}\end{array}$ & $\begin{array}{c}\mathrm{S} \\
\mathrm{W} \\
\mathrm{L}\end{array}$ & $\begin{array}{l}\mathrm{P} \\
\mathrm{A}\end{array}$ & $\begin{array}{l}\mathrm{N} \\
\mathrm{A}\end{array}$ & $\begin{array}{l}\mathrm{P} \\
\mathrm{W} \\
\mathrm{B}\end{array}$ & $\mathrm{F}$ & $\begin{array}{l}\text { A } \\
\text { ge }\end{array}$ & $\begin{array}{l}\text { Cou } \\
\text { ntry }\end{array}$ & $\begin{array}{l}\text { Co } \\
\text { re }\end{array}$ & $\begin{array}{l}\text { Sou } \\
\text { rce }\end{array}$ \\
\hline Aghababaei \& Arji (2014) Big 5 Study 3 & 215 & IPIP & 10 & $\mathrm{D}$ & & & $\mathrm{W}$ & 61 & 22 & IR & $\mathrm{C}$ & FA \\
\hline $\begin{array}{l}\text { Aghababaei \& Arji (2014) HEXACO } \\
\text { Study } 3\end{array}$ & 215 & HEXACO & 10 & $\mathrm{D}$ & & & W & 61 & 22 & IR & $\mathrm{C}$ & FA \\
\hline Aghababaei et al. (2016) Sample 1 & 422 & HEXACO & 10 & $\mathrm{D}$ & & & & 70 & 23 & IR & $\mathrm{C}$ & FA \\
\hline Aghababaei et al. (2016) Sample 2 & 221 & HEXACO & 10 & $\mathrm{D}$ & & & & 77 & 22 & PL & $\mathrm{C}$ & FA \\
\hline Aghababaei et al. (2016) Sample 3 & 255 & HEXACO & 10 & $\mathrm{D}$ & & & & 76 & 24 & MY & $\mathrm{C}$ & FA \\
\hline Aghababaei et al. (2016) Sample 4 & 251 & HEXACO & 10 & $\mathrm{D}$ & & & W & 68 & 22 & IR & $\mathrm{C}$ & FA \\
\hline Aghababaei et al. (2016) Sample 5 & 226 & HEXACO & 10 & $\mathrm{D}$ & & & $\mathrm{W}$ & 91 & 20 & PL & $\mathrm{C}$ & FA \\
\hline Ahadi \& Puente-Diaz (2011) Study 1 & 107 & $\mathrm{NEO}$ & 36 & $\mathrm{D}$ & $\mathrm{P}$ & $\mathrm{P}$ & & 50 & 20 & US & $\mathrm{C}$ & FA \\
\hline Ahadi \& Puente-Diaz (2011) Study 2 & 88 & NEO & 36 & $\mathrm{D}$ & $\mathrm{P}$ & $\mathrm{P}$ & & 62 & 21 & US & $\mathrm{C}$ & FA \\
\hline Albrecht et al. (2014) & 913 & $\mathrm{NEO}$ & 48 & $\mathrm{D}$ & & & & 32 & 37 & & $\mathrm{C}$ & FA \\
\hline Albuquerque et al. (2012) & 398 & $\mathrm{NEO}$ & 48 & $\mathrm{D}$ & $\mathrm{P}$ & $\mathrm{P}$ & & 72 & 41 & PT & $\mathrm{C}$ & FA \\
\hline Alfonsi et al. (2011) & 341 & $\mathrm{NEO}$ & 12 & & & $\mathrm{P}$ & & 53 & 59 & $\mathrm{CA}$ & $\mathrm{C}$ & FA \\
\hline Anand et al. (2015) & 756 & NEO & 12 & $\mathrm{D}$ & & & & 58 & 39 & US & $\mathrm{C}$ & FA \\
\hline Anglim \& Grant (2016) & 337 & NEO & 60 & $\mathrm{D}$ & $\mathrm{P}$ & $\mathrm{P}$ & $\mathrm{W}$ & 76 & 21 & $\mathrm{AU}$ & $\mathrm{C}$ & FA \\
\hline Anglim \& Horwood (2019) Big 5 & 465 & $\mathrm{NEO}$ & 60 & $\mathrm{D}$ & $\mathrm{P}$ & $\mathrm{P}$ & $\mathrm{W}$ & 79 & 25 & $\mathrm{AU}$ & $\mathrm{C}$ & FA \\
\hline Anglim \& Horwood (2019) HEXACO & 465 & HEXACO & 32 & $\mathrm{D}$ & $\mathrm{P}$ & $\mathrm{P}$ & $\mathrm{W}$ & 79 & 25 & $\mathrm{AU}$ & $\mathrm{C}$ & FA \\
\hline Anwar (2017) & 274 & BFI & 9 & & $\mathrm{P}$ & $\mathrm{P}$ & & 22 & 47 & PK & $\mathrm{C}$ & FA \\
\hline Austin et al. (2010) & 475 & Adjectives & 8 & $\mathrm{D}$ & $\mathrm{P}$ & $\mathrm{P}$ & & 70 & 21 & $\mathrm{CA}$ & $\mathrm{C}$ & FA \\
\hline Aykac et al. (2011) & 131 & HEXACO & 32 & $\mathrm{D}$ & & & & 51 & 32 & GB & $\mathrm{C}$ & FA \\
\hline Baltes et al. (2010) & 289 & IPIP & 10 & & & $\mathrm{P}$ & & 61 & 38 & US & $\mathrm{C}$ & FA \\
\hline Barr (2018) & 142 & BFI & 9 & & $\mathrm{P}$ & $\mathrm{P}$ & & 98 & & AU & $\mathrm{C}$ & FA \\
\hline Baselmans et al. (2019) & 8622 & $\mathrm{NEO}$ & 12 & $\mathrm{D}$ & & & & 36 & 42 & NL & $\mathrm{C}$ & FA \\
\hline Baudin et al. (2011) & 313 & NEO & 48 & $\mathrm{D}$ & & & & 26 & 23 & FR & $\mathrm{C}$ & FA \\
\hline Bauer \& McAdams (2010) & 145 & BFI & 9 & $\mathrm{D}$ & $\mathrm{P}$ & $\mathrm{P}$ & & 74 & 20 & US & $\mathrm{C}$ & $\mathrm{CA}$ \\
\hline Beer et al. (2013) & 395 & BFI & 9 & & $\mathrm{P}$ & $\mathrm{P}$ & & 50 & 32 & US & $\mathrm{C}$ & $\mathrm{DA}$ \\
\hline Belsky et al. (1995) Fathers & 69 & NEO & 36 & & $\mathrm{P}$ & $\mathrm{P}$ & & 0 & 31 & US & $\mathrm{C}$ & FA \\
\hline Belsky et al. (1995) Mothers & 69 & $\mathrm{NEO}$ & 36 & & $\mathrm{P}$ & $\mathrm{P}$ & & 100 & 28 & US & $\mathrm{C}$ & FA \\
\hline $\begin{array}{l}\text { Benet-Martínez \& Karakitapoğlu-Aygün } \\
\text { (2003) Asian }\end{array}$ & 199 & BFI & 9 & $\mathrm{D}$ & & & & 59 & 20 & US & $\mathrm{C}$ & FA \\
\hline $\begin{array}{l}\text { Benet-Martínez \& Karakitapoğlu-Aygün } \\
\text { (2003) European }\end{array}$ & 122 & BFI & 9 & $\mathrm{D}$ & & & & 59 & 20 & US & $\mathrm{C}$ & FA \\
\hline Benotsch et al. (2000) & 198 & BFI & 9 & & $\mathrm{P}$ & $\mathrm{P}$ & & 52 & 54 & US & $\mathrm{C}$ & $\mathrm{CA}$ \\
\hline Bianchi et al. (2018) Men & 222 & NEO & 12 & $\mathrm{D}$ & & & & 0 & 43 & FR & $\mathrm{C}$ & FA \\
\hline Bianchi et al. (2018) Women & 941 & NEO & 12 & $\mathrm{D}$ & & & & 100 & 43 & FR & $\mathrm{C}$ & FA \\
\hline Biderman et al. (2018) Big 5 & 1195 & $\mathrm{NEO}$ & 12 & & $\mathrm{P}$ & $\mathrm{P}$ & & 76 & 20 & US & $\mathrm{C}$ & FA \\
\hline Biderman et al. (2018) HEXACO & 1195 & HEXACO & 16 & & $\mathrm{P}$ & $\mathrm{P}$ & & 76 & 20 & US & $\mathrm{C}$ & FA \\
\hline Blatný et al. (2015) & 138 & $\mathrm{NEO}$ & 12 & $\mathrm{D}$ & & & & 61 & 40 & $\mathrm{CZ}$ & $\mathrm{C}$ & FA \\
\hline Bogin (2018) & 283 & Adjectives & 8 & $\mathrm{D}$ & & & & 67 & 18 & US & $\mathrm{C}$ & FA \\
\hline Boland \& Cappeliez (1997) & 113 & NEO & 36 & $\mathrm{D}$ & & & & 100 & 73 & $\mathrm{CA}$ & $\mathrm{C}$ & FA \\
\hline Bono (2011) & 228 & $\mathrm{NEO}$ & 12 & $\mathrm{D}$ & & & & & & US & $\mathrm{C}$ & FA \\
\hline Boudreau et al. (2001) Americans & 1885 & NEO & 12 & $\mathrm{D}$ & & & & 10 & 47 & US & $\mathrm{C}$ & FA \\
\hline Boudreau et al. (2001) Europeans & 1871 & NEO & 12 & $\mathrm{D}$ & & & & 6 & 42 & & $\mathrm{C}$ & FA \\
\hline Brajša-Žganec et al. (2011) & 392 & IPIP & 10 & $\mathrm{D}$ & $\mathrm{P}$ & $\mathrm{P}$ & & 50 & 20 & HR & $\mathrm{C}$ & FA \\
\hline Bratko \& Sabol (2006) & 1166 & IPIP & 10 & $\mathrm{D}$ & & & & 66 & 26 & HR & $\mathrm{C}$ & FA \\
\hline Brenner et al. (2011) Community & 29 & $\mathrm{NEO}$ & 12 & $\mathrm{D}$ & & & & 29 & 28 & $\mathrm{CA}$ & $\mathrm{C}$ & FA \\
\hline Brenner et al. (2011) Schizophrenia & 30 & NEO & 12 & $\mathrm{D}$ & & & & 30 & 20 & $\mathrm{CA}$ & $\mathrm{C}$ & FA \\
\hline Burles et al. (2014) & 179 & NEO & 60 & & $\mathrm{P}$ & $\mathrm{P}$ & & 75 & 20 & $\mathrm{CA}$ & $\mathrm{C}$ & $\mathrm{CA}$ \\
\hline Burton et al. (2015) Study 1 & 619 & BFAS & 20 & $\mathrm{D}$ & & & & 55 & 32 & US & $\mathrm{C}$ & FA \\
\hline Burton et al. (2015) Study 2 & 700 & BFAS & 20 & $\mathrm{D}$ & & & & 52 & 33 & US & $\mathrm{C}$ & FA \\
\hline Bye \& Pushkar (2009) & 385 & NEO & 12 & & $\mathrm{P}$ & $\mathrm{P}$ & & 52 & 60 & $\mathrm{CA}$ & $\mathrm{C}$ & FA \\
\hline Cabrera-Darias \& Marrero-Quevedo & 108 & $\mathrm{NEO}$ & 48 & $\mathrm{D}$ & $\mathrm{P}$ & $\mathrm{P}$ & & 71 & 36 & ES & $\mathrm{C}$ & FA \\
\hline
\end{tabular}




\begin{tabular}{|c|c|c|c|c|c|c|c|c|c|c|c|c|}
\hline $\begin{array}{l}\text { Cabrera-Darias \& Marrero-Quevedo } \\
\text { (2015) Paper }\end{array}$ & 45 & NEO & 48 & $\mathrm{D}$ & $\mathrm{P}$ & $\mathrm{P}$ & & 71 & 36 & ES & $\mathrm{C}$ & FA \\
\hline Caprara et al. (2002) Females & 300 & Other & 12 & $\mathrm{D}$ & & & & 100 & 17 & IT & $\mathrm{C}$ & FA \\
\hline Caprara et al. (2002) Males & 292 & Other & 12 & $\mathrm{D}$ & & & & 0 & 17 & IT & $\mathrm{C}$ & FA \\
\hline Caprara et al. (2012) Study 3 & 3589 & Other & 12 & $\mathrm{D}$ & & & & 58 & 39 & IT & $\mathrm{C}$ & FA \\
\hline Caprara et al. (2012) Study 5 Italy & 689 & Other & 12 & $\mathrm{D}$ & & & & 56 & 19 & IT & $\mathrm{C}$ & FA \\
\hline Caprara et al. (2012) Study 5 Japan & 281 & Other & 12 & $\mathrm{D}$ & & & & 60 & 20 & JP & $\mathrm{C}$ & FA \\
\hline Caprara et al. (2012) Study 5 Spain & 302 & Other & 12 & $\mathrm{D}$ & & & & 64 & 28 & ES & $\mathrm{C}$ & FA \\
\hline Carmona-Halty \& Rojas-Paz (2014) & 235 & Other & 19 & $\mathrm{D}$ & & & & 34 & 21 & $\mathrm{CL}$ & $\mathrm{C}$ & FA \\
\hline Carrillo et al. (2012) & 356 & BFI & 9 & $\mathrm{D}$ & & & & 24 & 24 & ES & $\mathrm{C}$ & FA \\
\hline Castro Solano \& Cosentino (2018) & 302 & BFI & 9 & $\mathrm{D}$ & & & & 52 & 39 & AR & $\mathrm{C}$ & $\mathrm{CA}$ \\
\hline Cellini et al. (2017) & 498 & BFI & 9 & & $\mathrm{P}$ & $\mathrm{P}$ & & 71 & 27 & IT & $\mathrm{C}$ & FA \\
\hline Chambers (2004) & 238 & NEO & 12 & $\mathrm{D}$ & $\mathrm{P}$ & $\mathrm{P}$ & & 0 & 30 & & $\mathrm{C}$ & FA \\
\hline Chan et al. (2018) & 349 & BFI & 9 & $\mathrm{D}$ & $\mathrm{P}$ & $\mathrm{P}$ & & 55 & 62 & & $\mathrm{C}$ & $\mathrm{CA}$ \\
\hline Chen \& Carey (2009) & 113 & NEO & 12 & $\mathrm{D}$ & & & & 54 & 20 & HK & $\mathrm{C}$ & FA \\
\hline Chen (2011) & 107 & NEO & 48 & $\mathrm{D}$ & & & & 63 & 35 & US & $\mathrm{C}$ & FA \\
\hline Chen et al. (2012) & 383 & $\mathrm{NEO}$ & 48 & $\mathrm{D}$ & $\mathrm{P}$ & $\mathrm{P}$ & & 58 & 19 & US & $\mathrm{C}$ & FA \\
\hline Chen (2015) & 371 & $\mathrm{NEO}$ & 12 & $\mathrm{D}$ & $\mathrm{P}$ & $\mathrm{P}$ & & 75 & 21 & $\mathrm{CN}$ & $\mathrm{C}$ & FA \\
\hline Choi \& Lee (2014) & 373 & IPIP & 10 & $\mathrm{D}$ & & & & 23 & 33 & KR & $\mathrm{C}$ & FA \\
\hline Clark et al. (2010) & 322 & IPIP & 10 & & $\mathrm{P}$ & $\mathrm{P}$ & & 73 & 24 & US & $\mathrm{C}$ & FA \\
\hline Clifton et al. (2019) Study 2 & 562 & BFI & 9 & $\mathrm{D}$ & $\mathrm{O}$ & $\mathrm{O}$ & & 51 & 37 & US & $\mathrm{C}$ & $\mathrm{CA}$ \\
\hline Compton et al. (1996) & 338 & NEO & 36 & $\mathrm{D}$ & & & & 39 & 26 & US & $\mathrm{C}$ & FA \\
\hline Costa \& MacCrae (1992) & 364 & $\mathrm{NEO}$ & 48 & & $\mathrm{O}$ & $\mathrm{O}$ & & & & & $\mathrm{C}$ & FA \\
\hline Cotter \& Fouad (2011) & 172 & NEO & 12 & $\mathrm{D}$ & & & & 67 & 21 & US & $\mathrm{C}$ & FA \\
\hline Courneya et al. (2000) & 56 & NEO & 12 & $\mathrm{D}$ & $\mathrm{O}$ & $\mathrm{O}$ & & 41 & 60 & $\mathrm{CA}$ & $\mathrm{C}$ & FA \\
\hline Cowan (2019) & 159 & NEO & 12 & $\mathrm{D}$ & & & & 64 & 56 & US & $\mathrm{C}$ & FA \\
\hline Crouch (2016) & 562 & NEO & 12 & $\mathrm{D}$ & & & & 41 & 21 & US & $\mathrm{C}$ & FA \\
\hline Crowe et al. (2016) & 914 & IPIP & 12 & $\mathrm{D}$ & $\mathrm{P}$ & $\mathrm{P}$ & & 62 & 34 & US & $\mathrm{C}$ & $\mathrm{CA}$ \\
\hline de Frias et al. (2003) & 528 & NEO & 36 & & $\mathrm{O}$ & $\mathrm{O}$ & & 67 & 68 & $\mathrm{CA}$ & $\mathrm{C}$ & FA \\
\hline De Gucht et al. (2004) & 377 & NEO & 12 & & $\mathrm{P}$ & $\mathrm{P}$ & & 73 & 44 & & $\mathrm{C}$ & FA \\
\hline Delfabbro et al. (2011) & 2266 & NEO & 12 & $\mathrm{O}$ & & & & 60 & 15 & $\mathrm{AU}$ & $\mathrm{C}$ & $\mathrm{CA}$ \\
\hline Di Fabio \& Saklofske (2014) & 164 & Other & 12 & $\mathrm{D}$ & & & & 56 & 18 & IT & $\mathrm{C}$ & FA \\
\hline Di Fabio \& Palazzeschi (2015) & 168 & Other & 12 & $\mathrm{D}$ & $\mathrm{P}$ & & & 63 & 20 & IT & $\mathrm{C}$ & FA \\
\hline Di Fabio et al. (2017) & 258 & Other & 12 & $\mathrm{D}$ & & & & 41 & 46 & IT & $\mathrm{C}$ & FA \\
\hline Di Fabio \& Kenny (2018) & 241 & Other & 12 & $\mathrm{D}$ & $\mathrm{P}$ & $\mathrm{P}$ & & 63 & 24 & IT & $\mathrm{C}$ & FA \\
\hline Di Nuovo (2009) & 1080 & Other & 12 & $\mathrm{D}$ & & & & 50 & & IT & $\mathrm{C}$ & FA \\
\hline Dimotakis et al. (2012) & 112 & NEO & 48 & & $\mathrm{P}$ & & & 39 & 21 & US & $\mathrm{C}$ & FA \\
\hline Donofrio (2005) & 138 & NEO & 48 & $\mathrm{D}$ & & & & 75 & 33 & US & $\mathrm{C}$ & FA \\
\hline Drezno et al. (2019) & 379 & IPIP & 10 & $\mathrm{D}$ & & & & 34 & 36 & PL & $\mathrm{C}$ & FA \\
\hline Drobnjaković et al. (2017) Study 1 & 400 & HEXACO & 16 & & $\mathrm{P}$ & $\mathrm{P}$ & & 74 & & $\mathrm{RS}$ & $\mathrm{C}$ & DA \\
\hline Drobnjaković (2019) & 377 & HEXACO & 10 & & $\mathrm{P}$ & $\mathrm{P}$ & & 49 & 33 & $\mathrm{RS}$ & $\mathrm{C}$ & $\mathrm{DA}$ \\
\hline Dumitrache et al. (2015) & 400 & NEO & 12 & $\mathrm{D}$ & & & $\mathrm{W}$ & 62 & 75 & ES & $\mathrm{C}$ & $\mathrm{CA}$ \\
\hline Egan et al. (2014) & 860 & IPIP & 10 & $\mathrm{D}$ & & & & 69 & 30 & I & $\mathrm{C}$ & $\mathrm{CA}$ \\
\hline Etxeberria et al. (2019) 65 to 84 & 155 & NEO & 12 & $\mathrm{D}$ & $\mathrm{P}$ & $\mathrm{P}$ & & 58 & 74 & ES & $\mathrm{C}$ & FA \\
\hline Etxeberria et al. (2019) 85 to 104 & 102 & NEO & 12 & $\mathrm{D}$ & $\mathrm{P}$ & $\mathrm{P}$ & & 61 & 94 & ES & $\mathrm{C}$ & FA \\
\hline Fagley (2012) & 243 & BFI & 9 & $\mathrm{D}$ & & & & 63 & 23 & US & $\mathrm{C}$ & $\mathrm{CA}$ \\
\hline Fagley (2018) & 236 & BFI & 9 & & $\mathrm{P}$ & $\mathrm{P}$ & & 64 & 19 & US & $\mathrm{C}$ & FA \\
\hline FitzMedrud (2009) & 119 & NEO & 12 & $\mathrm{D}$ & $\mathrm{P}$ & $\mathrm{P}$ & & 82 & 35 & US & $\mathrm{C}$ & FA \\
\hline Fortunato (2002) & 206 & Adjectives & 8 & $\mathrm{D}$ & & & & 34 & 50 & US & $\mathrm{C}$ & FA \\
\hline Fossum \& Barrett (2000) Sample 1 & 205 & NEO & 48 & & $\mathrm{P}$ & $\mathrm{P}$ & & 71 & & US & $\mathrm{C}$ & FA \\
\hline Fossum \& Barrett (2000) Sample 2 & 241 & NEO & 48 & & $\mathrm{P}$ & $\mathrm{P}$ & & 65 & & US & $\mathrm{C}$ & FA \\
\hline Fowler et al. (2018) & 448 & BFI & 9 & $\mathrm{D}$ & & & & 75 & 29 & $\mathrm{CA}$ & $\mathrm{C}$ & FA \\
\hline Fox \& Moore (2019) & 142 & NEO & 12 & & $\mathrm{P}$ & $\mathrm{P}$ & & 70 & 21 & I & $\mathrm{C}$ & $\mathrm{CA}$ \\
\hline Froehlich (2005) & 350 & NEO & 12 & $\mathrm{D}$ & & & & 0 & & US & $\mathrm{C}$ & FA \\
\hline Furr \& Funder (1998) & 146 & NEO & 36 & $\mathrm{D}$ & & & & 56 & & US & $\mathrm{C}$ & FA \\
\hline Galea (2014) & 121 & BFI & 9 & $\mathrm{D}$ & & & & 65 & & MT & $\mathrm{C}$ & FA \\
\hline Ganginis Del Pino (2012) & 305 & BFI & 9 & $\mathrm{D}$ & & & & 100 & 38 & US & $\mathrm{C}$ & FA \\
\hline Gannon \& Ranzijn (2005) & 191 & NEO & 12 & $\mathrm{D}$ & & & & 67 & 36 & $\mathrm{AU}$ & $\mathrm{C}$ & FA \\
\hline Garcia \& Erlandsson (2011) & 151 & NEO & 48 & $\mathrm{D}$ & & & & 67 & 23 & $\mathrm{SE}$ & $\mathrm{C}$ & FA \\
\hline Garcia (2011) & 98 & NEO & 48 & $\mathrm{D}$ & $\mathrm{P}$ & $\mathrm{P}$ & & 68 & 17 & $\mathrm{SE}$ & $\mathrm{C}$ & FA \\
\hline Goldberg et al. (2017) & 156 & BFI & 9 & & $\mathrm{P}$ & $\mathrm{P}$ & $\mathrm{W}$ & 62 & 19 & US & $\mathrm{C}$ & DA \\
\hline Golden (2002) & 321 & Adjectives & 16 & $\mathrm{D}$ & & & & 19 & 51 & US & $\mathrm{C}$ & FA \\
\hline
\end{tabular}


Gore et al. (2014) Study 2

Grady (1996)

Graham (2012) Entrepreneurs

Graham (2012) Students

Grant et al. (2009)

Guilera et al. (2018)

Gutiérrez et al. (2005)

Habarth (2009)

Halama \& Dědová (2007)

Halama (2010)

Harris (2002)

Hart (1999) Wave 1

Hayes \& Joseph (2003)

Hébert \& Weaver (2014)

Heller et al. (2002)

Heller (2004)

Hemenover (2001)

Hengartner et al. (2017)

Henriett (2018)

Herringer (1998)

Hill \& Allemand (2011)

Hirsh et al. (2010)

Hofer et al. (2008)

Hogan (2006)

Holder et al. (2015)

Hossack (1997)

Howell (2006)

Hudson \& Roberts (2014)

Hutz et al. (2014) American

Hutz et al. (2014) Brazilian

Ioannidis \& Siegling (2015)

Isaacowitz \& Smith (2003)

Iş1k \& Üzbe (2015)

Jacques-Hamilton et al. (2019)

Jaksic et al. (2015)

James et al. (2012)

Jensen et al. (2019)

Jibeen (2014)

Johnson (2003)

Jokela et al. (2015)

Jones et al. (2015)

Joshanloo \& Afshari (2011)

Jovanovic (2011)

Jovanović (2014)

Jovanović (2019)

Kahlbaugh \& Huffman (2017)

Kahn \& Hessling (2001)

Kampfe \& Parriaux (2010) Sample 1

Kampfe \& Parriaux (2010) Sample 3

Kaynak (2018) Older

Kaynak (2018) Younger

Kirkland et al. (2015) Sample 1 Students

Kirkland et al. (2015) Sample 2 MTurk

Kirkland et al. (2015) Sample 3 MTurk

Kjell et al. (2013) Iranian

Kjell et al. (2013) Swedish

Kluemper (2008)

Kokinda (2011)

Kong et al. (2015)

Kong et al. (2019)

Kovacs (2007)

Koydemir \& Schütz (2012) German

\begin{tabular}{|c|c|c|c|c|c|c|c|c|c|c|c|}
\hline 260 & IPIP & 10 & $\mathrm{D}$ & & & & 71 & & US & $\mathrm{C}$ & FA \\
\hline 140 & NEO & 48 & & $\mathrm{P}$ & $\mathrm{P}$ & & 100 & 39 & $\mathrm{CA}$ & $\mathrm{C}$ & FA \\
\hline 88 & NEO & 12 & $\mathrm{D}$ & & & & 25 & & US & $\mathrm{C}$ & FA \\
\hline 102 & NEO & 12 & $\mathrm{D}$ & & & & 54 & 17 & US & $\mathrm{C}$ & FA \\
\hline 211 & NEO & 12 & $\mathrm{D}$ & $\mathrm{P}$ & $\mathrm{P}$ & W & 58 & 36 & $\mathrm{AU}$ & $\mathrm{C}$ & FA \\
\hline 364 & BFI & 9 & $\mathrm{D}$ & & & & 60 & 38 & ES & $\mathrm{C}$ & $\mathrm{AD}$ \\
\hline 236 & NEO & 12 & & $\mathrm{O}$ & $\mathrm{O}$ & & 86 & 35 & ES & $\mathrm{C}$ & FA \\
\hline 576 & Adjectives & 8 & $\mathrm{D}$ & & & & 55 & 45 & US & $\mathrm{C}$ & FA \\
\hline 148 & NEO & 12 & $\mathrm{D}$ & & & & 51 & 17 & SK & $\mathrm{C}$ & FA \\
\hline 451 & NEO & 12 & $\mathrm{D}$ & & & & 52 & 20 & SK & $\mathrm{C}$ & FA \\
\hline 147 & BFI & 9 & $\mathrm{D}$ & $\mathrm{P}$ & $\mathrm{P}$ & & 74 & 22 & US & $\mathrm{C}$ & FA \\
\hline 282 & NEO & 48 & D & & & & 10 & 34 & $\mathrm{AU}$ & $\mathrm{C}$ & FA \\
\hline 129 & $\mathrm{NEO}$ & 12 & $\mathrm{D}$ & & & & 58 & 38 & GB & $\mathrm{C}$ & FA \\
\hline 270 & HEXACO & 10 & $\mathrm{D}$ & & & & 62 & 25 & I & $\mathrm{C}$ & FA \\
\hline 159 & NEO & 12 & $\mathrm{D}$ & $\mathrm{P}$ & $\mathrm{P}$ & & & & US & $\mathrm{C}$ & FA \\
\hline 76 & BFI & 9 & $\mathrm{D}$ & $\mathrm{P}$ & $\mathrm{P}$ & & 80 & & US & $\mathrm{C}$ & FA \\
\hline 236 & NEO & 48 & & $\mathrm{P}$ & $\mathrm{P}$ & & 71 & 20 & US & $\mathrm{C}$ & FA \\
\hline 831 & IPIP & 48 & & $\mathrm{O}$ & $\mathrm{O}$ & & 66 & 34 & $\mathrm{CH}$ & $\mathrm{C}$ & FA \\
\hline 421 & BFI & 9 & $\mathrm{D}$ & & & & 61 & 24 & $\mathrm{HU}$ & $\mathrm{C}$ & FA \\
\hline 162 & NEO & 48 & $\mathrm{D}$ & & & & 65 & 22 & US & $\mathrm{C}$ & FA \\
\hline 962 & BFI & 9 & $\mathrm{D}$ & $\mathrm{O}$ & $\mathrm{O}$ & & 57 & 52 & $\mathrm{CH}$ & $\mathrm{C}$ & FA \\
\hline 137 & BFI & 9 & & $\mathrm{P}$ & $\mathrm{P}$ & & 72 & 20 & $\mathrm{CA}$ & $\mathrm{C}$ & $\mathrm{CA}$ \\
\hline 131 & NEO & 12 & $\mathrm{D}$ & & & W & 55 & 25 & $\mathrm{DE}$ & $\mathrm{C}$ & FA \\
\hline 318 & IPIP & 10 & & $\mathrm{P}$ & $\mathrm{P}$ & & 85 & 60 & US & $\mathrm{C}$ & FA \\
\hline 437 & NEO & 12 & $\mathrm{D}$ & $\mathrm{P}$ & $\mathrm{P}$ & & 69 & 20 & $\mathrm{CA}$ & $\mathrm{C}$ & $\mathrm{CA}$ \\
\hline 520 & NEO & 12 & $\mathrm{D}$ & & & & 50 & & $\mathrm{CA}$ & $\mathrm{C}$ & FA \\
\hline 314 & BFI & 9 & $\mathrm{D}$ & & & & 62 & 19 & US & $\mathrm{C}$ & FA \\
\hline 264 & BFI & 9 & $\mathrm{D}$ & & & & 53 & 19 & US & $\mathrm{C}$ & FA \\
\hline 179 & NEO & 48 & $\mathrm{D}$ & $\mathrm{P}$ & $\mathrm{P}$ & & 63 & 25 & US & $\mathrm{C}$ & FA \\
\hline 168 & Other & 25 & $\mathrm{D}$ & $\mathrm{P}$ & $\mathrm{P}$ & & 60 & 22 & $\mathrm{BR}$ & $\mathrm{C}$ & FA \\
\hline 203 & BFI & 9 & & $\mathrm{P}$ & $\mathrm{P}$ & & 71 & 23 & GB & $\mathrm{C}$ & FA \\
\hline 516 & NEO & 36 & & $\mathrm{P}$ & $\mathrm{P}$ & & & 85 & $\mathrm{DE}$ & $\mathrm{C}$ & FA \\
\hline 335 & Adjectives & 8 & & $\mathrm{P}$ & $\mathrm{P}$ & & 57 & 46 & TR & $\mathrm{C}$ & FA \\
\hline 223 & BFAS & 20 & $\mathrm{D}$ & $\mathrm{P}$ & $\mathrm{P}$ & & 68 & 23 & $\mathrm{AU}$ & $\mathrm{C}$ & $\mathrm{AD}$ \\
\hline 319 & IPIP & 10 & $\mathrm{D}$ & & & & 58 & 44 & HR & $\mathrm{C}$ & $\mathrm{CA}$ \\
\hline 150 & IPIP & 20 & $\mathrm{D}$ & & & & 53 & 21 & $\mathrm{AU}$ & $\mathrm{C}$ & FA \\
\hline 259 & NEO & 12 & $\mathrm{D}$ & & & & & 44 & DK & $\mathrm{C}$ & FA \\
\hline 251 & NEO & 12 & D & & & & 39 & 30 & PK & $\mathrm{C}$ & FA \\
\hline 140 & NEO & 48 & & $\mathrm{P}$ & $\mathrm{P}$ & & & & US & $\mathrm{C}$ & FA \\
\hline 6019 & BFI & 9 & $\mathrm{D}$ & & & & 63 & 33 & GB & $\mathrm{C}$ & FA \\
\hline 207 & Other & 12 & & & & W & 59 & & $\mathrm{ZA}$ & $\mathrm{C}$ & FA \\
\hline 235 & BFI & 9 & D & & & & 74 & 21 & IR & $\mathrm{C}$ & FA \\
\hline 225 & Other & 10 & D & & & & 56 & 24 & $\mathrm{RS}$ & $\mathrm{C}$ & FA \\
\hline 380 & Other & 10 & $\mathrm{D}$ & $\mathrm{P}$ & $\mathrm{P}$ & & 59 & 22 & $\mathrm{RS}$ & $\mathrm{C}$ & $\mathrm{CA}$ \\
\hline 500 & BFI & 9 & D & & & & 68 & 17 & $\mathrm{RS}$ & $\mathrm{C}$ & FA \\
\hline 49 & BFI & 9 & & $\mathrm{P}$ & $\mathrm{P}$ & & 65 & 74 & US & $\mathrm{C}$ & FA \\
\hline 278 & NEO & 12 & & $\mathrm{P}$ & $\mathrm{P}$ & & 52 & 20 & US & $\mathrm{C}$ & FA \\
\hline 467 & NEO & 12 & $\mathrm{D}$ & & & & 56 & 26 & $\mathrm{DE}$ & $\mathrm{C}$ & FA \\
\hline 679 & NEO & 12 & $\mathrm{D}$ & $\mathrm{P}$ & $\mathrm{P}$ & & 69 & 28 & $\mathrm{DE}$ & $\mathrm{C}$ & FA \\
\hline 61 & Other & 15 & & $\mathrm{P}$ & $\mathrm{P}$ & & 48 & 78 & TR & $\mathrm{C}$ & FA \\
\hline 64 & Other & 15 & & $\mathrm{P}$ & $\mathrm{P}$ & & 52 & 21 & TR & $\mathrm{C}$ & FA \\
\hline 352 & BFAS & 20 & & $\mathrm{P}$ & $\mathrm{P}$ & & 61 & 19 & US & $\mathrm{C}$ & FA \\
\hline 459 & BFAS & 20 & & $\mathrm{P}$ & $\mathrm{P}$ & & 62 & 33 & US & $\mathrm{C}$ & FA \\
\hline 178 & BFAS & 20 & & $\mathrm{P}$ & $\mathrm{P}$ & & 58 & 34 & US & $\mathrm{C}$ & FA \\
\hline 122 & BFI & 9 & D & $\mathrm{P}$ & $\mathrm{P}$ & W & 59 & 15 & IR & $\mathrm{C}$ & FA \\
\hline 109 & BFI & 9 & D & $\mathrm{P}$ & $\mathrm{P}$ & W & 65 & 17 & SE & $\mathrm{C}$ & FA \\
\hline 180 & NEO & 12 & D & & & & 42 & 27 & US & $\mathrm{C}$ & FA \\
\hline 108 & Adjectives & 8 & $\mathrm{D}$ & & & & 73 & 38 & US & $\mathrm{C}$ & FA \\
\hline 274 & NEO & 24 & $\mathrm{D}$ & & & & 54 & & $\mathrm{CN}$ & $\mathrm{C}$ & $\mathrm{CA}$ \\
\hline 136 & NEO & 12 & $\mathrm{D}$ & & & & 40 & & $\mathrm{CN}$ & $\mathrm{C}$ & $\mathrm{CA}$ \\
\hline 450 & $\mathrm{NEO}$ & 12 & $\mathrm{D}$ & & & & 57 & 22 & US & $\mathrm{C}$ & FA \\
\hline 101 & BFI & 9 & $\mathrm{D}$ & $\mathrm{P}$ & $\mathrm{P}$ & & 68 & 24 & $\mathrm{DE}$ & $\mathrm{C}$ & FA \\
\hline
\end{tabular}


Koydemir \& Schütz (2012) Turkey

Krick \& Felfe (2019)

Kwan et al. (1997) American

Kwan et al. (1997) Hong Kong

Lang et al. (2001)

Langvik et al. (2016)

Lee et al. (2013)

Letrzing (2019)

Letzring (2015)

Lightsey et al. (2013)

Lodewyk (2018)

Lönnqvist \& große Deters (2016) Study 1

Lönnqvist \& große Deters (2016) Study 2

Lopez et al. (2015)

Lounsbury et al. (1999)

Lucas \& Fujita (2000) Study 2

Lucas \& Fujita (2000) Study 3

Lucas \& Fujita (2000) Study 5

MacCann et al. (2012)

MacInnis et al. (2013)

Mangino (2018)

Marcionetti \& Rossier (2016)

Margolis et al. (2018) Study 1

Margolis et al. (2018) Study 2

Margolis \& Lyubomirsky (2019)

Marrero Quevedo \& Carballeira Abella (2011)

Marrero (2019)

Marshall et al. (1992) Sample 1

Marshall et al. (1992) Sample 2

Martin et al. (2013)

McCrae \& Costa (1991)

McCullough et al. (2002) Study 2

McKay (2017) Big 5

McKay (2017) HEXACO

Meléndez et al. (2019)

Mellor et al. (2003)

Michel \& Clark (2013)

Miciuk, Jankowski, \& Oleś (2016)

Miciuk, Jankowski, Laskowska, et al. (2016)

Mongrain et al. (2018)

Morris et al. (2015)

Morrison (1997)

Murray (2002)

Musek (2007)

Navarro-Prados et al. (2018)

Neff et al. (2007)

$\mathrm{Ng}$ et al. (2019)

Novak et al. (2017)

Novakov \& Popovic-Petrovic (2017)

Novoa \& Barra (2015)

O'Rourke (2004)

O'Rourke (2005)

Odacı \& Cikrikci (2018)

Oken et al. (2017)

Olesen et al. (2015)

Osma et al. (2018)

Panaccio \& Vandenberghe (2012)

Parker et al. (2008)

Paulson \& Leuty (2015)

Pavani et al. (2017)

$\begin{array}{rccllll}86 & \text { BFI } & 9 & \mathrm{D} & \mathrm{P} & \mathrm{P} & \\ 259 & \text { NEO } & 12 & & \mathrm{P} & \mathrm{P} & \\ 184 & \text { NEO } & 12 & \mathrm{O} & & & \\ 194 & \text { NEO } & 12 & \mathrm{O} & & & \\ 480 & \text { BFI } & 9 & & \mathrm{P} & \mathrm{P} & \\ 372 & \text { NEO } & 12 & & \mathrm{P} & \mathrm{P} & \\ 1584 & \text { BFI } & 9 & & \mathrm{P} & & \\ 206 & \text { BFI } & 9 & \mathrm{D} & \mathrm{P} & \mathrm{P} & \mathrm{W} \\ 152 & \text { IPIP } & 10 & \mathrm{D} & \mathrm{P} & \mathrm{P} & \\ 199 & \text { BFI } & 9 & & \mathrm{P} & \mathrm{P} & \\ 300 & \text { HEXACO } & 16 & & & \mathrm{P} & \\ 153 & \text { BFI } & 9 & \mathrm{D} & \mathrm{P} & \mathrm{P} & \\ 187 & \text { BFI } & 9 & \mathrm{D} & & & \\ 1643 & \text { NEO } & 12 & & \mathrm{P} & \mathrm{P} & \\ 249 & \text { NEO } & 12 & \mathrm{O} & & & \\ 142 & \text { NEO } & 36 & & \mathrm{P} & & \\ 212 & \text { NEO } & 12 & & \mathrm{P} & & \\ 221 & \text { NEO } & 36 & & \mathrm{P} & & \\ 354 & \text { IPIP } & 24 & \mathrm{O} & & & \\ 245 & \text { HEXACO } & 10 & \mathrm{O} & \mathrm{P} & \mathrm{P} & \\ 220 & \text { IPIP } & 20 & \mathrm{D} & & & \\ 437 & \text { NEO } & 12 & \mathrm{D} & & & \\ 504 & \text { BFI } & 12 & \mathrm{D} & \mathrm{P} & \mathrm{P} & \mathrm{W} \\ 303 & \text { BFI } & 12 & \mathrm{D} & \mathrm{P} & \mathrm{P} & \mathrm{W} \\ 129 & \text { BFI } & 12 & \mathrm{D} & \mathrm{O} & \mathrm{O} & \\ 554 & \text { NEO } & 48 & \mathrm{D} & \mathrm{P} & \mathrm{P} & \\ 1673 & \text { NEO } & 48 & \mathrm{D} & \mathrm{P} & \mathrm{P} & \mathrm{W} \\ 346 & \text { NEO } & 12 & & \mathrm{P} & \mathrm{P} & \\ 543 & \text { NEO } & 12 & & \mathrm{P} & \mathrm{P} & \\ 969 & \text { Other } & 8 & \mathrm{D} & & & \\ 364 & \text { NEO } & 36 & \mathrm{O} & \mathrm{O} & \mathrm{O} & \\ 1179 & \text { Adjectives } & 8 & \mathrm{D} & & & \\ 127 & \text { IPIP } & 24 & \mathrm{D} & \mathrm{P} & \mathrm{P} & \\ 127 & \text { HEXACO } & 10 & \mathrm{D} & \mathrm{P} & \mathrm{P} & \\ 618 & \text { NEO } & 12 & \mathrm{D} & \mathrm{P} & \mathrm{P} & \mathrm{W} \\ 450 & \text { NEO } & 12 & \mathrm{O} & & & \\ 130 & \text { IPIP } & 10 & & \mathrm{P} & \mathrm{P} & \\ & \text { NEO } & 12 & \mathrm{D} & & & \\ & \text { NEO } & 12 & \mathrm{D} & & & \end{array}$

$\begin{array}{lllll}55 & 22 & \text { TR } & \text { C } & \text { FA }\end{array}$

2126 DE $\mathrm{C}$ CA

$\begin{array}{lllll}71 & 22 & \text { US } & \mathrm{C} & \mathrm{FA}\end{array}$

5522 HK $\mathrm{C}$ FA

56 DE C FA

$\begin{array}{lllll}76 & 22 & \mathrm{NO} & \mathrm{C} & \mathrm{FA}\end{array}$

$0 \quad 26 \quad$ CA $\quad$ C FA

$\begin{array}{lllll}68 & 39 & \text { US } & \mathrm{C} & \mathrm{DA}\end{array}$

$\begin{array}{lllll}64 & 25 & \text { US } & \mathrm{C} & \mathrm{DA}\end{array}$

$\begin{array}{lllll}69 & 24 & \text { US } & \mathrm{C} & \mathrm{FA}\end{array}$

51 CA C FA

6120 US $\mathrm{C}$ FA

7924 DE $\mathrm{C}$ FA

$\begin{array}{lllll}55 & 55 & \mathrm{NL} & \mathrm{C} & \mathrm{AD}\end{array}$

$\begin{array}{lllll}67 & 22 & \text { US } & \text { C } & \text { HM }\end{array}$

73 US C FA

62 US C FA

61 US $\mathrm{C}$ FA

5216 US $\mathrm{C}$ FA

$88 \quad 20 \quad$ CA $\quad$ C $\quad$ FA

56 US C FA

$\begin{array}{lllll}47 & 13 & \mathrm{CH} & \mathrm{C} & \mathrm{FA}\end{array}$

$\begin{array}{llll}51 & 35 & \mathrm{C} & \mathrm{CA}\end{array}$

$\begin{array}{lllll}45 & 32 & \mathrm{I} & \mathrm{C} & \mathrm{CA}\end{array}$

6919 US $\quad$ C $\quad$ CA

$\begin{array}{lllll}64 & 28 & \text { ES } & \text { C } & \text { FA }\end{array}$

$\begin{array}{ccccc}52 & 39 & \text { ES } & \text { C } & \text { FA } \\ 0 & 20 & \text { US } & \text { C } & \text { FA } \\ 0 & 19 & \text { US } & \text { C } & \text { FA } \\ 48 & 14 & \text { AU } & \text { C } & \text { FA } \\ 47 & & \text { US } & \text { C } & \text { FA } \\ 84 & 45 & \text { I } & \text { C } & \text { HM } \\ 61 & 22 & \text { US } & \text { C } & \text { FA } \\ 61 & 22 & \text { US } & \text { C } & \text { FA } \\ 64 & 70 & \text { CO } & \text { C } & \text { FA } \\ 96 & 45 & \text { AU } & \text { C } & \text { FA } \\ 54 & 36 & \text { US } & \text { C } & \text { FA } \\ 62 & 25 & \text { PL } & \text { C } & \text { FA } \\ 50 & 23 & \text { PL } & \text { C } & \text { FA }\end{array}$

$\begin{array}{llllllllll}648 & \text { BFI } & 9 & \text { D } & 67 & 32 & \text { I } & \text { C } & \text { FA }\end{array}$

$\begin{array}{lllllllllll}337 & \text { NEO } & 48 & \mathrm{D} & \mathrm{P} & \mathrm{P} & 66 & 20 & \text { US } & \mathrm{C} & \text { FA }\end{array}$

$\begin{array}{llllllll}307 & \text { NEO } & 12 & \text { D } & 12 & \text { US } & \text { C } & \text { FA }\end{array}$

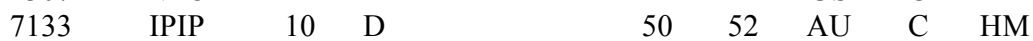

$\begin{array}{lllllllllll}301 & \text { BFI } & 9 & \text { D } & \text { P } & \text { P } & 40 & 37 & \text { SI } & \text { C } & \text { FA }\end{array}$

$\begin{array}{lllllllll}342 & \text { NEO } & 12 & \mathrm{D} & 66 & 68 & \mathrm{ES} & \mathrm{C} & \text { FA }\end{array}$

$\begin{array}{lllllllllll}177 & \text { NEO } & 12 & \text { D } & \text { P } & \text { P } & 71 & 20 & \text { US } & \text { C } & \text { FA }\end{array}$

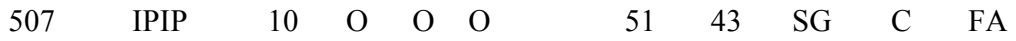

$\begin{array}{llllllllll}117 & \text { BFI } & 9 & \text { P } & \text { P } & 43 & 57 & \text { US } & \text { C } & \text { FA }\end{array}$

$\begin{array}{llllllllll}40 & \text { BFI } & 9 & \text { P } & \text { P } & 100 & 55 & \text { RS } & \text { C } & \text { FA }\end{array}$

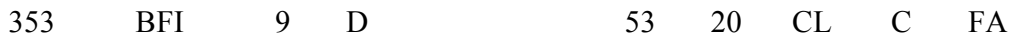

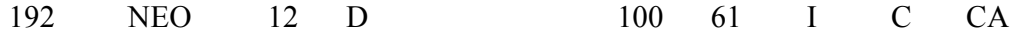

$\begin{array}{lllllllllll}208 & \text { NEO } & 12 & \mathrm{D} & \mathrm{O} & \mathrm{O} & 54 & 64 & \mathrm{CA} & \mathrm{C} & \text { FA }\end{array}$

$\begin{array}{lllllllll}620 & \text { BFI } & 9 & \mathrm{D} & 74 & 21 & \text { TR } & \text { C } & \text { FA }\end{array}$

$\begin{array}{llllllllll}134 & \text { NEO } & 12 & \mathrm{P} & \mathrm{P} & 80 & 60 & \text { US } & \mathrm{C} & \mathrm{CA}\end{array}$

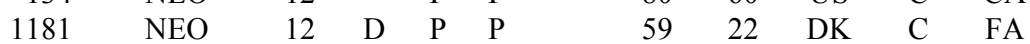

$\begin{array}{lllllllll}428 & \text { NEO } & 12 & \mathrm{P} & \mathrm{P} & \mathrm{ES} & \mathrm{C} & \mathrm{CA}\end{array}$

$\begin{array}{llllllllll}181 & \text { BFI } & 9 & \text { P } & \text { P } & 52 & 36 & \text { CA } & \text { C } & \text { FA }\end{array}$

523 NEO 12 D $\quad 70 \quad 22$ AU $\quad$ C $\quad$ FA

$\begin{array}{llllllllll}270 & \text { IPIP } & 10 & \mathrm{P} & \mathrm{P} & 42 & 33 & \text { US } & \mathrm{C} & \text { FA }\end{array}$

$\begin{array}{llllllllll}78 & \mathrm{NEO} & 60 & \mathrm{O} & \mathrm{O} & 62 & 45 & \mathrm{FR} & \mathrm{C} & \mathrm{FA}\end{array}$ 
Pazda \& Thorstenson (2018)

Petrides et al. (2007)

Kandler et al. (2017)

Plopa et al. (2017)

Pollock et al. (2016)

Pratt (2006)

Purvis et al. (2011) Sample 1

Purvis et al. (2011) Sample 2

Pychyl \& Little (1998)

Qing-Guo et al. (2011)

Ramanaiah et al. (1995)

Ro (2011) Study 1

Ro (2011) Study 2

Robinson et al. (2006) Study 1

Robinson et al. (2006) Study 2

Romero et al. (2002)

Romero et al. (2009)

Romero et al. (2012)

Romero et al. (2015)

Røysamb et al. (2018)

Ryan \& Frederick (1997) Study 3

Rzeszutek et al. (2018)

Sadiković et al. (2018) Dizygotic

Sadiković et al. (2018) Monozygotic

Saeed Abbasi et al. (2018)

Saklofske et al. (2012)

Salter et al. (2013) Control

Salter et al. (2013) Spinal Cord Injury

Schimmack et al. (2004) Study 1

Schimmack et al. (2004) Study 2

Schimmack et al. (2004) Study 3

Schimmack et al. (2004) Study 4

Schmutte \& Ryff (1997) Sample 1

Schmutte \& Ryff (1997) Sample 2

Schneider et al. (2012)

Schwartz et al. (2018)

Selnes et al. (2004)

Sheu et al. (2016)

Sheu et al. (2017)

Shi et al. (2019) Study 2

Shulman \& Hemenover (2006)

Sibley (2011) Study 3

Şimşek (2011) Study 4

Şimşek \& Koydemir (2013)

Şimşek \& Kocayörük (2013) Study 4 SWB

Singh \& Shejwal (2017) Females

Singh \& Shejwal (2017) Males

Sirianni Molnar (2011) Ill

Sirianni Molnar (2011) Student

Skomorovsky \& Sudom (2011)

Sliter et al. (2015)

Sobocko \& Zelenski (2015) Study 1

Sobocko \& Zelenski (2015) Study 2

Sorondo (2017) Public Services

Sorondo (2017) Technical Services

Soto \& John (2017) Study 3

Soubelet \& Salthouse (2011)

Spörrle et al. (2010)

Stamatopoulou et al. (2016)

Stanton et al. (2016) Big 5

Stanton et al. (2016) HEXACO

\begin{tabular}{|c|c|c|c|c|c|c|c|c|c|c|c|}
\hline 262 & $\mathrm{NEO}$ & 12 & & $\mathrm{P}$ & $\mathrm{P}$ & & 68 & & US & $\mathrm{C}$ & FA \\
\hline 274 & Other & 40 & $\mathrm{D}$ & & & & 66 & 26 & GR & $\mathrm{C}$ & FA \\
\hline 576 & NEO & 48 & D & & & & 58 & 37 & US & $\mathrm{C}$ & $\mathrm{AD}$ \\
\hline 359 & NEO & 12 & $\mathrm{D}$ & & & & 81 & 39 & PL & $\mathrm{C}$ & FA \\
\hline 149 & HEXACO & 10 & $\mathrm{D}$ & $\mathrm{P}$ & $\mathrm{P}$ & & 47 & 34 & US & $\mathrm{C}$ & FA \\
\hline 305 & IPIP & 10 & & $\mathrm{P}$ & $\mathrm{P}$ & & 62 & 36 & US & $\mathrm{C}$ & FA \\
\hline 1858 & Adjectives & 8 & D & $\mathrm{P}$ & $\mathrm{P}$ & & 73 & 29 & US & $\mathrm{C}$ & FA \\
\hline 1065 & BFI & 9 & $\mathrm{D}$ & & & & 56 & 41 & I & $\mathrm{C}$ & FA \\
\hline 81 & NEO & 36 & D & $\mathrm{O}$ & $\mathrm{O}$ & & 56 & 35 & CA & $\mathrm{C}$ & FA \\
\hline 818 & BFI & 9 & $\mathrm{O}$ & & & & 44 & 34 & $\mathrm{CN}$ & $\mathrm{C}$ & FA \\
\hline 245 & $\mathrm{NEO}$ & 36 & $\mathrm{D}$ & & & & 55 & 23 & US & $\mathrm{C}$ & HM \\
\hline 429 & BFI & 9 & D & & & W & 65 & 25 & US & $\mathrm{C}$ & FA \\
\hline 181 & BFI & 9 & & & & W & 75 & 41 & US & $\mathrm{C}$ & FA \\
\hline 246 & IPIP & 10 & & $\mathrm{P}$ & $\mathrm{P}$ & & 74 & & US & $\mathrm{C}$ & FA \\
\hline 68 & IPIP & 10 & & $\mathrm{P}$ & $\mathrm{P}$ & & 72 & & US & $\mathrm{C}$ & FA \\
\hline 324 & NEO & 48 & & $\mathrm{P}$ & $\mathrm{P}$ & & 36 & 16 & ES & $\mathrm{C}$ & FA \\
\hline 405 & NEO & 48 & D & $\mathrm{P}$ & $\mathrm{P}$ & & 61 & 32 & ES & $\mathrm{C}$ & FA \\
\hline 583 & NEO & 48 & $\mathrm{D}$ & $\mathrm{P}$ & $\mathrm{P}$ & & 72 & 35 & ES & $\mathrm{C}$ & FA \\
\hline 876 & HEXACO & 16 & $\mathrm{D}$ & $\mathrm{P}$ & $\mathrm{P}$ & W & 57 & 41 & ES & $\mathrm{C}$ & FA \\
\hline 1516 & NEO & 48 & $\mathrm{D}$ & & & & 65 & 57 & NO & $\mathrm{C}$ & FA \\
\hline 102 & NEO & 36 & & $\mathrm{P}$ & $\mathrm{P}$ & & 59 & 21 & US & $\mathrm{C}$ & FA \\
\hline 530 & NEO & 12 & $\mathrm{D}$ & $P$ & $\mathrm{P}$ & & 16 & 40 & PL & $\mathrm{C}$ & FA \\
\hline 122 & NEO & 48 & $\mathrm{D}$ & & & & 63 & 25 & $\mathrm{RS}$ & $\mathrm{C}$ & FA \\
\hline 242 & NEO & 48 & $\mathrm{D}$ & & & & 76 & 25 & $\mathrm{RS}$ & $\mathrm{C}$ & FA \\
\hline 819 & BFI & 9 & & & $\mathrm{P}$ & & 62 & 27 & US & $\mathrm{C}$ & FA \\
\hline 216 & Adjectives & 8 & $\mathrm{D}$ & $\mathrm{P}$ & $\mathrm{P}$ & & 78 & 20 & GB & $\mathrm{C}$ & FA \\
\hline 36 & $\mathrm{NEO}$ & 48 & & $\mathrm{P}$ & $\mathrm{P}$ & & & & US & $\mathrm{C}$ & FA \\
\hline 36 & NEO & 48 & & $\mathrm{P}$ & $\mathrm{P}$ & & & & US & $\mathrm{C}$ & FA \\
\hline 136 & $\mathrm{NEO}$ & 48 & $\mathrm{D}$ & & & & 74 & 20 & US & $\mathrm{C}$ & FA \\
\hline 124 & NEO & 60 & $\mathrm{D}$ & & & & 71 & 21 & US & $\mathrm{C}$ & FA \\
\hline 143 & NEO & 48 & $\mathrm{D}$ & & & & & & US & $\mathrm{C}$ & FA \\
\hline 344 & BFI & 9 & $\mathrm{D}$ & & & & 74 & & CA & $\mathrm{C}$ & FA \\
\hline 215 & NEO & 12 & & $\mathrm{O}$ & $\mathrm{O}$ & W & 53 & 54 & US & $\mathrm{C}$ & FA \\
\hline 139 & NEO & 12 & & & & W & 47 & & US & $\mathrm{C}$ & FA \\
\hline 152 & IPIP & 10 & & $\mathrm{P}$ & $\mathrm{P}$ & & 72 & 20 & US & $\mathrm{C}$ & FA \\
\hline 541 & NEO & 12 & & & & W & 76 & 44 & US & $\mathrm{C}$ & $\mathrm{CA}$ \\
\hline 131 & NEO & 12 & $\mathrm{D}$ & $\mathrm{O}$ & $\mathrm{O}$ & W & 52 & 44 & $\mathrm{NO}$ & $\mathrm{C}$ & FA \\
\hline 849 & Adjectives & 10 & $\mathrm{D}$ & & & & 58 & 20 & US & $\mathrm{C}$ & FA \\
\hline 757 & Adjectives & 10 & $\mathrm{D}$ & & & & 70 & 21 & $\mathrm{CN}$ & $\mathrm{C}$ & FA \\
\hline 208 & IPIP & 10 & $\mathrm{D}$ & & & & 54 & 20 & $\mathrm{CN}$ & $\mathrm{C}$ & FA \\
\hline 112 & NEO & 12 & & & & W & 47 & 19 & US & $\mathrm{C}$ & FA \\
\hline 148 & HEXACO & 10 & $\mathrm{O}$ & & & & 64 & 20 & NZ & $\mathrm{C}$ & FA \\
\hline 106 & BFI & 9 & $\mathrm{D}$ & $\mathrm{P}$ & $\mathrm{P}$ & & 45 & 22 & TR & $\mathrm{C}$ & FA \\
\hline 721 & BFI & 9 & $\mathrm{D}$ & $\mathrm{P}$ & $\mathrm{P}$ & & 66 & 29 & TR & $\mathrm{C}$ & $\mathrm{CA}$ \\
\hline 99 & BFI & 9 & $\mathrm{D}$ & $\mathrm{P}$ & $\mathrm{P}$ & & 54 & 19 & TR & $\mathrm{C}$ & FA \\
\hline 98 & NEO & 12 & & $\mathrm{P}$ & $\mathrm{P}$ & & 100 & 18 & IN & $\mathrm{C}$ & $\mathrm{CA}$ \\
\hline 102 & NEO & 12 & & $\mathrm{P}$ & $\mathrm{P}$ & & 0 & 18 & IN & $\mathrm{C}$ & $\mathrm{CA}$ \\
\hline 773 & Adjectives & 8 & $\mathrm{D}$ & $\mathrm{P}$ & $\mathrm{P}$ & & 93 & 49 & US & $\mathrm{C}$ & FA \\
\hline 538 & Adjectives & 8 & $\mathrm{D}$ & $\mathrm{P}$ & $\mathrm{P}$ & & 78 & 22 & US & $\mathrm{C}$ & FA \\
\hline 200 & Other & 15 & $\mathrm{D}$ & & & & 19 & & CA & $\mathrm{C}$ & FA \\
\hline 708 & IPIP & 10 & & $\mathrm{P}$ & $\mathrm{P}$ & & 72 & 21 & US & $\mathrm{C}$ & FA \\
\hline 154 & BFI & 9 & $\mathrm{D}$ & $\mathrm{P}$ & $\mathrm{P}$ & & 68 & 22 & $\mathrm{CA}$ & $\mathrm{C}$ & $\mathrm{CA}$ \\
\hline 118 & BFI & 9 & & $\mathrm{P}$ & $\mathrm{P}$ & & 63 & 20 & CA & $\mathrm{C}$ & $\mathrm{CA}$ \\
\hline 25 & BFI & 9 & & $\mathrm{P}$ & $\mathrm{P}$ & & 62 & 45 & US & $\mathrm{C}$ & FA \\
\hline 21 & BFI & 9 & & $\mathrm{P}$ & $\mathrm{P}$ & & 62 & 45 & US & $\mathrm{C}$ & FA \\
\hline 179 & BFI & 12 & & & & W & & & US & $\mathrm{C}$ & FA \\
\hline 1175 & IPIP & 10 & $\mathrm{D}$ & $\mathrm{P}$ & $\mathrm{P}$ & & 63 & & & $\mathrm{C}$ & FA \\
\hline 200 & NEO & 12 & $\mathrm{D}$ & & & & 50 & 28 & $\mathrm{DE}$ & $\mathrm{C}$ & FA \\
\hline 602 & Other & 15 & $\mathrm{D}$ & & & & 62 & 34 & GR & $\mathrm{C}$ & FA \\
\hline 293 & $\mathrm{NEO}$ & 48 & $\mathrm{D}$ & & & & 71 & 46 & US & $\mathrm{C}$ & $\mathrm{CA}$ \\
\hline 293 & HEXACO & 16 & $\mathrm{D}$ & & & & 71 & 46 & US & $\mathrm{C}$ & $\mathrm{CA}$ \\
\hline
\end{tabular}


Stanton et al. (2017) Students

Steca et al. (2005) Females

Steca et al. (2005) Males

Stimson (2010)

Stolarski (2016)

Suh et al. (1996)

Sulaiman et al. (2013)

Suldo et al. (2015)

Sun et al. (2017)

Sun et al. (2018)

Szcześniak et al. (2019)

Tan et al. (2017)

Tanksale (2015)

Teachman et al. (2007)

Terracciano (2003)

Tett et al. (2005)

Thingujam (2011)

Thomas (2011)

Thoresen (2000)

Thorpe (2015)

Tov (2012) Study 1

Tov (2012) Study 2

Trankle \& Haw (2009)

Tuce \& Fako (2014) Boys

Tuce \& Fako (2014) Girls

van Allen \& Zelenski (2018)

Vilhena et al. (2014)

Villieux et al. (2016)

Vittersø (2001)

Vorkapić \& Lončarić (2013)

Wahl et al. (2012) Hearing Impaired

Wahl et al. (2012) Sensory Unimpaired

Wahl et al. (2012) Visually Impaired

Watson \& Clark (1992) Sample 1

Watson \& Clark (1992) Sample 2

Watson \& Clark (1992) Sample 3

Watson \& Clark (1992) Sample 4

Watson et al. (2000) Dating females

Watson et al. (2000) Dating males

Watson et al. (2000) Friends

Watson et al. (2002) Study 2

Watson et al. (2002) Study 3

Watson et al. (2004)

Watson et al. (2007) Study 2

Watson et al. (2007) Study 3 Patients

Watson et al. (2007) Study 3 Students

Watson et al. (2015) Community

Watson et al. (2015) Iowa

Watson et al. (2015) Notre Dame

Watson et al. (2017)

Webb et al. (2013)

Weber \& Huebner (2015)

West (2007)

White (2011) Dating

White (2011) Married

Williams \& Wiebe (2000)

Williams \& Simms (2018)

Wilt et al. (2016) Community

Wilt et al. (2016) University Student

Shyh Shin et al. (2009) Australian

Shyh Shin et al. (2009) Singaporean

Wong et al. (2015)
381

549

601

89

265

115

315

624

205

706

213

330

183

325

575

152

300

176

440

197

206

139

157

225

200

221

729

403

264

290

116

150

121

532

236

224

325

136

136

558

287

346

576

370

329

306

372

554

493

448

65

344

148

262

202

140

336

965

418

189

243

401

$\begin{array}{ccllll}\text { BFI } & 9 & \mathrm{D} & \mathrm{P} & \mathrm{P} & \\ \text { Other } & 12 & \mathrm{D} & & & \\ \text { Other } & 12 & \mathrm{D} & & & \\ \text { BFI } & 9 & \mathrm{D} & & & \\ \text { NEO } & 12 & \mathrm{D} & & & \\ \text { NEO } & 24 & \mathrm{D} & \mathrm{O} & \mathrm{O} & \\ \text { NEO } & 12 & \mathrm{D} & \mathrm{P} & \mathrm{P} & \\ \text { Other } & 23 & \mathrm{O} & & & \\ \text { BFAS } & 20 & & \mathrm{P} & & \\ \text { BFAS } & 20 & \mathrm{D} & \mathrm{O} & \mathrm{O} & \mathrm{W} \\ \text { NEO } & 12 & \mathrm{D} & & & \\ \text { NEO } & 12 & \mathrm{D} & & & \\ \text { NEO } & 12 & \mathrm{D} & \mathrm{P} & \mathrm{P} & \\ \text { IPIP } & 10 & & \mathrm{P} & \mathrm{P} & \\ \text { NEO } & 48 & & \mathrm{P} & \mathrm{P} & \\ \text { Adjectives } & 8 & \mathrm{D} & \mathrm{P} & \mathrm{P} & \\ \text { NEO } & 12 & \mathrm{D} & \mathrm{P} & \mathrm{P} & \\ \text { IPIP } & 10 & & \mathrm{P} & \mathrm{P} & \\ \text { NEO } & 12 & \mathrm{D} & \mathrm{P} & \mathrm{P} & \\ \text { BFI } & 9 & & \mathrm{O} & & \\ \text { IPIP } & 10 & \mathrm{O} & \mathrm{O} & \mathrm{O} & \\ \text { IPIP } & 10 & \mathrm{D} & \mathrm{O} & \mathrm{O} & \\ \text { BFI } & 9 & & \mathrm{P} & \mathrm{P} & \\ \text { Other } & 10 & \mathrm{O} & & \\ \text { Other } & 10 & \mathrm{O} & & \end{array}$

$\begin{array}{llllll}\text { IPIP } & 24 & \mathrm{D} & \mathrm{P} & \mathrm{P} & \text { W }\end{array}$

NEO 48

$\begin{array}{lllll}\text { BFI } & 9 & \mathrm{D} & \mathrm{P} & \mathrm{P}\end{array}$

$\begin{array}{lllll}\text { Other } & 12 & \mathrm{D} & \mathrm{O} & \mathrm{O}\end{array}$

BFI

NEO

NEO

NEO

Adjectives

Adjectives

NEO

NEO

NEO

NEO

BFI

BFI

NEO

BFI

BFI

BFI

BFI

BFI

BFI

BFI

BFI

NEO

Other

Other

BFI

BFI

NEO

NEO

$$
\text { BFI }
$$

BFI

Adjectives

Adjectives

NEO $\begin{array}{ccccc}67 & 19 & \text { US } & \text { C } & \text { CA } \\ 100 & 43 & \text { IT } & \text { C } & \text { FA } \\ 0 & 45 & \text { IT } & \text { C } & \text { FA }\end{array}$

$\begin{array}{lllll}79 & 18 & \text { US } & \text { C } & \text { FA }\end{array}$

$\begin{array}{lllll}54 & 23 & \text { PL } & \mathrm{C} & \mathrm{FA}\end{array}$

$\begin{array}{lllll}63 & 22 & \text { US } & \mathrm{C} & \mathrm{FA}\end{array}$

$\begin{array}{lllll}41 & 19 & \text { MY } & \text { C } & \text { FA }\end{array}$

6316 US $\mathrm{C}$ FA

$\begin{array}{lllll}48 & 35 & \text { US } & \mathrm{C} & \text { FA }\end{array}$

5436 US $\mathrm{C}$ FA

$\begin{array}{lllll}72 & 32 & \text { PL } & \mathrm{C} & \text { FA }\end{array}$

$100 \quad 69$ AU $\mathrm{C}$ FA

$\begin{array}{lllll}51 & 35 & \text { IN } & \mathrm{C} & \mathrm{FA}\end{array}$

64 US C CA

$\begin{array}{lllll}63 & 28 & \text { IT } & \text { C } & \text { FA }\end{array}$

$\begin{array}{lllll}66 & 22 & \text { US } & \mathrm{C} & \mathrm{FA}\end{array}$

$\begin{array}{lllll}49 & 23 & \text { IN } & \text { C } & \text { FA }\end{array}$

$\begin{array}{lllll}54 & 31 & \text { US } & \mathrm{C} & \text { FA }\end{array}$

3940 US $\mathrm{C}$ FA

$\begin{array}{lllll}58 & 34 & \text { US } & \mathrm{C} & \text { FA }\end{array}$

$\begin{array}{lllll}59 & 22 & \text { SG } & \mathrm{C} & \text { FA }\end{array}$

$\begin{array}{lllll}66 & 21 & \text { SG } & \text { C } & \text { FA }\end{array}$

8322 AU C FA

$\begin{array}{llll}18 & \text { BA } & \mathrm{C} & \mathrm{FA}\end{array}$

$\begin{array}{lllll}75 & 22 & \mathrm{CA} & \mathrm{C} & \mathrm{DA}\end{array}$

$\begin{array}{lllll}71 & 42 & \text { PT } & \text { C } & \text { FA }\end{array}$

$\begin{array}{lllll}86 & 23 & \text { FR } & \text { C } & \text { FA }\end{array}$

$\begin{array}{lllll}99 & 37 & \mathrm{HR} & \mathrm{C} & \mathrm{FA}\end{array}$

$42 \quad 83$ DE $\mathrm{C}$ FA

$49 \quad 82$ DE $\mathrm{C}$ FA

$\begin{array}{lllll}59 & 83 & \text { DE } & \mathrm{C} & \text { FA }\end{array}$

US C FA

US C FA

US C FA

US C FA

$\begin{array}{cccc}100 & \text { US } & \text { C } & \text { HM } \\ 0 & \text { US } & \text { C } & \text { HM }\end{array}$

US C CA

51 US $\mathrm{C}$ FA

61 US C FA

$\begin{array}{lllll}50 & 28 & \text { US } & \mathrm{C} & \mathrm{CA}\end{array}$

$\begin{array}{lllll}67 & 39 & \text { US } & \mathrm{C} & \mathrm{CA}\end{array}$

$\begin{array}{lllll}68 & 42 & \text { US } & \mathrm{C} & \mathrm{CA}\end{array}$

63 US C CA

$\begin{array}{lllll}74 & 37 & \text { US } & \text { C } & \text { CA }\end{array}$

$\begin{array}{lllll}67 & 19 & \text { US } & \mathrm{C} & \mathrm{CA}\end{array}$

$\begin{array}{lllll}60 & 19 & \text { US } & \mathrm{C} & \mathrm{CA}\end{array}$

$\begin{array}{lllll}53 & 36 & \text { US } & \mathrm{C} & \mathrm{CA}\end{array}$

4930 US $\mathrm{C}$ FA

$\begin{array}{lllll}55 & 12 & \text { US } & \mathrm{C} & \text { FA }\end{array}$

$\begin{array}{lllll}63 & 19 & \text { US } & \text { C } & \text { FA } \\ & & \text { C } & \text { FA }\end{array}$

$\begin{array}{lllll}50 & 39 & \text { US } & \text { C } & \text { FA }\end{array}$

5521 US $\mathrm{C}$ FA

$\begin{array}{lllll}68 & 40 & \text { US } & \mathrm{C} & \mathrm{FA}\end{array}$

$\begin{array}{lllll}62 & 35 & \text { US } & \mathrm{C} & \mathrm{FA}\end{array}$

70 US C FA

$\begin{array}{lllll}69 & 19 & \text { AU } & \mathrm{C} & \text { FA }\end{array}$

$\begin{array}{lllll}66 & 18 & \text { SG } & \text { C } & \text { FA }\end{array}$ 
Wood et al. (2010)

Woyciekoski et al. (2014)

Wu et al. (2019) Husband

Wu et al. (2019) Wife

$\mathrm{Xu}$ et al. (2017)

Yeo (2015)

Yilmaz \& Kafadar (2019)

Zeidner \& Olnick-Shemesh (2010)

Zellars et al. (2006)

Zhai et al. (2010)

Zhai et al. (2013)

Zhang et al. (2010)

Zhang \& Howell (2011)

Zhang \& Tsingan (2014)

Zhu et al. (2013)

Agbo \& Ngwu (2017)

Aghababaei \& Tabik (2013)

Aghababaei (2014)

Aghababaei \& Arji (2014) Big 5 Study 1

Aghababaei \& Arji (2014) HEXACO Study 1

Aghababaei \& Arji (2014) Study 2

Antunes et al. (2017) Sample 1

Balgiu (2018)

Blatný et al. (2018)

Brailovskaia \& Margraf (2016) Facebook non-users

Brailovskaia \& Margraf (2016) Facebook users

Brailovskaia \& Margraf (2018)

Brailovskaia et al. (2019)

Carciofo \& Song (2019)

Chopik \& Lucas (2019) Men

Chopik \& Lucas (2019) Women

Cikrikci (2019)

Correa et al. (2010)

Csarny (1998)

Datu (2014)

Datu et al. (2018)

Denovan \& Michael (2018)

Deventer et al. (2019)

Dijkstra \& Barelds (2009)

Duckworth et al. (2012)

Eakman \& Eklund (2012)

Ebner et al. (2018) Study 2

Freund \& Baltes (1998)

Furler et al. (2013) Men

Furler et al. (2013) Women

Gibson (2007) Study 1

Glidden et al. (2006)

Goldstein \& Flett (2009)

Gore et al. (2014) Study 1

Goswami (2014)

Grevenstein \& Bluemke (2015)

Grevenstein et al. (2018)

Halama et al. (2010) Hungarian

Halama et al. (2010) Slovak

Hengartner et al. (2016)

Jennings (2004)

Joshanloo \& Nosratabadi (2009)

Kashdan \& Steger (2007)

Kim et al. (2016) American

$\begin{array}{rccllll}259 & \text { BFI } & 9 & \mathrm{D} & & & \\ 274 & \text { Other } & 25 & \mathrm{D} & \mathrm{P} & \mathrm{P} & \\ 587 & \text { BFI } & 9 & \mathrm{D} & & & \\ 587 & \text { BFI } & 9 & \mathrm{D} & & & \\ 2357 & \text { Other } & 8 & \mathrm{O} & & & \\ 260 & \text { IPIP } & 10 & \mathrm{D} & & & \mathrm{W} \\ 100 & \text { Other } & 9 & & \mathrm{P} & \mathrm{P} & \\ 203 & \text { Other } & 12 & \mathrm{D} & & & \\ 188 & \text { NEO } & 12 & & \mathrm{P} & \mathrm{P} & \\ 413 & \text { BFI } & 9 & \mathrm{O} & & & \\ 818 & \text { BFI } & 9 & \mathrm{O} & & & \\ 139 & \text { BFI } & 9 & \mathrm{D} & & & \\ 754 & \text { Adjectives } & 8 & \mathrm{D} & & & \\ 238 & \text { BFI } & 9 & & \mathrm{P} & \mathrm{P} & \\ 309 & \text { BFI } & 9 & \mathrm{D} & & & \\ 238 & \text { TIPI } & 2 & & \mathrm{O} & \mathrm{O} & \\ 256 & \text { IPIP } & 4 & \mathrm{D} & & & \\ 288 & \text { HEXACO } & 10 & \mathrm{O} & & & \\ 183 & \text { IPIP } & 10 & \mathrm{O} & & & \\ 183 & \text { HEXACO } & 10 & \mathrm{O} & & \end{array}$

$\begin{array}{rcccccc}109 & \text { HEXACO } & 10 & \text { O } & & & \\ 542 & \text { IPIP } & 4 & & \text { P } & \text { P } & \\ 496 & \text { BFI } & 2 & \text { D } & \text { O } & \text { O } & \text { W } \\ 2229 & \text { BFI } & 2 & \text { D } & & & \\ 155 & \text { BFI } & 2 & \text { D } & & & \end{array}$

$\begin{array}{ccccc}69 & 27 & \text { UR } & \text { C } & \text { FA } \\ 0 & 42 & \text { CN } & \text { C } & \text { FA } \\ 100 & 41 & \text { CN } & \text { C } & \text { FA } \\ 58 & 16 & \text { CN } & \text { C } & \text { FA } \\ 51 & 37 & \text { ID } & \text { C } & \text { FA } \\ 59 & 20 & \text { TR } & \text { C } & \text { DA } \\ 58 & 16 & \text { IL } & \text { C } & \text { FA } \\ 90 & 40 & \text { US } & \text { C } & \text { FA } \\ 59 & 31 & \text { CN } & \text { C } & \text { FA } \\ 56 & 34 & \text { CN } & \text { C } & \text { FA } \\ 52 & 25 & \text { DE } & \text { C } & \text { FA } \\ 70 & 25 & \text { US } & \text { C } & \text { FA } \\ 71 & 19 & \text { CN } & \text { C } & \text { FA } \\ 58 & 19 & \text { US } & \text { C } & \text { FA } \\ 48 & 22 & \text { NG } & \text { N } & \text { FA } \\ 49 & 23 & \text { IR } & \text { N } & \text { FA } \\ 64 & 21 & \text { IR } & \text { N } & \text { FA } \\ 68 & 21 & \text { IR } & \text { N } & \text { FA } \\ 68 & 21 & \text { IR } & \text { N } & \text { FA }\end{array}$

$\begin{array}{lllll}59 & 20 & \text { IR } & \mathrm{N} & \text { FA }\end{array}$

$\begin{array}{lllll}56 & 33 & \text { PT } & \mathrm{N} & \text { FA }\end{array}$

$\begin{array}{lllll}39 & 19 & \text { RO } & \mathrm{N} & \mathrm{FA}\end{array}$

$\begin{array}{lllll}43 & 42 & \mathrm{CZ} & \mathrm{N} & \mathrm{FA}\end{array}$

$\begin{array}{lllll}64 & 25 & \mathrm{DE} & \mathrm{N} & \mathrm{FA}\end{array}$

790

633

438

767

2578

2578

292

959

386

210

356

306

896

3626

9649

224

322

200

1608

1608

240

295

138

2566

893

1842

1033

249

274

1125

794

227

97

174

BFI 2 D

\section{BFI 2 D}

BFI 2 D

$\begin{array}{lllll}\text { BFI } & 2 & \mathrm{O} & \mathrm{P} & \mathrm{P}\end{array}$

BFI 3 O

BFI 3 O

TIPI 2 D

TIPI 2 O

NEO $12 \quad \mathrm{O}$

TIPI 2 D

TIPI

TIPI

BFI

Adjectives

Other

TIPI

BFI

NEO

BFI

BFI

TIPI

NEO

TIPI

Other

IPIP

BFI

BFI

Adjectives

Adjectives

BFI

Adjectives

BFI

Other

BFI $\begin{array}{lllll}71 & 23 & \text { DE } & \mathrm{N} & \mathrm{FA}\end{array}$

$\begin{array}{lllll}66 & 22 & \mathrm{DE} & \mathrm{N} & \mathrm{AD}\end{array}$

$\begin{array}{lllll}66 & 22 & \mathrm{DE} & \mathrm{N} & \mathrm{CA}\end{array}$

$\begin{array}{lllll} & 20 & \mathrm{CN} & \mathrm{N} & \mathrm{CA}\end{array}$

$100 \quad 51$ DE N FA

$\begin{array}{lllll}66 & 20 & \text { TR } & \mathrm{N} & \text { FA }\end{array}$

3346 US N

$\begin{array}{lllll}58 & 52 & \text { US } & \mathrm{N} & \mathrm{FA}\end{array}$

$\begin{array}{lllll}63 & 18 & \mathrm{PH} & \mathrm{N} & \mathrm{FA}\end{array}$

$\begin{array}{lllll}67 & 14 & \mathrm{PH} & \mathrm{N} & \mathrm{FA}\end{array}$

$82 \quad 20$ GB N FA

$\begin{array}{lllll}29 & 18 & \text { DE } & \mathrm{N} & \mathrm{FA}\end{array}$

$100 \quad 46 \quad$ NL N $\quad$ FA

$\begin{array}{lllll}58 & 68 & \text { US } & \mathrm{N} & \mathrm{FA}\end{array}$

$\begin{array}{lllll}54 & 28 & \text { US } & \mathrm{N} & \text { FA }\end{array}$

$67 \quad 30 \quad$ DE $\quad \mathrm{N} \quad \mathrm{FA}$

$\begin{array}{lllll}51 & 84 & \text { DE } & \mathrm{N} & \text { FA }\end{array}$

$\begin{array}{lllll}0 & 52 & \mathrm{CH} & \mathrm{N} & \mathrm{FA}\end{array}$

$\begin{array}{lllll}100 & 19 & \mathrm{CH} & \mathrm{N} & \mathrm{FA}\end{array}$

73 US N DA

$\begin{array}{lllll}62 & 43 & \text { US } & \mathrm{N} & \mathrm{DA}\end{array}$

$\begin{array}{lllll}70 & 19 & \mathrm{CA} & \mathrm{N} & \mathrm{FA}\end{array}$

70 US N FA

$\begin{array}{lllll}61 & 12 & \text { GB } & \mathrm{N} & \mathrm{FA}\end{array}$

$86 \quad 28$ DE N FA

$\begin{array}{lllll}75 & 42 & \text { DE } & \mathrm{N} & \mathrm{FA}\end{array}$

$\begin{array}{llll}62 & 22 & \text { HU } & \mathrm{N} \\ & \mathrm{FA}\end{array}$

$53 \quad 22$ SK N FA

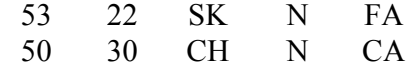

$\begin{array}{lllll}30 & 72 & \text { US } & \mathrm{N} & \mathrm{FA}\end{array}$

W $49 \quad 23$ IR $\quad$ N $\quad$ FA

$\begin{array}{lllll}66 & 20 & \text { US } & \mathrm{N} & \text { FA }\end{array}$ 


\begin{tabular}{|c|c|c|c|c|c|c|c|c|c|c|c|c|}
\hline Kim et al. (2016) Hong Kong & 97 & BFI & 9 & $\mathrm{O}$ & & & & 76 & 20 & HK & $\mathrm{N}$ & $\mathrm{CA}$ \\
\hline Knöpfli et al. (2016) & 2508 & BFI & 2 & $\mathrm{D}$ & & & & 58 & 60 & $\mathrm{CH}$ & $\mathrm{N}$ & $\mathrm{DA}$ \\
\hline Lai (2018) & 13424 & Adjectives & 6 & $\mathrm{O}$ & & & & 47 & 44 & $\mathrm{AU}$ & $\mathrm{N}$ & FA \\
\hline Augusto Landa et al. (2010) & 228 & NEO & 12 & & & & $\mathrm{~W}$ & 84 & 21 & ES & $\mathrm{N}$ & FA \\
\hline Leffel et al. (2018) & 499 & $\mathrm{NEO}$ & 3 & $\mathrm{D}$ & & & & 45 & & US & $\mathrm{N}$ & FA \\
\hline Levinson \& Rodebaugh (2011) & 323 & IPIP & 4 & & & $\mathrm{P}$ & & 68 & 19 & US & $\mathrm{N}$ & FA \\
\hline Lönnqvist \& Itkonen (2014) & 4701 & Adjectives & 6 & $\mathrm{D}$ & & & & 66 & 33 & FI & $\mathrm{N}$ & FA \\
\hline Losoncz (2007) & 10512 & Adjectives & 6 & $\mathrm{O}$ & & & & 53 & 44 & $\mathrm{AU}$ & $\mathrm{N}$ & FA \\
\hline Luhmann et al. (2014) & 414 & BFI & 2 & $\mathrm{D}$ & $\mathrm{P}$ & $\mathrm{P}$ & & 64 & 35 & US & $\mathrm{N}$ & FA \\
\hline Margolis et al. (2018) Study 3 & 407 & BFI & 3 & $\mathrm{O}$ & $\mathrm{O}$ & $\mathrm{O}$ & & 62 & 36 & I & $\mathrm{N}$ & CA \\
\hline Martinez-Molina \& Arias (2018) & 278 & IPIP & 4 & $\mathrm{D}$ & $\mathrm{P}$ & $\mathrm{P}$ & & 71 & 22 & ES & $\mathrm{N}$ & $\mathrm{AD}$ \\
\hline McMahan et al. (2013) & 464 & TIPI & 2 & $\mathrm{D}$ & $\mathrm{P}$ & $\mathrm{P}$ & $\mathrm{W}$ & 65 & 21 & US & $\mathrm{N}$ & FA \\
\hline Montasem et al. (2013) & 218 & TIPI & 2 & $\mathrm{D}$ & $\mathrm{P}$ & $\mathrm{P}$ & & 58 & 22 & GB & $\mathrm{N}$ & FA \\
\hline Morsunbul (2014) & 793 & Other & 6 & $\mathrm{D}$ & & & & 64 & 18 & TR & $\mathrm{N}$ & FA \\
\hline Naukkarinen et al. (2016) & 187 & TIPI & 2 & $\mathrm{D}$ & & & & & & FI & $\mathrm{N}$ & FA \\
\hline $\mathrm{Ng}(2015)$ & 1972 & BFI & 2 & $\mathrm{O}$ & & & & 55 & 42 & SG & $\mathrm{N}$ & FA \\
\hline Nishimura \& Suzuki (2016) & 463 & Other & 5 & $\mathrm{D}$ & & & & 36 & 19 & $\mathrm{JP}$ & $\mathrm{N}$ & FA \\
\hline Oishi et al. (2012) African American & 33 & Other & 5 & $\mathrm{D}$ & $\mathrm{O}$ & $\mathrm{O}$ & & 76 & & US & $\mathrm{N}$ & FA \\
\hline Oishi et al. (2012) Asian American & 46 & Other & 5 & $\mathrm{D}$ & $\mathrm{O}$ & $\mathrm{O}$ & & 76 & & US & $\mathrm{N}$ & FA \\
\hline Oishi et al. (2012) European American & 41 & Other & 5 & $\mathrm{D}$ & $\mathrm{O}$ & $\mathrm{O}$ & & 76 & & US & $\mathrm{N}$ & FA \\
\hline Oishi et al. (2018) & 1546 & BFI & 2 & $\mathrm{O}$ & & & & 52 & 61 & $\mathrm{JP}$ & $\mathrm{N}$ & $\mathrm{CA}$ \\
\hline Pavot et al. (1998) Study 3 & 66 & NEO & 12 & $\mathrm{O}$ & & & & 61 & 79 & US & $\mathrm{N}$ & FA \\
\hline Rammstedt et al. (2018) & 1338 & BFI & 6 & $\mathrm{O}$ & & & & 50 & 43 & $\mathrm{DE}$ & $\mathrm{N}$ & FA \\
\hline Reich et al. (2019) & 223 & TIPI & 2 & $\mathrm{D}$ & & & & 77 & 21 & US & $\mathrm{N}$ & FA \\
\hline Rigby \& Huebner (2005) & 211 & Other & 5 & $\mathrm{O}$ & & & & 51 & 16 & US & $\mathrm{N}$ & FA \\
\hline $\begin{array}{l}\text { Robinson et al. (2010) Approaching } \\
\text { Retirement }\end{array}$ & 86 & TIPI & 2 & $\mathrm{D}$ & & & & 54 & 61 & GB & $\mathrm{N}$ & FA \\
\hline Robinson et al. (2010) In Retirement & 279 & TIPI & 2 & $\mathrm{D}$ & & & & 54 & 64 & GB & $\mathrm{N}$ & FA \\
\hline Rodgers et al. (2018) & 244 & TIPI & 2 & $\mathrm{D}$ & & & $\mathrm{W}$ & 77 & 25 & I & $\mathrm{N}$ & CA \\
\hline Ryan et al. (2017) & 716 & Other & 6 & & $\mathrm{P}$ & $\mathrm{P}$ & & 55 & 62 & US & $\mathrm{N}$ & FA \\
\hline Saeki et al. (2014) & 404 & BFI & 4 & $\mathrm{O}$ & $\mathrm{O}$ & $\mathrm{O}$ & & 43 & 20 & $\mathrm{JP}$ & $\mathrm{N}$ & FA \\
\hline Saiz et al. (2011) & 655 & Other & 12 & $\mathrm{O}$ & & & & & & ES & $\mathrm{N}$ & $\mathrm{CA}$ \\
\hline Schimmack et al. (2008) & 1053 & BFI & 3 & $\mathrm{O}$ & & & & & & $\mathrm{DE}$ & $\mathrm{N}$ & FA \\
\hline Schoeps et al. (2016) Female & 182 & BFI & 2 & $\mathrm{D}$ & & & & 100 & 42 & ES & $\mathrm{N}$ & FA \\
\hline Schoeps et al. (2016) Male & 182 & BFI & 2 & $\mathrm{D}$ & & & & 0 & 44 & ES & $\mathrm{N}$ & FA \\
\hline Seder \& Oishi (2012) Study 1 & 48 & Other & 1 & $\mathrm{D}$ & & & & 58 & & US & $\mathrm{N}$ & FA \\
\hline Seder \& Oishi (2012) Study 2 & 36 & Other & 1 & $\mathrm{D}$ & & & & 64 & & US & $\mathrm{N}$ & FA \\
\hline Selvarajan et al. (2016) & 1130 & Adjectives & 7 & & & $\mathrm{P}$ & & 51 & 50 & US & $\mathrm{N}$ & FA \\
\hline Sibley et al. (2011) & 21219 & IPIP & 4 & $\mathrm{O}$ & & & & 59 & 47 & $\mathrm{NZ}$ & $\mathrm{N}$ & $\mathrm{CA}$ \\
\hline Sodermans \& Matthijs (2014) & 506 & BFI & 9 & $\mathrm{O}$ & & & & 49 & 18 & $\mathrm{BE}$ & $\mathrm{N}$ & FA \\
\hline Soto \& Luhmann (2013) BHPS & 13825 & BFI & 3 & $\mathrm{O}$ & & & & 55 & 48 & GB & $\mathrm{N}$ & CA \\
\hline Tartaglia et al. (2017) & 600 & Other & 1 & $\mathrm{D}$ & & & & 40 & 22 & IT & $\mathrm{N}$ & FA \\
\hline Tian \& Zheng (2007) & 1151 & Other & 5 & $\mathrm{O}$ & & & & 48 & & $\mathrm{CN}$ & $\mathrm{N}$ & FA \\
\hline Vollmann et al. (2016) & 158 & BFI & 2 & $\mathrm{O}$ & & & & 68 & 56 & $\mathrm{DE}$ & $\mathrm{N}$ & FA \\
\hline Wang et al. (2017) & 545 & IPIP & 4 & $\mathrm{D}$ & & & & 28 & 20 & $\mathrm{CN}$ & $\mathrm{N}$ & $\mathrm{CA}$ \\
\hline Whisman et al. (2006) Female & 416 & NEO & 12 & $\mathrm{O}$ & & & & 100 & 68 & US & $\mathrm{N}$ & FA \\
\hline Whisman et al. (2006) Male & 416 & NEO & 12 & $\mathrm{O}$ & & & & 0 & 72 & US & $\mathrm{N}$ & FA \\
\hline Wicker (2016) & 183 & TIPI & 2 & $\mathrm{D}$ & & & & 80 & & US & $\mathrm{N}$ & FA \\
\hline Wigert (2002) & 125 & $\mathrm{NEO}$ & 12 & $\mathrm{O}$ & & & & 57 & 53 & US & $\mathrm{N}$ & FA \\
\hline
\end{tabular}

Note. Items indicates the rounded mean number of items per personality factor. SWL indicates whether life satisfaction was measured using either $\mathrm{D}=$ Diener's Satisfaction with Life Scale or $\mathrm{O}=$ other measure. PA and NA indicates whether the positive and negative affect measures were measured with either $\mathrm{P}=$ PANAS or $\mathrm{O}=$ other measure. $\mathrm{PWB}$ is $\mathrm{W}$ when $\mathrm{PWB}$ was measured in the study. A blank cell for SWL, PA, NA, or PWB indicates that the construct was not measured in the study in a way that met inclusion criteria for this meta-analysis. F indicates the percentage of females in the sample. Age is the mean age of the sample. Country is the 2-digit ISO country code, and "I" indicates a multi-country English-speaking Internet sample. Core is coded C = Core and $\mathrm{N}=$ Noncore, where core studies included at least one correlation involving a 
personality scale with at least 8 items per factor and a well-being measure with at least 5 items. Source indicates the source of the correlations using the following codes: FA = From article, AD = Accompanying dataset, $\mathrm{CA}=$ Correlations provided following contact with the author, $\mathrm{DA}=$ Data was provided following contact with the author, $\mathrm{HM}=$ otherwise unpublished correlations taken from the Heller et al. (2004) Meta-Analysis. Further details about the nature of the sample in each study are provided in the online repository that accompanies this paper. Samples where HEXACO and Big Five were measured are treated as two separate studies for reporting purposes. 
Table 3

Combined Sample Sizes and Number of Studies across Study Features

\begin{tabular}{|c|c|c|c|c|c|c|}
\hline \multirow[b]{2}{*}{ Category } & \multicolumn{2}{|c|}{ Combined } & \multicolumn{2}{|l|}{ Core } & \multicolumn{2}{|l|}{ Noncore } \\
\hline & $\mathrm{n}$ & $\mathrm{k}$ & $\mathrm{n}$ & $\mathrm{k}$ & $\mathrm{n}$ & $\mathrm{k}$ \\
\hline Total & 334567 & 462 & 206364 & 370 & 128203 & 92 \\
\hline \multicolumn{7}{|l|}{ Personality Items } \\
\hline Extra Short 1 to 3 & 47941 & 45 & & & 47941 & 45 \\
\hline Short 4 to 7 & 75012 & 30 & & & 75012 & 30 \\
\hline Standard 8 to 15 & 180646 & 292 & 175396 & 275 & 5250 & 17 \\
\hline Long 16 or more & 30968 & 95 & 30968 & 95 & & \\
\hline \multicolumn{7}{|l|}{ Measure Type } \\
\hline HEXACO & 7146 & 22 & 6566 & 19 & 580 & 3 \\
\hline NEO & 64398 & 170 & 61767 & 161 & 2631 & 9 \\
\hline IPIP & 44359 & 43 & 20120 & 35 & 24239 & 8 \\
\hline BFAS & 3442 & 8 & 3442 & 8 & & \\
\hline BFI & 131342 & 125 & 87251 & 93 & 44091 & 32 \\
\hline TIPI & 4847 & 17 & & & 4847 & 17 \\
\hline Adjectives & 45290 & 28 & 10580 & 20 & 34710 & 8 \\
\hline Other & 33743 & 49 & 16638 & 34 & 17105 & 15 \\
\hline \multicolumn{7}{|l|}{ Year } \\
\hline Pre-2000 & 7256 & 30 & 6604 & 27 & 652 & 3 \\
\hline $2000-2004$ & 23903 & 49 & 22984 & 47 & 919 & 2 \\
\hline $2005-2009$ & 30664 & 51 & 12282 & 39 & 18382 & 12 \\
\hline $2010-2014$ & 106176 & 146 & 42598 & 112 & 63578 & 34 \\
\hline $2015-2019$ & 166568 & 186 & 121896 & 145 & 44672 & 41 \\
\hline \multicolumn{7}{|l|}{ Sample Size } \\
\hline Under 100 & 2239 & 36 & 1689 & 27 & 550 & 9 \\
\hline $100-199$ & 16288 & 111 & 14329 & 99 & 1959 & 12 \\
\hline $200-299$ & 23904 & 99 & 19230 & 80 & 4674 & 19 \\
\hline $300-499$ & 38454 & 102 & 32344 & 87 & 6110 & 15 \\
\hline $500-999$ & 47609 & 70 & 37520 & 56 & 10089 & 14 \\
\hline 1000 or more & 206073 & 44 & 101252 & 21 & 104821 & 23 \\
\hline \multicolumn{7}{|l|}{ Mean Age } \\
\hline Under 18 & 13722 & 29 & 10753 & 23 & 2969 & 6 \\
\hline 18 to 29 & 65597 & 192 & 49522 & 155 & 16075 & 37 \\
\hline 30 to 59 & 213033 & 147 & 127288 & 122 & 85745 & 25 \\
\hline 60 or over & 21082 & 29 & 4406 & 18 & 16676 & 11 \\
\hline
\end{tabular}

Note. Correlations between a trait and a well-being variable were classified as core if the personality trait was measured with 8 or more items and the well-being variable was measured with five or more items. Studies were classified as core if they had one or more core correlation. 
Table 4

Meta-Analytic Correlations of Big Five and HEXACO Personality with SWB and PWB

\begin{tabular}{lrrrrrrrrrr}
\hline & SWL & PA & NA & PR & AU & EM & PG & PL & SA & $\begin{array}{c}\text { Mea } \\
n\end{array}$ \\
\hline NEO & & & & & & & & & & \\
Neuroticism & $\mathbf{- . 3 9}$ & $\mathbf{- . 3 4}$ & $\mathbf{. 5 6}$ & $\mathbf{- . 4 3}$ & $\mathbf{- . 4 5}$ & $\mathbf{- . 5 8}$ & $\mathbf{- . 3 4}$ & $\mathbf{- . 4 5}$ & $\mathbf{- . 6 0}$ & $\mathbf{- . 4 6}$ \\
Extraversion & $\mathbf{. 3 2}$ & $\mathbf{. 4 4}$ & -.21 & $\mathbf{. 4 7}$ & .26 & $\mathbf{. 3 8}$ & $\mathbf{. 3 9}$ & $\mathbf{. 3 9}$ & $\mathbf{. 4 3}$ & $\mathbf{. 3 7}$ \\
Openness & .08 & .24 & -.05 & .20 & .24 & .11 & $\mathbf{. 4 4}$ & .21 & .16 & .19 \\
Agreeableness & .20 & .19 & -.25 & $\mathbf{. 3 9}$ & .10 & .28 & $\mathbf{. 3 1}$ & .28 & .28 & .25 \\
Conscientiousness & .27 & $\mathbf{. 3 5}$ & -.25 & $\mathbf{. 3 2}$ & $\mathbf{. 3 0}$ & $\mathbf{. 5 1}$ & $\mathbf{. 3 2}$ & $\mathbf{. 5 0}$ & $\mathbf{. 4 4}$ & $\mathbf{. 3 6}$ \\
HEXACO & & & & & & & & & & \\
$\quad$ Honesty-Humility & .11 & .07 & -.15 & .20 & .19 & .20 & .21 & .18 & .14 & .16 \\
Emotionality & -.09 & -.12 & $\mathbf{. 3 1}$ & .01 & $\mathbf{- . 3 6}$ & -.19 & -.11 & -.03 & -.24 & -.16 \\
Extraversion & $\mathbf{. 4 3}$ & $\mathbf{. 5 5}$ & $\mathbf{- . 3 9}$ & $\mathbf{. 5 7}$ & $\mathbf{. 3 9}$ & $\mathbf{. 5 2}$ & $\mathbf{. 4 5}$ & $\mathbf{. 4 1}$ & $\mathbf{. 6 1}$ & $\mathbf{. 4 8}$ \\
$\quad$ Agreeableness & .17 & .14 & -.25 & .27 & .02 & .22 & .16 & .13 & .23 & .18 \\
Conscientiousness & .22 & $\mathbf{. 3 2}$ & -.17 & .18 & .23 & $\mathbf{. 4 1}$ & $\mathbf{. 3 1}$ & $\mathbf{. 4 7}$ & .23 & .28 \\
Openness & .10 & .15 & -.01 & .14 & .25 & .10 & $\mathbf{. 3 4}$ & .14 & .18 & .16 \\
\hline
\end{tabular}

Note. $\mathrm{SWL}=$ satisfaction with life, $\mathrm{PA}=$ positive affect, $\mathrm{NA}=$ negative affect, $\mathrm{PR}=$ positive relations, $\mathrm{AU}=$ autonomy, $\mathrm{EM}=$ environmental mastery, $\mathrm{PG}=$ personal growth, $\mathrm{PL}=$ purpose in life, $\mathrm{SA}=$ self-acceptance. Absolute correlations above .30 are bolded. Mean is the mean correlation between the personality trait and well-being variables, where the correlation with negative affect (NA) is reversed. 
Table 5

Detailed Meta-Analytic results for Big Five Domains and Subjective Well-being

\begin{tabular}{|c|c|c|c|c|c|c|c|c|c|c|}
\hline & $k$ & $n$ & $\bar{r}$ & $\tau_{\bar{r}}$ & $\begin{array}{l}\text { Lower } \\
95 \% \mathrm{CI} \\
\bar{r}\end{array}$ & $\begin{array}{l}\text { Upper } \\
95 \% \mathrm{CI} \\
\bar{r}\end{array}$ & $\rho$ & $\tau_{\rho}$ & $\begin{array}{l}\text { Lower } \\
95 \% \text { CI } \\
\rho\end{array}$ & $\begin{array}{l}\text { Upper } \\
95 \% \text { CI } \\
\rho\end{array}$ \\
\hline \multicolumn{11}{|l|}{ Satisfaction with Life } \\
\hline Neuroticism & 224 & 158934 & -.39 & .10 & -.41 & -.38 & -.46 & .13 & -.48 & -.44 \\
\hline Extraversion & 219 & 158905 & .32 & .08 & .31 & .33 & .38 & .11 & .36 & .39 \\
\hline Openness & 194 & 146668 & .08 & .08 & .07 & .10 & .10 & .11 & .08 & .12 \\
\hline Agreeableness & 188 & 145623 & .20 & .07 & .19 & .21 & .24 & .10 & .23 & .26 \\
\hline Conscientiousness & 196 & 149681 & .27 & .07 & .26 & .28 & .31 & .09 & .30 & .33 \\
\hline \multicolumn{11}{|l|}{ Positive Affect } \\
\hline Neuroticism & 167 & 54816 & -.34 & .11 & -.36 & -.32 & -.39 & .13 & -.41 & -.36 \\
\hline Extraversion & 157 & 51731 & .44 & .10 & .42 & .46 & .51 & .13 & .49 & .53 \\
\hline Openness & 123 & 41406 & .24 & .13 & .21 & .26 & .28 & .15 & .25 & .31 \\
\hline Agreeableness & 122 & 40714 & .19 & .13 & .16 & .21 & .22 & .16 & .19 & .25 \\
\hline Conscientiousness & 128 & 43497 & .35 & .10 & .33 & .37 & .40 & .12 & .38 & .43 \\
\hline \multicolumn{11}{|l|}{ Negative Affect } \\
\hline Neuroticism & 172 & 55495 & .56 & .11 & .55 & .58 & .65 & .13 & .63 & .67 \\
\hline Extraversion & 152 & 49212 & -.21 & .10 & -.22 & -.19 & -.24 & .12 & -.26 & -.22 \\
\hline Openness & 121 & 39538 & -.05 & .08 & -.07 & -.03 & -.06 & .10 & -.08 & -.04 \\
\hline Agreeableness & 120 & 39023 & -.25 & .11 & -.28 & -.23 & -.30 & .14 & -.33 & -.28 \\
\hline Conscientiousness & 128 & 42358 & -.25 & .11 & -.27 & -.22 & -.29 & .14 & -.31 & -.26 \\
\hline
\end{tabular}

Note. Only core studies using at least 8 items per personality factor and at least 5 items for wellbeing were included. $k$ is the number of studies. $\bar{r}$ is mean observed correlation estimated from random-effects model and inverse-variance weighting. $\rho$ is the equivalent correlation estimated using correlations corrected for measurement error. $\tau_{\bar{r}}$ and $\tau_{\rho}$ are the estimated standard deviations of true unadjusted and corrected correlations, respectively. 
Table 6

Detailed Meta-Analytic results for Big Five Domains and Psychological Well-being

\begin{tabular}{|c|c|c|c|c|c|c|c|c|c|c|}
\hline & $k$ & $n$ & $\bar{r}$ & $\tau_{\bar{r}}$ & $\begin{array}{l}\text { Lower } \\
95 \% \mathrm{CI} \\
\bar{r}\end{array}$ & $\begin{array}{l}\text { Upper } \\
95 \% \mathrm{CI} \\
\bar{r}\end{array}$ & $\rho$ & $\tau_{\rho}$ & $\begin{array}{l}\text { Lower } \\
95 \% \text { CI } \\
\rho\end{array}$ & $\begin{array}{l}\text { Upper } \\
95 \% \mathrm{CI} \\
\rho\end{array}$ \\
\hline \multicolumn{11}{|c|}{ Positive relation with others } \\
\hline Neuroticism & 18 & 6440 & -.43 & .11 & -.49 & -.37 & -.51 & .14 & -.57 & -.44 \\
\hline Extraversion & 19 & 6840 & .47 & .12 & .41 & .53 & .56 & .15 & .49 & .63 \\
\hline Openness & 17 & 6233 & .20 & .09 & .15 & .25 & .24 & .12 & .17 & .30 \\
\hline Agreeableness & 17 & 6233 & .39 & .09 & .34 & .44 & .47 & .12 & .41 & .53 \\
\hline Conscientiousness & 18 & 6440 & .32 & .12 & .26 & .38 & .38 & .16 & .30 & .46 \\
\hline \multicolumn{11}{|l|}{ Autonomy } \\
\hline Neuroticism & 17 & 6309 & -.45 & .08 & -.50 & -.41 & -.54 & .11 & -.60 & -.49 \\
\hline Extraversion & 17 & 6309 & .26 & .10 & .20 & .32 & .31 & .13 & .25 & .38 \\
\hline Openness & 16 & 6102 & .24 & .09 & .18 & .29 & .29 & .13 & .23 & .36 \\
\hline Agreeableness & 16 & 6102 & .10 & .11 & .04 & .16 & .13 & .14 & .05 & .20 \\
\hline Conscientiousness & 17 & 6309 & .30 & .05 & .27 & .34 & .36 & .07 & .32 & .41 \\
\hline \multicolumn{11}{|l|}{ Environmental mastery } \\
\hline Neuroticism & 16 & 6160 & -.58 & .11 & -.64 & -.52 & -.69 & .13 & -.76 & -.63 \\
\hline Extraversion & 16 & 6160 & .38 & .14 & .31 & .45 & .45 & .16 & .37 & .53 \\
\hline Openness & 15 & 5953 & .11 & .11 & .04 & .17 & .13 & .15 & .04 & .21 \\
\hline Agreeableness & 15 & 5953 & .28 & .10 & .22 & .34 & .35 & .13 & .27 & .42 \\
\hline Conscientiousness & 16 & 6160 & .51 & .10 & .45 & .56 & .61 & .11 & .55 & .67 \\
\hline \multicolumn{11}{|l|}{ Personal growth } \\
\hline Neuroticism & 16 & 5920 & -.34 & .11 & -.40 & -.28 & -.41 & .15 & -.49 & -.33 \\
\hline Extraversion & 16 & 5920 & .39 & .09 & .34 & .44 & .47 & .12 & .41 & .54 \\
\hline Openness & 15 & 5713 & .44 & .10 & .39 & .50 & .55 & .12 & .48 & .61 \\
\hline Agreeableness & 15 & 5713 & .31 & .10 & .25 & .36 & .38 & .12 & .31 & .45 \\
\hline Conscientiousness & 16 & 5920 & .32 & .06 & .28 & .36 & .40 & .08 & .35 & .44 \\
\hline \multicolumn{11}{|l|}{ Purpose in life } \\
\hline Neuroticism & 15 & 5699 & -.45 & .12 & -.51 & -.38 & -.53 & .14 & -.61 & -.46 \\
\hline Extraversion & 15 & 5699 & .39 & .10 & .33 & .45 & .47 & .13 & .40 & .54 \\
\hline Openness & 14 & 5492 & .21 & .09 & .15 & .26 & .25 & .13 & .18 & .33 \\
\hline Agreeableness & 14 & 5492 & .28 & .06 & .24 & .32 & .35 & .09 & .29 & .40 \\
\hline Conscientiousness & 15 & 5699 & .50 & .10 & .44 & .55 & .60 & .10 & .54 & .66 \\
\hline \multicolumn{11}{|l|}{ Self-acceptance } \\
\hline Neuroticism & 14 & 5488 & -.60 & .13 & -.67 & -.53 & -.69 & .15 & -.77 & -.61 \\
\hline Extraversion & 14 & 5488 & .43 & .11 & .37 & .49 & .50 & .13 & .43 & .57 \\
\hline Openness & 13 & 5281 & .16 & .10 & .10 & .23 & .19 & .13 & .11 & .27 \\
\hline Agreeableness & 13 & 5281 & .28 & .06 & .24 & .32 & .35 & .09 & .29 & .41 \\
\hline Conscientiousness & 14 & 5488 & .44 & .05 & .40 & .47 & .51 & .08 & .46 & .56 \\
\hline
\end{tabular}


Table 7

Detailed Meta-Analytic Results for HEXACO Domains and Subjective Well-being

\begin{tabular}{|c|c|c|c|c|c|c|c|c|c|c|}
\hline & $\mathrm{k}$ & $\mathrm{n}$ & $\bar{r}$ & $\tau_{\bar{r}}$ & $\begin{array}{l}\text { Lower } \\
95 \% \mathrm{CI} \\
\bar{r}\end{array}$ & $\begin{array}{l}\text { Upper } \\
95 \% \mathrm{CI} \\
\bar{r} \\
\end{array}$ & $\rho$ & $\tau_{\rho}$ & $\begin{array}{l}\text { Lower } \\
95 \% \text { CI } \\
\rho \\
\end{array}$ & $\begin{array}{l}\text { Upper } \\
95 \% \text { CI } \\
\rho\end{array}$ \\
\hline \multicolumn{11}{|l|}{ Satisfaction with Life } \\
\hline Honesty-Humility & 14 & 4049 & .11 & .00 & .08 & .14 & .13 & .00 & .10 & .16 \\
\hline Emotionality & 14 & 4049 & -.09 & .07 & -.14 & -.04 & -.11 & .09 & -.16 & -.05 \\
\hline Extraversion & 14 & 4049 & .43 & .07 & .39 & .48 & .51 & .09 & .46 & .56 \\
\hline Agreeableness & 14 & 4049 & .17 & .06 & .13 & .22 & .21 & .08 & .15 & .26 \\
\hline Conscientiousness & 14 & 4049 & .22 & .00 & .19 & .25 & .27 & .02 & .24 & .30 \\
\hline Openness & 14 & 4049 & .10 & .12 & .03 & .17 & .11 & .14 & .03 & .19 \\
\hline \multicolumn{11}{|l|}{ Positive Affect } \\
\hline Honesty-Humility & 8 & 3834 & .07 & .05 & .02 & .13 & .09 & .06 & .03 & .14 \\
\hline Emotionality & 8 & 3834 & -.12 & .05 & -.17 & -.06 & -.15 & .09 & -.22 & -.08 \\
\hline Extraversion & 8 & 3834 & .55 & .04 & .51 & .58 & .63 & .05 & .59 & .67 \\
\hline Agreeableness & 8 & 3834 & .14 & .09 & .07 & .21 & .17 & .10 & .09 & .25 \\
\hline Conscientiousness & 8 & 3834 & .32 & .10 & .25 & .40 & .38 & .12 & .29 & .47 \\
\hline Openness & 8 & 3834 & .15 & .04 & .10 & .20 & .17 & .05 & .13 & .22 \\
\hline \multicolumn{11}{|l|}{ Negative Affect } \\
\hline Honesty-Humility & 9 & 4134 & -.15 & .05 & -.20 & -.11 & -.18 & .06 & -.23 & -.13 \\
\hline Emotionality & 9 & 4134 & .31 & .09 & .24 & .37 & .36 & .11 & .28 & .44 \\
\hline Extraversion & 9 & 4134 & -.39 & .11 & -.47 & -.32 & -.46 & .13 & -.55 & -.37 \\
\hline Agreeableness & 9 & 4134 & -.25 & .07 & -.31 & -.19 & -.30 & .09 & -.36 & -.23 \\
\hline Conscientiousness & 9 & 4134 & -.17 & .09 & -.24 & -.10 & -.20 & .11 & -.28 & -.12 \\
\hline Openness & 9 & 4134 & -.01 & .02 & -.04 & .03 & -.01 & .04 & -.05 & .03 \\
\hline
\end{tabular}


Table 8

Detailed Meta-Analytic results for HEXACO Domains and Psychological Well-being

\begin{tabular}{|c|c|c|c|c|c|c|c|c|c|c|}
\hline & $\mathrm{k}$ & $\mathrm{n}$ & $\bar{r}$ & $\tau_{\bar{r}}$ & $\begin{array}{l}\text { Lower } \\
95 \% \mathrm{CI} \\
\bar{r}\end{array}$ & $\begin{array}{l}\text { Upper } \\
95 \% \mathrm{CI} \\
\bar{r}\end{array}$ & $\rho$ & $\tau_{\rho}$ & $\begin{array}{l}\text { Lower } \\
95 \% \text { CI } \\
\rho\end{array}$ & $\begin{array}{l}\text { Upper } \\
95 \% \mathrm{CI} \\
\rho \\
\end{array}$ \\
\hline \multicolumn{11}{|c|}{ Positive relation with others } \\
\hline Honesty-Humility & 5 & 2033 & .20 & .00 & .16 & .24 & .24 & .00 & .20 & .28 \\
\hline Emotionality & 5 & 2033 & .01 & .09 & -.08 & .09 & .00 & .12 & -.11 & .12 \\
\hline Extraversion & 5 & 2033 & .57 & .04 & .52 & .61 & .68 & .00 & .66 & .70 \\
\hline Agreeableness & 5 & 2033 & .27 & .04 & .21 & .32 & .33 & .06 & .26 & .40 \\
\hline Conscientiousness & 5 & 2033 & .18 & .00 & .14 & .22 & .22 & .02 & .17 & .27 \\
\hline Openness & 5 & 2033 & .14 & .00 & .10 & .19 & .18 & .05 & .12 & .25 \\
\hline \multicolumn{11}{|l|}{ Autonomy } \\
\hline Honesty-Humility & 5 & 2033 & .19 & .05 & .13 & .25 & .24 & .06 & .17 & .31 \\
\hline Emotionality & 5 & 2033 & -.36 & .00 & -.40 & -.32 & -.45 & .00 & -.48 & -.41 \\
\hline Extraversion & 5 & 2033 & .39 & .00 & .36 & .43 & .49 & .02 & .45 & .53 \\
\hline Agreeableness & 5 & 2033 & .02 & .07 & -.05 & .10 & .03 & .09 & -.06 & .12 \\
\hline Conscientiousness & 5 & 2033 & .23 & .05 & .17 & .29 & .29 & .06 & .22 & .36 \\
\hline Openness & 5 & 2033 & .25 & .05 & .19 & .32 & .32 & .07 & .24 & .39 \\
\hline \multicolumn{11}{|l|}{ Environmental mastery } \\
\hline Honesty-Humility & 5 & 2033 & .20 & .02 & .15 & .25 & .26 & .06 & .19 & .32 \\
\hline Emotionality & 5 & 2033 & -.19 & .09 & -.28 & -.10 & -.23 & .10 & -.33 & -.13 \\
\hline Extraversion & 5 & 2033 & .52 & .08 & .44 & .61 & .64 & .09 & .56 & .72 \\
\hline Agreeableness & 5 & 2033 & .22 & .07 & .14 & .30 & .27 & .09 & .18 & .37 \\
\hline Conscientiousness & 5 & 2033 & .41 & .07 & .34 & .49 & .51 & .11 & .41 & .61 \\
\hline Openness & 5 & 2033 & .10 & .08 & .01 & .19 & .12 & .11 & .01 & .23 \\
\hline \multicolumn{11}{|l|}{ Personal growth } \\
\hline Honesty-Humility & 5 & 2033 & .21 & .07 & .13 & .29 & .27 & .10 & .17 & .37 \\
\hline Emotionality & 5 & 2033 & -.11 & .00 & -.15 & -.06 & -.14 & .05 & -.20 & -.07 \\
\hline Extraversion & 5 & 2033 & .45 & .04 & .40 & .50 & .56 & .00 & .53 & .59 \\
\hline Agreeableness & 5 & 2033 & .16 & .04 & .10 & .21 & .20 & .05 & .14 & .26 \\
\hline Conscientiousness & 5 & 2033 & .31 & .02 & .26 & .35 & .40 & .05 & .35 & .46 \\
\hline Openness & 5 & 2033 & .34 & .05 & .28 & .41 & .43 & .09 & .35 & .52 \\
\hline \multicolumn{11}{|l|}{ Purpose in life } \\
\hline Honesty-Humility & 5 & 2033 & .18 & .00 & .13 & .22 & .24 & .06 & .17 & .31 \\
\hline Emotionality & 5 & 2033 & -.03 & .04 & -.09 & .03 & -.03 & .05 & -.10 & .04 \\
\hline Extraversion & 5 & 2033 & .41 & .08 & .33 & .49 & .52 & .06 & .46 & .59 \\
\hline Agreeableness & 5 & 2033 & .13 & .07 & .05 & .21 & .17 & .09 & .08 & .27 \\
\hline Conscientiousness & 5 & 2033 & .47 & .00 & .43 & .50 & .60 & .04 & .55 & .64 \\
\hline Openness & 5 & 2033 & .14 & .00 & .10 & .19 & .19 & .02 & .15 & .24 \\
\hline \multicolumn{11}{|l|}{ Self-acceptance } \\
\hline Honesty-Humility & 5 & 2033 & .14 & .02 & .10 & .19 & .18 & .03 & .12 & .23 \\
\hline Emotionality & 5 & 2033 & -.24 & .00 & -.29 & -.20 & -.31 & .06 & -.37 & -.24 \\
\hline Extraversion & 5 & 2033 & .61 & .03 & .57 & .64 & .74 & .03 & .71 & .78 \\
\hline Agreeableness & 5 & 2033 & .23 & .06 & .17 & .30 & .29 & .07 & .21 & .37 \\
\hline Conscientiousness & 5 & 2033 & .23 & .07 & .15 & .30 & .27 & .09 & .18 & .36 \\
\hline Openness & 5 & 2033 & .18 & .10 & .08 & .27 & .22 & .14 & .09 & .35 \\
\hline
\end{tabular}


Table 9

Meta-Analytic Correlations between Big Five Personality and Subjective Well-Being by Study Type, Number of Personality Items, Personality Measure Type, and Comparison with Past MetaAnalyses

\begin{tabular}{|c|c|c|c|c|c|c|c|c|c|c|c|c|c|c|c|c|c|}
\hline \multirow[b]{2}{*}{ Personality Items } & \multicolumn{5}{|c|}{ SWL } & \multicolumn{5}{|c|}{ PA } & \multicolumn{5}{|c|}{ NA } & \multirow[b]{2}{*}{ Mean } & \multirow[b]{2}{*}{ SD } \\
\hline & $\mathrm{N}$ & E & $\mathrm{O}$ & A & $\mathrm{C}$ & $\mathrm{N}$ & E & $\mathrm{O}$ & A & $\mathrm{C}$ & $\mathrm{N}$ & E & $\mathrm{O}$ & A & $\mathrm{C}$ & & \\
\hline \multicolumn{18}{|l|}{ Study Status } \\
\hline Core Studies & -.39 & .32 & .08 & .20 & .27 & -.34 & .44 & .24 & .19 & .35 & .56 & -.21 & -.05 & -.25 & -.25 & .28 & .13 \\
\hline Noncore Studies & -.32 & .24 & .09 & .18 & .21 & -.36 & .40 & .27 & .24 & .26 & .53 & -.20 & -.08 & -.14 & -.24 & .25 & .12 \\
\hline \multicolumn{18}{|l|}{ Personality Items } \\
\hline Extra Short 1 to 3 & -.31 & .22 & .08 & .15 & .20 & -.34 & .33 & .20 & .12 & .23 & .46 & -.20 & -.05 & -.13 & -.21 & .22 & .11 \\
\hline Short 4 to 7 & -.32 & .27 & .14 & .19 & .23 & -.32 & .45 & .36 & .33 & .28 & .55 & -.18 & -.10 & -.12 & -.23 & .27 & .12 \\
\hline Standard 8 to 15 & -.38 & .31 & .09 & .21 & .26 & -.34 & .43 & .25 & .22 & .36 & .57 & -.20 & -.07 & -.27 & -.26 & .28 & .13 \\
\hline Long 16 or more & -.42 & .33 & .06 & .18 & .29 & -.35 & .46 & .19 & .11 & .31 & .57 & -.22 & -.01 & -.20 & -.22 & .26 & .15 \\
\hline \multicolumn{18}{|l|}{ Measure Type } \\
\hline NEO & -.42 & .34 & .05 & .17 & .28 & -.32 & .44 & .18 & .10 & .36 & .56 & -.20 & -.02 & -.20 & -.21 & .26 & .15 \\
\hline IPIP & -.38 & .28 & .09 & .19 & .25 & -.36 & .38 & .20 & .23 & .33 & .54 & -.21 & -.05 & -.23 & -.28 & .27 & .12 \\
\hline BFAS & -.43 & .37 & .06 & .14 & .31 & -.41 & .57 & .27 & .24 & .42 & .65 & -.34 & -.12 & -.24 & -.27 & .32 & .16 \\
\hline BFI & -.34 & .27 & .09 & .20 & .23 & -.37 & .43 & .28 & .24 & .34 & .57 & -.20 & -.06 & -.31 & -.29 & .28 & .13 \\
\hline TIPI & -.31 & .22 & .10 & .14 & .19 & -.32 & .38 & .27 & .09 & .19 & .39 & -.26 & -.16 & -.01 & -.22 & .22 & .11 \\
\hline Adjectives & -.35 & .26 & .06 & .21 & .23 & -.29 & .46 & .33 & .23 & .33 & .57 & -.22 & -.10 & -.19 & -.24 & .27 & .13 \\
\hline Other & -.34 & .31 & .17 & .25 & .25 & -.34 & .46 & .31 & .26 & .27 & .58 & -.17 & -.09 & -.15 & -.12 & .27 & .13 \\
\hline \multicolumn{18}{|l|}{ Meta-Analyses } \\
\hline Current (core) & -.39 & .32 & .08 & .20 & .27 & -.34 & .44 & .24 & .19 & .35 & .56 & -.21 & -.05 & -.25 & -.25 & .28 & .13 \\
\hline DeNeve (1998) & -.24 & .17 & .14 & .16 & .22 & -.14 & .20 & .14 & .17 & .14 & .23 & -.07 & .05 & -.13 & -.10 & .15 & .07 \\
\hline Steel (2008) & -.38 & .28 & .03 & .14 & .22 & -.30 & .44 & .20 & .12 & .27 & .54 & -.18 & -.02 & -.20 & -.20 & .23 & .14 \\
\hline Heller (2004) & -.48 & .28 & .08 & .29 & .31 & & & & & & & & & & & & \\
\hline
\end{tabular}

Note. Current (core) $k=120$ to $224, n=39,023$ to 158,934 ; Heller et al. (2004) $\mathrm{k}=19, n=$ 12,092; Steel et al. (2008) $k=22$ to 57, $n=6,040$ to 16,764; DeNeve and Cooper (1998) $\mathrm{k}=38$ to $102, n$ is a subset of 42,171 . Mean and SD is the mean and standard deviation of correlation after reversing $\mathrm{N}$ with $\mathrm{PA}, \mathrm{N}$ with $\mathrm{SWL}$, and $\mathrm{E}, \mathrm{O}, \mathrm{A}, \mathrm{C}$ with $\mathrm{NA}$. 
Table 10

Correlation Among Well-Being Scales for Combined Dataset (Lower Diagonal) and NEO Dataset (Upper Diagonal)

\begin{tabular}{lrrrrrrrrr}
\hline Variable & 1 & 2 & 3 & 4 & 5 & 6 & 7 & 8 & 9 \\
\hline SWB & & & & & & & & & \\
$\quad$ 1. Life Satisfaction & & .36 & -.29 & .41 & .25 & .51 & .27 & .52 & .65 \\
2. Positive Affect & .52 & & -.09 & .31 & .23 & .40 & .32 & .37 & .36 \\
3. Negative Affect & -.44 & -.39 & & -.32 & -.29 & -.43 & -.21 & -.33 & -.40 \\
PWB & & & & & & & & & \\
4. Positive Relations & .49 & .53 & -.41 & & .45 & .57 & .53 & .58 & .63 \\
5. Autonomy & .16 & .26 & -.42 & .25 & & .55 & .46 & .48 & .56 \\
6. Environmental Mastery & .58 & .60 & -.59 & .61 & .42 & & .47 & .72 & .74 \\
7. Personal Growth & .36 & .51 & -.38 & .53 & .44 & .58 & & .53 & .49 \\
8. Purpose in Life & .55 & .60 & -.49 & .53 & .38 & .76 & .69 & & .73 \\
9. Self-Acceptance & .74 & .63 & -.58 & .60 & .44 & .77 & .60 & .77 & \\
\hline
\end{tabular}

Note. $N=903$ for Combined Dataset; $N=1,673$ for NEO Dataset. 
Table 11

Correlations of NEO Facets with Well-Being Measures in NEO Dataset

\begin{tabular}{|c|c|c|c|c|c|c|c|c|c|c|}
\hline & SWL & $\mathrm{PA}$ & $\mathrm{NA}$ & $\mathrm{PR}$ & $\mathrm{AU}$ & EM & $\mathrm{PG}$ & $\mathrm{PL}$ & $\mathrm{SA}$ & Mean \\
\hline N1. Anxiety & -.28 & -.16 & .31 & -.21 & -.28 & -.34 & -.06 & -.15 & -.38 & -.23 \\
\hline N2. Angry hostility & -.23 & -.14 & .35 & -.39 & -.28 & -.39 & -.20 & -.29 & -.39 & -.29 \\
\hline N3. Depression & -.48 & -.32 & .41 & -.46 & -.41 & -.57 & -.27 & -.49 & -.66 & -.46 \\
\hline N4. Self-consciousness & -.31 & -.27 & .26 & -.40 & -.41 & -.43 & -.22 & -.34 & -.50 & -.36 \\
\hline N5. Impulsiveness & -.15 & -.07 & .19 & -.05 & -.14 & -.23 & .04 & -.15 & -.21 & -.12 \\
\hline N6. Vulnerability & -.39 & -.35 & .36 & -.36 & -.44 & -.60 & -.28 & -.48 & -.59 & -.44 \\
\hline E1. Warmth & .22 & .27 & -.13 & .59 & .24 & .32 & .35 & .31 & .32 & .33 \\
\hline E2. Gregariousness & .19 & .17 & -.07 & .40 & .04 & .14 & .24 & .18 & .18 & .19 \\
\hline E3. Assertiveness & .23 & .28 & -.04 & .31 & .23 & .28 & .22 & .23 & .32 & .26 \\
\hline E4. Activity & .18 & .29 & .02 & .22 & .19 & .25 & .23 & .30 & .25 & .24 \\
\hline E5. Excitement seeking & .00 & .12 & .05 & .07 & -.05 & -.06 & .25 & -.07 & -.03 & .03 \\
\hline E6. Positive emotions & .34 & .31 & -.14 & .49 & .22 & .36 & .42 & .34 & .40 & .36 \\
\hline O1. Fantasy & -.02 & .07 & .06 & .09 & .03 & -.05 & .30 & .01 & .00 & .05 \\
\hline O2. Aesthetics & .00 & .10 & .06 & .10 & .02 & -.02 & .30 & .01 & -.03 & .06 \\
\hline O3. Feelings & .07 & .17 & .04 & .25 & .14 & .13 & .41 & .18 & .12 & .18 \\
\hline O4. Actions & .08 & .13 & -.03 & .19 & .12 & .07 & .43 & .08 & .12 & .15 \\
\hline O5. Ideas & .01 & .19 & -.01 & .09 & .14 & .08 & .37 & .09 & .07 & .13 \\
\hline O6. Values & .02 & .06 & -.11 & .25 & .23 & .12 & .40 & .16 & .13 & .17 \\
\hline A1. Trust & .22 & .16 & -.15 & .41 & .12 & .25 & .17 & .24 & .27 & .23 \\
\hline A2. Straightforwardness & .02 & -.05 & -.15 & .11 & .13 & .08 & .05 & .11 & .07 & .07 \\
\hline A3. Altruism & .18 & .14 & -.16 & .43 & .22 & .28 & .24 & .30 & .26 & .26 \\
\hline A4. Compliance & .05 & -.04 & -.15 & .11 & -.06 & .07 & -.03 & .04 & .08 & .03 \\
\hline A5. Modesty & -.09 & -.13 & -.04 & .05 & .03 & -.06 & .02 & .00 & -.09 & -.03 \\
\hline A6. Tender-mindedness & .07 & .05 & -.11 & .27 & .22 & .17 & .27 & .23 & .18 & .18 \\
\hline C1. Competence & .37 & .33 & -.24 & .35 & .35 & .55 & .28 & .54 & .51 & .41 \\
\hline C2. Order & .15 & .14 & -.04 & .06 & .11 & .30 & .09 & .30 & .17 & .17 \\
\hline C3. Dutifulness & .17 & .16 & -.15 & .17 & .31 & .41 & .17 & .39 & .28 & .26 \\
\hline C4. Achievement striving & .24 & .33 & -.02 & .18 & .24 & .39 & .23 & .46 & .31 & .30 \\
\hline C5. Self-discipline & .28 & .29 & -.19 & .26 & .34 & .55 & .19 & .52 & .43 & .36 \\
\hline C6. Deliberation & .15 & .11 & -.14 & .04 & .09 & .24 & -.04 & .26 & .18 & .13 \\
\hline
\end{tabular}

Note. $N=1,673$. $\mathrm{SWL}=$ satisfaction with life, $\mathrm{PA}=$ positive affect, $\mathrm{NA}=$ negative affect, $\mathrm{PR}=$ positive relations, $\mathrm{AU}=$ autonomy, $\mathrm{EM}=$ environmental mastery, $\mathrm{PG}=$ personal growth, $\mathrm{PL}=$ purpose in life, $\mathrm{SA}=$ self-acceptance. Correlations .30 or above are in bold. Correlations equal to or larger than $.05, .07$ and .09 are significant at $.05, .01$, and .001 respectively. 
Table 12

Correlations between IPIP NEO Facets and Well-Being Measures in Combined Dataset

\begin{tabular}{|c|c|c|c|c|c|c|c|c|c|c|}
\hline & SWL & $\mathrm{PA}$ & NA & $\mathrm{PR}$ & $\mathrm{AU}$ & EM & PG & $\mathrm{PL}$ & $\mathrm{SA}$ & mean \\
\hline N1. Anxiety & -.38 & -.38 & .59 & -.33 & -.43 & -.56 & -.31 & -.36 & -.53 & -.43 \\
\hline N2. Angry hostility & -.32 & -.35 & .54 & -.32 & -.29 & -.45 & -.30 & -.33 & -.43 & -.37 \\
\hline N3. Depression & -.65 & -.58 & .70 & -.59 & -.45 & -.76 & -.50 & -.69 & -.83 & -.64 \\
\hline N4. Self-consciousness & -.36 & -.43 & .49 & -.45 & -.56 & -.56 & -.42 &.- .44 & -.55 & -.47 \\
\hline N5. Impulsiveness & -.20 & -.22 & .36 & -.13 & -.34 & -.36 & -.14 & -.27 & -.31 & -.26 \\
\hline N6. Vulnerability & -.41 & -.43 & .62 & -.36 & -.53 & -.65 & -.42 & -.49 & -.57 & -.50 \\
\hline E1. Warmth & .42 & .50 & -.40 & .69 & .25 & .52 & .44 & .47 & .53 & .47 \\
\hline E2. Gregariousness & .30 & .36 & -.24 & .46 & .07 & .33 & .25 & .24 & .33 & .29 \\
\hline E3. Assertiveness & .34 & .44 & -.30 & .42 & .42 & .47 & .44 & .46 & .47 & .42 \\
\hline E4. Activity & .28 & .41 & -.22 & .29 & .25 & .49 & .38 & .51 & .38 & .36 \\
\hline E5. Excitement seeking & .14 & .23 & -.03 & .17 & .03 & .09 & .20 & .04 & .12 & .12 \\
\hline E6. Positive emotions & .50 & .53 & -.37 & .59 & .23 & .48 & .49 & .47 & .55 & .47 \\
\hline O1. Fantasy & .00 & .11 & .08 & .09 & .06 & -.06 & .21 & .03 & .01 & .04 \\
\hline O2. Aesthetics & .08 & .24 & -.06 & .23 & .15 & .11 & .42 & .22 & .16 & .19 \\
\hline O3. Feelings & .01 & .09 & .19 & .19 & .02 & -.04 & .35 & .20 & .05 & .08 \\
\hline O4. Actions & .20 & .30 & -.26 & .27 & .29 & .29 & .54 & .32 & .32 & .31 \\
\hline O5. Ideas & .12 & .28 & -.17 & .20 & .41 & .29 & .48 & .35 & .26 & .28 \\
\hline O6. Values & -.04 & -.04 & .02 & .01 & .06 & -.08 & .17 & -.04 & -.01 & .00 \\
\hline A1. Trust & .35 & .32 & -.37 & .54 & .10 & .40 & .34 & .37 & .42 & .36 \\
\hline A2. Straightforwardness & .08 & .09 & -.25 & .22 & .15 & .22 & .21 & .27 & .17 & .18 \\
\hline A3. Altruism & .26 & .36 & -.25 & .52 & .15 & .34 & .47 & .43 & .34 & .35 \\
\hline A4. Compliance & .13 & .11 & -.21 & .19 & -.04 & .12 & .17 & .17 & .15 & .13 \\
\hline A5. Modesty & -.30 & -.26 & .16 & -.22 & -.18 & -.27 & -.17 & -.26 & -.39 & -.25 \\
\hline A6. Tender-mindedness & .10 & .15 & -.07 & .31 & .07 & .07 & .33 & .22 & .14 & .16 \\
\hline C1. Competence & .41 & .47 & -.48 & .42 & .52 & .66 & .56 & .68 & .60 & .53 \\
\hline C2. Order & .10 & .15 & -.14 & .02 & .12 & .25 & .10 & .28 & .13 & .14 \\
\hline C3. Dutifulness & .21 & .23 & -.34 & .27 & .30 & .40 & .34 & .43 & .32 & .32 \\
\hline C4. Achievement striving & .34 & .45 & -.27 & .29 & .34 & .54 & .49 & .67 & .45 & .43 \\
\hline C5. Self-discipline & .34 & .42 & -.37 & .26 & .33 & .61 & .33 & .58 & .45 & .41 \\
\hline C6. Deliberation & .09 & .06 & -.26 & .09 & .21 & .26 & .11 & .30 & .17 & .17 \\
\hline
\end{tabular}

Note. $N=903 . \mathrm{SWL}=$ satisfaction with life, $\mathrm{PA}=$ positive affect, $\mathrm{NA}=$ negative affect, $\mathrm{PR}=$ positive relations, $\mathrm{AU}=$ autonomy, $\mathrm{EM}=$ environmental mastery, $\mathrm{PG}=$ personal growth, $\mathrm{PL}=$ purpose in life, $\mathrm{SA}=$ self-acceptance. Correlations .30 or above are in bold. Correlations equal to or larger than $.07, .09$ and .11 are significant at $.05, .01$, and .001 respectively. 
Table 13

Correlations Between HEXACO Facets and Well-Being Measures in HEXACO Dataset

\begin{tabular}{|c|c|c|c|c|c|c|c|c|c|c|}
\hline & SWL & $\mathrm{PA}$ & NA & PR & $\mathrm{AU}$ & EM & PG & PL & SA & Mean \\
\hline H1: Sincerity & .14 & .10 & -.25 & .21 & .27 & .24 & .23 & .19 & .21 & .20 \\
\hline H2: Fairness & .19 & .21 & -.22 & .25 & .16 & .21 & .18 & .25 & .23 & .21 \\
\hline H3: Greed-Avoidance & .08 & .04 & -.14 & .11 & .23 & .03 & .15 & .07 & .10 & .11 \\
\hline H4: Modesty & -.05 & .00 & -.09 & .11 & .03 & .01 & .10 & .01 & -.06 & .03 \\
\hline E1: Fearfulness & -.04 & -.16 & .19 & -.15 & -.37 & -.27 & -.22 & -.14 & -.17 & -.19 \\
\hline E2: Anxiety & -.26 & -.22 & .47 & -.23 & -.35 & -.43 & -.23 & -.26 & -.40 & -.32 \\
\hline E3: Dependence & .09 & .05 & .25 & .17 & -.30 & -.19 & .01 & -.08 & -.05 & -.06 \\
\hline E4: Sentimentality & .13 & .17 & .11 & .25 & -.14 & .04 & .22 & .18 & .07 & .09 \\
\hline X1: Social Self-Esteem & .57 & .56 & -.55 & .62 & .37 & .70 & .50 & .62 & .75 & .58 \\
\hline X2: Social Boldness & .27 & .35 & -.27 & .39 & .44 & .38 & .40 & .38 & .40 & .36 \\
\hline X3: Sociability & .27 & .33 & -.20 & .51 & .09 & .32 & .30 & .24 & .31 & .29 \\
\hline X4: Liveliness & .52 & .59 & -.46 & .60 & .29 & .66 & .50 & .58 & .64 & .54 \\
\hline A1: Forgiveness & .21 & .21 & -.18 & .29 & .09 & .21 & .19 & .15 & .23 & .20 \\
\hline A2: Gentleness & .17 & .17 & -.15 & .18 & .06 & .10 & .13 & .07 & .13 & .13 \\
\hline A3: Flexibility & .14 & .14 & -.19 & .23 & -.02 & .16 & .14 & .10 & .17 & .14 \\
\hline A4: Patience & .22 & .27 & -.34 & .20 & .16 & .27 & .20 & .19 & .27 & .24 \\
\hline $\mathrm{C} 1$ : Organization & .11 & .19 & -.12 & .07 & .16 & .33 & .14 & .31 & .18 & .18 \\
\hline C2: Diligence & .26 & .44 & -.29 & .24 & .36 & .52 & .44 & .62 & .41 & .40 \\
\hline C3: Perfectionism & -.02 & .13 & -.03 & .02 & .16 & .15 & .20 & .27 & .10 & .12 \\
\hline C4: Prudence & .17 & .24 & -.35 & .15 & .27 & .34 & .17 & .33 & .27 & .25 \\
\hline O1: Aesthetic Appreciation & .09 & .20 & -.06 & .12 & .22 & .11 & .33 & .16 & .13 & .16 \\
\hline O2: Inquisitiveness & .06 & .21 & -.16 & .10 & .29 & .21 & .30 & .16 & .16 & .18 \\
\hline O3: Creativity & .05 & .23 & -.06 & .08 & .25 & .08 & .28 & .13 & .17 & .15 \\
\hline O4: Unconventionality & .00 & .14 & .05 & .02 & .22 & -.04 & .25 & .05 & .07 & .07 \\
\hline I: Altruism & .14 & .21 & -.06 & .28 & .00 & .12 & .32 & .25 & .18 & .17 \\
\hline
\end{tabular}

Note. $N=465$; $\mathrm{SWL}=$ satisfaction with life, $\mathrm{PA}=$ positive affect, $\mathrm{NA}=$ negative affect, $\mathrm{PR}=$ positive relations, $\mathrm{AU}=$ autonomy, $\mathrm{EM}=$ environmental mastery, $\mathrm{PG}=$ personal growth, $\mathrm{PL}=$ purpose in life, $\mathrm{SA}=$ self-acceptance. Correlations .30 or above are in bold. 
Table 14

Variance Explained by Broad and Narrow Traits across Measures

\begin{tabular}{|c|c|c|c|c|c|c|c|c|c|c|}
\hline & SWL & $\mathrm{PA}$ & NA & PR & $\mathrm{AU}$ & EM & $\mathrm{PG}$ & $\mathrm{PL}$ & SA & Mean \\
\hline \multicolumn{11}{|l|}{ Broad: adjusted $R^{2}$} \\
\hline NEO & .25 & .23 & .21 & .47 & .27 & .51 & .41 & .44 & .50 & .36 \\
\hline IPIP NEO & .32 & .43 & .52 & .50 & .38 & .65 & .54 & .58 & .57 & .50 \\
\hline HEXACO & .25 & .37 & .35 & .47 & .39 & .52 & .39 & .46 & .45 & .41 \\
\hline Big Five Aspects & .32 & .54 & .67 & .44 & .69 & .53 & .67 & .61 & .53 & .56 \\
\hline Mean & .29 & .39 & .44 & .47 & .43 & .56 & .50 & .52 & .51 & .46 \\
\hline \multicolumn{11}{|l|}{ Narrow: adj $R^{2}$} \\
\hline NEO & .30 & .25 & .24 & .54 & .38 & .55 & .48 & .51 & .56 & .42 \\
\hline IPIP NEO & .47 & .48 & .58 & .59 & .52 & .71 & .62 & .70 & .74 & .60 \\
\hline HEXACO & .38 & .44 & .44 & .51 & .44 & .63 & .45 & .58 & .61 & .50 \\
\hline Big Five Aspects & .39 & .59 & .69 & .52 & .73 & .55 & .72 & .65 & .55 & .60 \\
\hline Mean & .39 & .44 & .49 & .54 & .52 & .61 & .56 & .61 & .61 & .53 \\
\hline \multicolumn{11}{|l|}{ Adj $R^{2}$ Change } \\
\hline NEO & .06 & .02 & .03 & .06 & .11 & .04 & .07 & .07 & .06 & .06 \\
\hline IPIP NEO & .15 & .05 & .06 & .10 & .14 & .06 & .07 & .12 & .17 & .10 \\
\hline HEXACO & .13 & .07 & .09 & .04 & .05 & .11 & .06 & .11 & .16 & .09 \\
\hline Big Five Aspects & .07 & .06 & .03 & .08 & .03 & .02 & .05 & .04 & .02 & .04 \\
\hline Mean & .10 & .05 & .05 & .07 & .08 & .06 & .06 & .09 & .10 & .07 \\
\hline \multicolumn{11}{|l|}{ Adj $R^{2}$ Prop Increase } \\
\hline NEO & .24 & .09 & .16 & .13 & .43 & .08 & .16 & .16 & .13 & .17 \\
\hline IPIP NEO & .47 & .12 & .11 & .19 & .37 & .09 & .14 & .21 & .30 & .22 \\
\hline HEXACO & .51 & .19 & .26 & .09 & .13 & .20 & .14 & .24 & .36 & .24 \\
\hline Big Five Aspects & .21 & .11 & .04 & .18 & .05 & .03 & .07 & .06 & .03 & .09 \\
\hline Mean & .36 & .13 & .14 & .15 & .24 & .10 & .13 & .17 & .20 & .18 \\
\hline
\end{tabular}




\section{Table 15}

Correlations Among HEXACO and IPIP NEO Personality Domains from Combined Dataset

\begin{tabular}{lcccccccccc}
\hline \multicolumn{1}{c}{ Variable } & 1 & 2 & 3 & 4 & 5 & 6 & 7 & 8 & 9 & 10 \\
\hline HEXACO & & & & & & & & & & \\
1. Honesty-Humility & & & & & & & & & \\
2. Emotionality & .06 & & & & & & & & \\
3. Extraversion & .01 & -.21 & & & & & & & \\
4. Agreeableness & .37 & -.18 & .31 & & & & & & \\
5. Conscientiousness & .31 & -.11 & .21 & .22 & & & & & \\
6. Openness & .13 & -.18 & .19 & .19 & .17 & & & & \\
IPIP NEO & & & & & & & & & & \\
7. Neuroticism & -.19 & .56 & -.65 & -.46 & -.36 & -.26 & & & & \\
8. Extraversion & -.09 & -.08 & .83 & .17 & .11 & .13 & -.49 & & & \\
9. Agreeableness &. $\mathbf{. 6 7}$ & .22 & .12 &. $\mathbf{5 3}$ & .26 & .05 & -.17 & .08 & & \\
10. Conscientiousness & .32 & -.14 & .28 & .19 & .84 & .09 & -.48 & .19 & .32 & \\
11. Openness & .16 & .06 & .23 & .14 & .15 &. $\mathbf{7 1}$ & -.19 & .30 & .20 & .14 \\
\hline
\end{tabular}

Note. $N=465$; Cross-correlations between personality measures greater than .50 are shown in bold. 
Table 16

Correlations between HEXACO and IPIP NEO Domains and Well-Being Measures for Combined Dataset

\begin{tabular}{|c|c|c|c|c|c|c|c|c|c|c|}
\hline & SWL & $\mathrm{PA}$ & NA & PR & AU & EM & PG & PL & $\mathrm{SA}$ & Mean \\
\hline \multicolumn{11}{|l|}{ IPIP NEO } \\
\hline Neuroticism & -.45 & -.52 & .69 & -.46 & -.55 & -.70 & -.47 & -.56 & -.68 & -.56 \\
\hline Extraversion & .42 & .55 &.- .30 & .63 & .30 & .53 & .53 & .49 & .52 & .47 \\
\hline Openness & .09 & .32 & -.04 & .26 & .28 & .15 & .57 & .31 & .24 & .25 \\
\hline Agreeableness & .15 & .20 & -.21 & .35 & .04 & .19 & .29 & .24 & .19 & .21 \\
\hline Conscientiousness & .27 & .39 & -.37 & .26 & .39 & .59 & .38 & .61 & .45 & .41 \\
\hline \multicolumn{11}{|l|}{ HEXACO } \\
\hline Honesty-Humility & .12 & .12 & -.23 & .22 & .23 & .16 & .21 & .17 & .16 & .18 \\
\hline Emotionality & -.03 & -.07 & .37 & .00 & -.41 & -.31 & -.09 & -.12 & -.20 & -.18 \\
\hline Extraversion & .49 & .56 & -.45 & .64 & .37 & .62 & .52 & .55 & .64 & .54 \\
\hline Agreeableness & .24 & .26 & -.28 & .29 & .10 & .24 & .21 & .17 & .26 & .23 \\
\hline Conscientiousness & .17 & .33 & -.26 & .16 & .30 & .44 & .31 & .50 & .31 & .31 \\
\hline Openness & .07 & .25 & -.08 & .11 & .31 & .12 & .37 & .17 & .17 & .18 \\
\hline HEXACO Neuroticism & -.48 & -.49 & .64 & -.48 & -.45 & -.70 & -.44 & -.55 & -.68 & -.55 \\
\hline
\end{tabular}

Note. $N=465 ; \mathrm{SWL}=$ satisfaction with life, $\mathrm{PA}=$ positive affect, $\mathrm{NA}=$ negative affect, $\mathrm{PR}=$ positive relations, $\mathrm{AU}=$ autonomy, $\mathrm{EM}=$ environmental mastery, $\mathrm{PG}=$ personal growth, $\mathrm{PL}=$ purpose in life, $\mathrm{SA}=$ self-acceptance. Correlations equal to or larger than .10, .12 and .16 are significant at $.05, .01$, and .001 respectively. Mean is the mean correlation between the personality trait and well-being variables, where the correlation with negative affect (NA) is reversed. Correlations .30 or above in bold. 
Table 17

Adjusted R Squared for Regression Models Predicting Well-Being Measures in Combined Dataset

\begin{tabular}{lccccccccccc}
\hline Predictors & $\mathrm{k}$ & SWL & PA & NA & PR & AU & EM & PG & PL & SA & Mean \\
\hline HEXACO Domains & 6 & .25 & .37 & .35 & .47 & .39 & .52 & .39 & .46 & .45 & .41 \\
NEO Domains & 5 & .26 & .43 & .49 & .50 & .36 & .63 & .55 & .55 & .53 & .48 \\
HEXACO Facets & 25 & .38 & .44 & .44 & .51 & .44 & .63 & .45 & .58 & .61 & .50 \\
NEO Domains + HEXACO Domains & 11 & .31 & .45 & .50 & .53 & .45 & .64 & .55 & .57 & .57 & .51 \\
NEO Domains + HEXACO Facets & 30 & .41 & .50 & .52 & .59 & .49 & .70 & .57 & .64 & .67 & .57 \\
NEO Facets & 30 & .44 & .50 & .57 & .59 & .52 & .70 & .64 & .70 & .70 & .60 \\
HEXACO Domains + NEO Facets & 36 & .46 & .50 & .57 & .59 & .54 & .71 & .64 & .71 & .71 & .60 \\
HEXACO Facets + NEO Facets & 55 & .48 & .52 & .56 & .61 & .56 & .72 & .64 & .70 & .73 & .61 \\
\hline
\end{tabular}

Note. $n=465 . \mathrm{NEO}=\mathrm{IPIP} \mathrm{NEO}, \mathrm{SWL}=$ satisfaction with life, $\mathrm{PA}=$ positive affect, $\mathrm{NA}=$ negative affect, $\mathrm{PR}=$ positive relations, $\mathrm{AU}=$ autonomy, $\mathrm{EM}=$ environmental mastery, $\mathrm{PG}=$ personal growth, $\mathrm{PL}=$ purpose in life, $\mathrm{SA}=$ self-acceptance. $\mathrm{k}$ is number of predictors. Mean represents the average variance explained for the predictor set over the 9 well-being measures. 